University of Rhode Island

DigitalCommons@URI

Open Access Master's Theses

2017

\title{
Modeling Sediment Transport Around Artificial Reefs in Southern Rhode Island
}

Scott J. Hayward

University of Rhode Island, shayward310@my.uri.edu

Follow this and additional works at: https://digitalcommons.uri.edu/theses

\section{Recommended Citation}

Hayward, Scott J., "Modeling Sediment Transport Around Artificial Reefs in Southern Rhode Island" (2017). Open Access Master's Theses. Paper 1126.

https://digitalcommons.uri.edu/theses/1126

This Thesis is brought to you for free and open access by DigitalCommons@URI. It has been accepted for inclusion in Open Access Master's Theses by an authorized administrator of DigitalCommons@URI. For more information, please contact digitalcommons-group@uri.edu. 
MODELING SEDIMENT TRANSPORT AROUND ARTIFICIAL REEFS IN SOUTHERN RHODE ISLAND

BY

SCOTT J. HAYWARD

A THESIS SUBMITTED IN PARTIAL FULFILLMENT OF THE

REQUIREMENTS FOR THE DEGREE OF

MASTER OF SCIENCE

IN

OCEAN ENGINEERING

UNIVERSITY OF RHODE ISLAND

2017 
MASTER OF SCIENCE THESIS

$\mathrm{OF}$

SCOTT J. HAYWARD

\section{APPROVED:}

Thesis Committee:

$\begin{array}{ll}\text { Major Professor } & \text { M. Reza Hashemi } \\ & \text { Annette Grilli } \\ & \text { Tetsu Hara } \\ & \text { Malcolm Spaulding } \\ & \text { Nasser H. Zawia } \\ & \text { DEAN OF THE GRADUATE SCHOOL }\end{array}$

UNIVERSITY OF RHODE ISLAND

2017 


\begin{abstract}
This document contains two papers which address threats by tropical and extratropical systems in the northeastern United States. A suite of numerical models are used to assess waves, storm surge and coastal erosion during extreme storms.
\end{abstract}

Modeling Waves and Sediment Transport Around Artificial Reefs: Simulation of the Impact of Multi-purpose Reefs on Dune Erosion in Southern Rhode Island Barrier Beaches

The objective of this study is to set up a suite of numerical models capable of simulating the impacts of storms on coastal flooding and erosion, and use it to assess performance of mitigation measures. Three numerical models were used to analyze the possible erosion due to inundation and overwash for a small section of coast in southern Rhode Island. SWAN (Simulating Waves Nearshore), a third-generation wave model was used to compute the wave conditions. ADCIRC (ADvanced CIRCulation Model), a three-dimensional circulation model used atmospheric and tidal forcing to generate water levels, and currents. A regional coupled SWAN+ADCIRC model was used to calculate water levels and wave conditions over an unstructured mesh. XBeach, a sediment transport model, encompasses a barrier system on the southern coast of Rhode Island, and is nested within the regional domain. A non-uniform cartesian grid with a resolution across dunes of $5 \times 10$ meters is used to calculate the sediment transport during storms, the resolution decreases to $25 \times 25$ meters resolution at the boundaries. Hurricane Sandy (2012) was used to calibrate the models, where volume of erosion was compared along transects monitored by the University of Rhode Island. The model was then forced with winds from Hurricane Irene (2011) for validation. The regional model had a root mean squared error (RMSE) of 0.21 meters for storm surge, and a RMSE of 0.18 meters for offshore significant wave height. The nearshore model 
was able to estimate erosion with an error of $24.26 \%$. Once validated, two synthetic storms from the North Atlantic Coast Comprehensive Study (NACCS) were modeled. These storms both produced storm surges of around the same magnitude in comparison to the 100-year event in Rhode Island.

\section{Development of a Realtime Wave and Storm Surge Forecasting Model For Rhode Island}

A set of MATLAB and bash programs were designed for preprocessing and automating the coupled wave and hydrodynamic model SWAN+ADCIRC for real time forecasting of waves and storm surge. The method allows the user to locally preprocess, package, and automate the system, while running the system externally using High Performance Computing (HPC). Each of the user input files are described, and the forecasting process is explained. The system is then applied to a SWAN+ADCIRC domain in Rhode Island, and tested during Stella, an extratropical event in March 2017, Nor'Easter Stella. The three day forecast system had a maximum offshore significant wave height Root Mean Squared Error (RMSE) of less than $1.2 \mathrm{~m}$, and a storm surge RMSE of less than 0.2 meters during simulation of NorEaster Stella. The system was shown to be conveniently activated and monitored in the event of an emergency. 


\section{ACKNOWLEDGMENTS}

I would first like to thank my advisor, Dr. Reza Hashemi, for the advice and insight he has shown me during this research. You have given countless hours of your time to help me improve my skills, and expand my knowledge of coastal modeling. I would also like to extend my gratitude to Dr. Malcolm Spaulding, for providing me with a funding opportunity through the NERACOOS project.

To the members and chair of my Master's committee, Drs. Isaac Ginis, Annette Grilli, Tetsu Hara, Reza Hashemi, and Malcolm Spaulding: thank you all for the experience, and the advice and feedback on my thesis.

Gail, I could not thank you enough for the advice, and information you have given me throughout my graduate career. You carry such a positive energy, its always a privilege to walk downstairs and share a friendly chat. Without you, the Ocean Engineering department wouldn't be the same.

My colleagues, Marissa, and Chris, it has truly been an honor working with you. Our projects have been both challenging, and rewarding, and we have accomplished and learned a lot together. Best luck to both of you.

Sheets 223: Amin, Boma, Chris, Fatima, Greg, Lauren, Mike, and Pat. I share your grievances towards myself as much as you do, work is not a place for puns. Nonetheless, I could not have asked for better people to share jokes, stories, and advice with. Thank you, and good luck to all of you on your future endeavors.

Mom, Dad, Will and Layne: thank you for your loving support. I have missed you all these past two years, being across the country has been difficult, but It makes time spent with you all the better. Finally, to the countless friends I have met over the past two years: I will forever remember and cherish the countless experiences I have shared with all of you. 


\section{PREFACE}

The contents of this thesis have been prepared in manuscript format.

Manuscripts 1 and 2 were both funded under the NERACOOS Coastal Resiliency Project. Findings from Manuscript 1 were presented at the 2017 American Shore and Beach Preservation Assosiation in Ft. Lauterdale FL, on October 27, 2017. It will be submitted to Continental Shelves Research.

Portions of Manuscript 2 and the following appendices serve as a report for the NERACOOS coastal Resilience project. They are being prepared for submission to Computers and Geoscience. 


\section{TABLE OF CONTENTS}

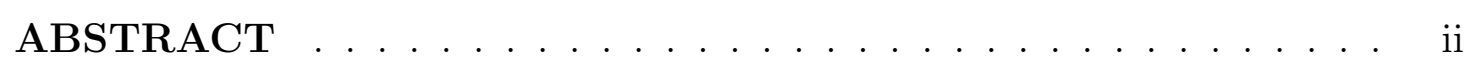

ACKNOWLEDGMENTS .................. iv

PREFACE .......................

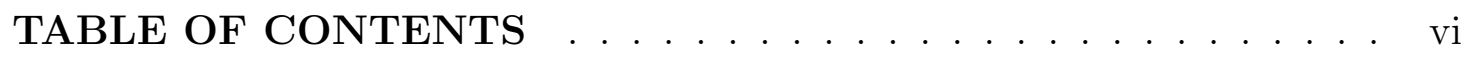

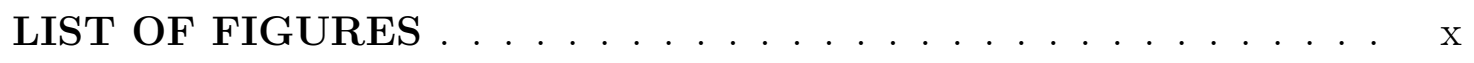

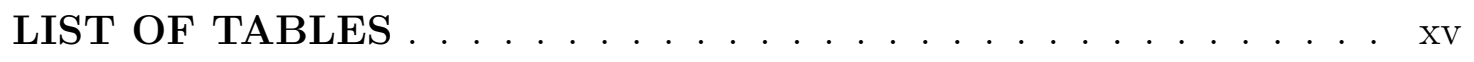

\section{MANUSCRIPT}

1 Modeling Waves and Sediment Transport Around Artificial Reefs: Simulation of the Impact of Multi-purpose Reefs on Dune Erosion in Southern Rhode Island Barrier Beaches . . 1

1.1 Introduction . . . . . . . . . . . . . . 3

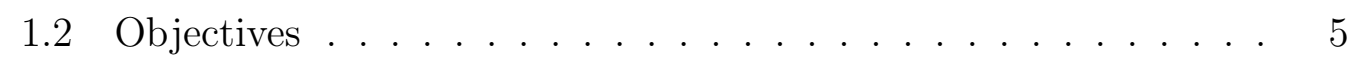

1.3 Methods . . . . . . . . . . . . . . . . . . . 6 6

1.3.1 Numerical Models . . . . . . . . . . . . . . . . . . . . 6

1.3 .2 Area of Study . . . . . . . . . . . . . . . . . 7

1.3.3 Historic and Synthetic Storms . . . . . . . . . . 10

1.3 .4 Data . . . . . . . . . . . . . . . . . . 13

1.3.5 Numerical Model Setup and Physical Processes _. . . . 14

1.4 Results . . . . . . . . . . . . . . . . . . . . . . . . 19

1.4.1 Development of Beach Erosion Model . . . . . . . . . . 19

1.4.2 Calibration and validation of the nearshore model . . . . 22 


\section{Page}

1.4.3 Modeling synthetic storms from the NACCS dataset . . . 33

1.4.4 Assesment of a hypothetical beach erosion mitigation: artificial reef . . . . . . . . . . . . . 37

1.5 Discussion . . . . . . . . . . . . . . . . . . . 42

1.5.1 Regional model . . . . . . . . . . . . . . . . . . . . . 42

1.5.2 Nearshore model . . . . . . . . . . . . . . . . . . . 43

1.6 Conclusion . . . . . . . . . . . . . . . . . . . . . . . . 45

2 Development of a Realtime Wave and Storm Surge Forecasting Model For Rhode Island . . . . . . . . . . . . . . . . . 52

2.1 Introduction $\ldots \ldots \ldots \ldots \ldots \ldots \ldots \ldots \ldots$

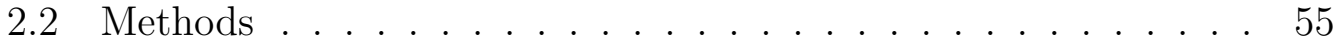

2.2 .1 Bash and MATLAB Codes . . . . . . . . . . . . 56

2.2 .2 Automation . . . . . . . . . . . . . . . . . . . 59

2.2.3 Application of Forecasting System in Rhode Island . . . 60

2.2.4 Modeling Synthetic Storms Representing the 100-year Event . . . . . . . . . . . . . . . 61

2.3 Discussion and Conclusion . . . . . . . . . . . . . . . 67

\section{APPENDIX}

A Introduction to SWAN and ADCIRC models . . . . . . 70

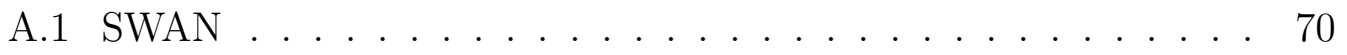

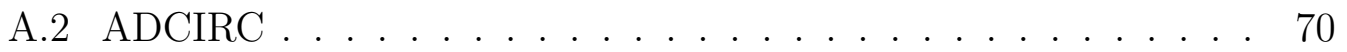

A.3 SWAN+ADCIRC coupling . . . . . . . . . . . . 71

B Introduction to XBeach $\ldots \ldots \ldots \ldots \ldots \ldots$

B.1 Hydrodynamics . . . . . . . . . . . . . . . . 75 


\section{Page}

B.1.1 Short wave module . . . . . . . . . . . . . . 75

B.1.2 Flow module. . . . . . . . . . . . . . . 76

B.2 Morphodynamics . . . . . . . . . . . . . 76

B.2.1 Sediment transport module . . . . . . . . . . . . 76

B.2.2 Morphology module . . . . . . . . . . . . . . . . 77

C An Efficient Method to Study Long-Term Sediment Transport 78

C.1 Introduction . . . . . . . . . . . . . . . . 78

C.2 Wave climate look-up table . . . . . . . . . . . 78

C.3 XBeach model . . . . . . . . . . . . . . . . . . . . . . . . . 81

C.4 Results . . . . . . . . . . . . . . . . . . . . 83

C.5 Significant Wave height look-up table . . . . . . . . . . 84

D Forecasting model: Bash and MATLAB scripts . . . . . . 86

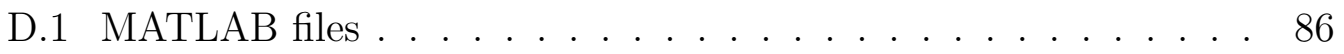

D.1.1 preprocess1.m ................ 86

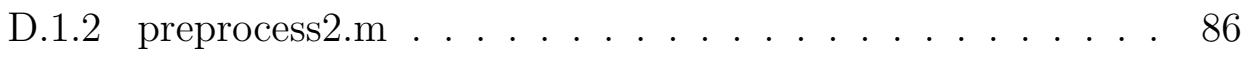

D.1.3 met_inputs.m . . . . . . . . . . 86

D.1.4 make_fort22.m . . . . . . . . . . . . . 88

D.1.5 makefort15.m . . . . . . . . . . . . . 90

D.1.6 makefort26.m . . . . . . . . . . . . . . . . . 92

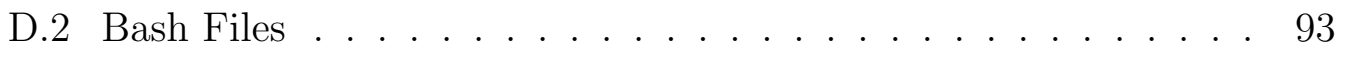

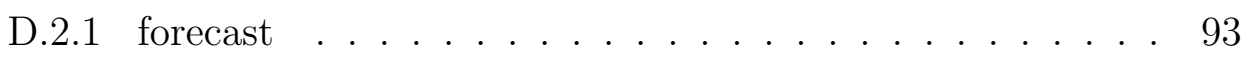

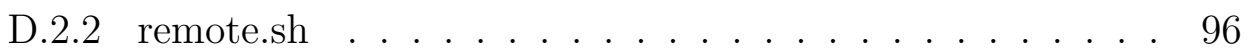

D.2.3 upload.sh . . . . . . . . . . . . . . 96 
D.2.4 prep.sh .......................... 97

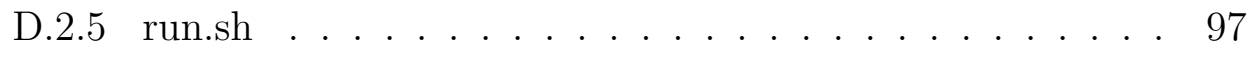

E Effect of Sea Level Rise on Historic Storms . . . . . . . . . . . 98

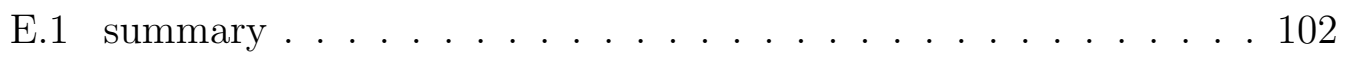

LIST OF REFERENCES ..................... . . 103 


\section{LIST OF FIGURES}

Figure

Page

1 The study area for the nearshore sediment transport model. . .

2 SWAN+ADCIRC computational domain (top), and the nested XBeach grid (bottom) . . . . . . . . . . . 8

3 Google Maps image of Charlestown, with XBeach domain overlay. Elevation shown by contours in meters . . . . . . . . . . 9

4 Hurriucane tracks and Radii of Maximum Winds (RMW) for Hurricanes Irene (blue) and Sandy (black), along with NACCS synthetic storms 457 (green) and 492(red). The RMW are shown in 24-hour increments to illustrate forward velocity. . . . 10

$5 \quad$ Overwash in Misquamicuit, Rhode Island after hurricane Sandy. Photo: Rhode Island Department of Transportation . . . . . . . 12

6 WRF forcing over SWAN+ADCIRC computational domain, snapshot from NorEaster Stella, March 14, 2017 6:00am . . . . 15

$7 \quad$ Grid spacing of XBeach domain over bathymetry (every 10th node shown), resolution is highest across the barrier beach in the middle of the domain . . . . . . . . . . . . . . 18

8 Locations of data used for validation of SWAN+ADCIRC. Spectral Wave Buoys (diamond), Tidal Stations (triangle), other wave data (circle), and the location of the XBeach domain (rectangle) are shown. . . . . . . . . . . . . . . 19

9 Time series of water levels measured at the Newport tidal gauge (top) and waves measured at CDIP buoy 154 (bottom) during hurricane sandy, compared to modeled data. Water level RMSE: 0.21 , Significant Wave height RMSE: $0.15 \mathrm{~m}$. . . . . . . . . 20

$10 \mathrm{r}^{2}$ for water elevation at the Newport gauge (left) and waves at the CDIP 154 buoy (right) during Hurricane Sandy SWAN+ADCIRC simulation. . . . . . . . . . . . . 21 
11 9-band spectral validation of SWAN results for Hurricane Sandy. The energy in each of the 9 observed frequency bins (dotted) are compared to the swan spectral output (solid). Y-axes are scaled for clarity. . . . . . . . . . . . . . . . . . . . 23

12 Locations of transects used for validation of the XBeach model: Charlestown Breachway (CBW), Charlestown Beach (CTB), and Green Hill beach $(\mathrm{GH})$. . . . . . . . . . . . . . . 24

13 Left: XBeach hourly input for Hurricane Sandy along the seaward boundary. Water elevation due to tide and surge (a) is applied in hourly increments, along with the 2-dimensional wave spectrum. The significant wave height (b), peak period (c), and peak direction $(\mathrm{d})$ corresponding to the wave spectrum are shown for clarity. Right: The 2-dimensional wave spectrum applied to the boundary, during the peak of the storm. . . . . . . 26

14 Comparison of accumulated erosion/accretion due to Hurricane sandy with fua value ranging from 0.25 to 0.3 . . . . . . . 26

15 Modeled (top) and measured (middle) elevation before and after Hurricane Sandy are shown along Charlestown Beach (CTB) and Green Hill (GH) transects. The change in elevation along these transects (bottom) are compared for facua values of 0.3

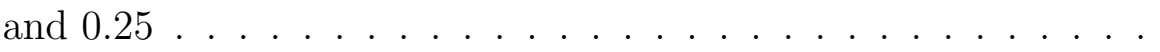

16 A stretch of barrier beach in May, 2012 (top) and September 2014 (middle) taken before and after Hurricane Sandy. Calculated bed level change in XBeach (bottom) shows sediment pushed over the dunes and created overwash fans. . . . . . . . 28

17 Left: XBeach hourly input for Hurricane Sandy along the seaward boundary, from 00:00 Oct 28, 2012. Water elevation due to tide and surge (a) is applied in hourly increments, along with the 2-dimensional wave spectrum. The significant wave height (b), peak period (c), and peak direction (d) corresponding to the wave spectrum are shown for clarity. Right: The 2-dimensional wave spectrum applied to the boundary, during the peak of the storm. . . . . . . . . . . . . . . .

18 Simulated bed level change for Irene(a) in relation to Sandy (b). Initial bottom contours are shown for reference (black). . . . . . 
19 Maximum inundation during Irene (a), compared to Sandy (b), with initial bottom contours (black). . . . . . . . . . 31

20 Modeled (top) vs. measured (middle) dune transects from before and after Hurricane Irene along Charlestown Breachway CHBW), Charlestown Beach (CHTB) and Green Hill (GH) transects. Bottom: the simulated elevation change (black) along these transects is compared to the observations (blue). . . . . . 32

21 Comparison of the recreated synthetic hurricane wind field at the location of NACCS save points in Charlestown (A), Newport (B), Providence $(\mathrm{C}) . \ldots \ldots \ldots$

22 Time series water elevation over the high-resolution mesh, near NACCS save points in Charlestown (A), Newport (B), Providence $(\mathrm{C}) \ldots \ldots \ldots \ldots \ldots$. . . . . . . . . . . . . .

23 Left: XBeach hourly input for NACCS 457 along the seaward boundary. Water elevation due to tide and surge (a) is applied in hourly increments, along with the 2-dimensional wave spectrum. The significant wave height (b), peak period (c), and peak direction $(d)$ corresponding to the wave spectrum are shown for clarity. Right: The 2-dimensional wave spectrum applied to the boundary, during the peak of the storm. . . . . . . . . .

24 Left: XBeach hourly input for NACCS 492 along the seaward boundary. Water elevation due to tide and surge (a) is applied in hourly increments, along with the 2-dimensional wave spectrum. The significant wave height (b), peak period (c), and peak direction (d) corresponding to the wave spectrum are shown for clarity. Right: The 2-dimensional wave spectrum applied to the boundary, during the peak of the storm. . . . . . . . . 35

25 Simulated bed level change for NACCS 457 (a) and NACCS 492 (b), with initial bottom contours (black). . . . . . . . . 36

26 Maximum inundation over bed level (meters) during NACCS 457 (a) and 492 (b). . . . . . . . . . . . . . 36

27 Artificial reef geometry, and location within the domain . . . . 38 
28 Location of artificial reef within domain (right), and location of transects for analysis of sediment transport in the wake of the reef (left). Units in meters. . . . . . . . . . . . . . .

29 Above: Difference in accumulated bed level change $\left(h_{\text {reef }}-\right.$ $\left.h_{\text {control }}\right)$ for Sandy (A) and Irene (B). Below: Comparison of sediment change for Irene (red) and Sandy (blue) without the artificial reef (dashed), and with the reef (solid) along the dune crest (a) and three cross-shore (b-d) transects . . . . . . . . .

$30 \quad$ Flow chart of process for Rhode Island real-time forecasting system. Summaries of these codes are located in Table 7, and full codes are listed in Appendix D. . . . . . . . . . . . . . . . 55

31 Wind Velocity and Direction Vectors during Nor'Easter Stella over the computational grid. . . . . . . . . . . . . 61

32 Comparison of measured and modeled data, taken on $3 / 13 / 2017$. The blue region represents the hindcast period, used as to ensure the model is running properly. The forecast period is shown in green. . . . . . . . . . . . . . . .

33 Daily root-mean squared error (RMSE) for the surge at NOAA Newport tidal gauge in Newport (top) and daily RMSE of waves at CDIP 157 buoy(bottom). . . . . . . . . . . .

34 Track of NACCS storm ID 457, with radius of maximum wind (RMW) plotted every 24 hours. . . . . . . . . . . . . . 64

35 Comparison of the recreated synthetic hurricane wind field at the location of NACCS save points in Charlestown (A), Newport (B), Providence $(\mathrm{C}) . \ldots \ldots \ldots \ldots$

36 Time series water elevation over the high-resolution mesh, near NACCS save points in Charlestown (A), Newport (B), Providence $(\mathrm{C}) \ldots \ldots \ldots \ldots \ldots \ldots$

37 Maximum water elevation over the high-resolution mesh during the synthetic 100 year storm. . . . . . . . . . . . 66

A.38 SWAN+ADCIRC coupling schematic, https://ccht.ccee.ncsu.edu 72

A.39 Breakdown of regional model on 48 processors . . . . . . . . . 73 
C.40 Stationary SWAN model domain, and validation locations for boundary forcing method. . . . . . . . . . . . . 79

C.41 Stationary SWAN model sensitivity test for Jonswap Gamma, and Whitecapping at Woods Hole West ADCP. Time-series of significant wave height(top), peak period(center), and peak direction (bottom) from $08 / 20 / 2011$ to $09 / 01 / 2011$. . . . . . . 80

C.42 Change in bathymetry $\left(h_{\text {reef }}-h_{\text {control }}\right)$ over 1 year XBeach simulation, control run(top) in comparison to the artificial reef(middle). The difference between the control run and the Artificial reef is shown below. . . . . . . . . . . . 83

C.43 SWAN model results for $H s=1 \mathrm{~m}$. The wave period varies with each row, direction varies with columns. . . . . . . . . . . . . 84

C.44 SWAN model results for $H s=2 m$. The wave period varies with each row, direction varies with columns. . . . . . . . . . . . 84

C.45 SWAN model results for $H s=5 \mathrm{~m}$. The wave period varies with each row, direction varies with columns. . . . . . . . . 85

C.46 SWAN model results for $H s=9 \mathrm{~m}$. The wave period varies with each row, direction varies with columns. . . . . . . . . 85

E.47 Locations of water level tidal stations used to analyze the impact of sea level rise. . . . . . . . . . . . . . . . . . . . . . . . . . . . 98

E.48 Comparison of water elevations during hurricane Sandy with 3 feet (top) and 7 feet (bottom) of sea level rise in Newport, Rhode Island. The Observations (black) are compared to the linear (blue) and nonlinear (red dashed) methods. . . . . . . . . 100

E.49 Comparison of water elevations during hurricane Sandy with 3 feet (top) and 7 feet (bottom) of sea level rise in Providence, Rhode Island. The Observations (black) are compared to the linear (blue) and nonlinear (red dashed) methods. . . . . . . . . 101 


\section{LIST OF TABLES}

Table

Page

1 XBeach variables and descriptions . . . . . . . . . . . 17

2 RMSE of water levels, waves, and 1-Dimensional spectrum during Hurricane Sandy. . . . . . . . . . . . . . . . . . . . . . 22

3 Comparison of volume of dune eroded during hurricane Sandy (meters cubed per meter along the beach) . . . . . . . . . 27

4 Percent error along the observed transects during hurricane Sandy. 29

$5 \quad$ Percent error for eroded volume along the observed transects during Hurricane Irene. . . . . . . . . . . . . . . . . . 32

6 Required Software and Codes . . . . . . . . . . . . . 56

$7 \quad$ List and description of Files and Scripts within the Master Directory, refer to Appendix D for full codes. . . . . . . . . . . . . 57

$8 \quad$ Format of the tidal constituent input file tideinput.txt . . . . 58

9 Format of swanlines.txt . . . . . . . . . . . . . . 59

B.10 List of Variables . . . . . . . . . . . . . . . . . 74

C.11 Root Mean Squared Error (RMSE) of Significant wave height, period, and direction at West ADCP, from 08/20/2011 to

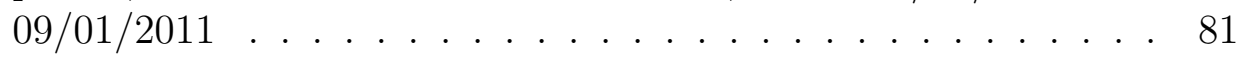

C.12 Root Mean Squared Error (RMSE) of Significant wave height, period, and direction at Center ADCP, from 08/20/2011 to

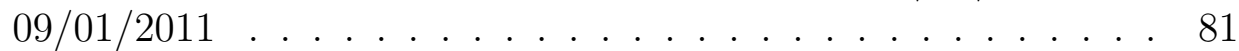

C.13 Long-term XBeach variables and descriptions . . . . . . . . . 82 


\section{MANUSCRIPT 1}

Modeling Waves and Sediment Transport Around Artificial Reefs: Simulation of the Impact of Multi-purpose Reefs on Dune Erosion in Southern Rhode Island Barrier Beaches

by Scott Hayward, M. Reza Hashemi, Marissa Torres, John King \& Malcolm Spaulding

This manuscript is being prepared for submission to Continental Shelf Research. 


\section{Abstract}

The objective of this study is to set up a suite of numerical models capable of simulating the impacts of storms on coastal flooding and erosion, and use it to assess performance of mitigation measures. Three numerical models were used to analyze the possible erosion due to inundation and overwash for a small section of coast in southern Rhode Island. SWAN (Simulating Waves Nearshore), a third-generation wave model was used to compute the wave conditions. ADCIRC (ADvanced CIRCulation Model), a three-dimensional circulation model used atmospheric and tidal forcing to generate water levels, and currents. A regional coupled SWAN+ADCIRC model was used to calculate water levels and wave conditions over an unstructured mesh. XBeach, a sediment transport model, encompasses a barrier system on the southern coast of Rhode Island, and is nested within the regional domain. A non-uniform cartesian grid with a resolution across dunes of $5 \times 10$ meters is used to calculate the sediment transport during storms, the resolution decreases to $25 \times 25$ meters resolution at the boundaries. Hurricane Sandy (2012) was used to calibrate the models, where volume of erosion was compared along transects monitored by the University of Rhode Island. The model was then forced with winds from Hurricane Irene (2011) for validation. The regional model had a root mean squared error (RMSE) of 0.21 meters for storm surge, and a RMSE of 0.18 meters for offshore significant wave height. The nearshore model was able to estimate erosion with an error of $24.26 \%$. Once validated, two synthetic storms from the North Atlantic Coast Comprehensive Study (NACCS) were modeled. These storms both produced storm surges of around the same magnitude in comparison to the 100-year event in Rhode Island.

Overwash and dune profile changes before and after the storms were compared. The validated model was used to analyze a hypothetical erosion mitigation effort, 
by altering the bathymetry within the model to simulate the presence of an artificial offshore reef. The impact on erosion was compared with and without the offshore reef, along both longshore and cross-shore transects and in two-dimensions across the entire domain. It was shown that in the collision and overwash regimes (i.e. Sandy, Irene) the artificial reef will protect dunes directly in its wake, however, foreshore erosion was accelerated. During a 100-year event, the reef will provide little to no protection to the dunes or beach.

\section{$1.1 \quad$ Introduction}

Coastal communities in the northeast of the United States are expected to see an increase in tropical storm activity and Nor'easters in the current century[19]. After Superstorm Sandy, the USACE performed the North Atlantic Coastal Comprehensive Study [8], a coastal hazard study for resilience adaptation towards an increased risk to ports, coastal communities, and businesses. The study addressed the threats of storms to the northeastern United States by modeling the surge and waves during 1050 synthetic tropical and 100 historic extra-tropical storms.

With over 300 miles of coastline, the state of Rhode Island is threatened by tropical and extra-tropical events. Barrier systems that make up much of the southern shore are especially succeptable to damage due to waves and surge during storms. In order to further assess possible future risks to coastal communities, numerical models can be used to analyze past events, or a synthetic event can be modeled to generate 100 year storm conditions. By re-creating significant synthetic storms from the NACCS, and applying them over a domain focused on the state of Rhode Island, wave heights and storm surge can be calculated at high resolution across the state.

Although the NACCS study provided results to the public, the data was condensed to a number of save points, where the time series of waves, water levels, 
wind, and other variables could be analyzed. To increase the applicability of these results, the wind forcing from NACCS could be applied on a higher resolution domain. Furthermore, the NACCS domain resolution was not high enough to fully resolve the shoreline in Rhode Island, specifically near inlets of coastal ponds [35]. The coupled spectral third-generation wave and hydrodynamic model SWAN+ADCIRC $[7,13,5]$ can be used for further analysis of the results of the NACCS study for the state of Rhode Island.

The southern coast of Rhode Island consists of barrier systems: coastal lagoons between headlands, protected by barrier beaches. Low lying coastal communities such as Charlestown, Matunuck, Misquamicut, and Quonochontaug are already experiencing a trend of coastal erosion. During storms, sediment is pushed over the top of the dunes, into the coastal lagoons [45]. Shaw, et al. (2016) [35] showed that the dunes in these regions are susceptible to erosion during hurricanes, and removal of these dunes would lead to a $200 \%$ increase of inland flooded area if Rhode Island were to experience an event similar to hurricane Bob (1991). These barrier systems along the southern Rhode Island coast protect many other homes and communities from waves and flooding during storms. Because of this, efforts are being made to preserve and restore these systems [44].

A near ban on the construction of new hard structures in Rhode Island means breakwaters or seawalls cannot be used to protect the dunes on these barrier systems [45]. Instead, many areas have looked into dune restoration, using endemic plants to reinforce the dunes [14]. Narragansett town beach is just one example of a location that has made efforts to maintain the coastline by restoring dunes and adding artificial sand to increase total beach area [44]. However, without protection from storms, restored beaches will likely continue eroding until they return to their natural equilibrium. While it is natural for the beach face to increase and 
decrease seasonally, beaches that are altered beyond the extent of these normal fluctuations will retreat due to sea level rise [10].

Historically, beach nourishment projects have focused on hardening the shoreline, recently, methods for erosion mitigation have taken a less invasive approach. One approach is the construction of multi-purpose artificial reefs. Black et. al (2001) discussed the applications of multi-purpose artificial reefs, which mitigate the effects of erosion, while generating tourism by either attracting sightseers, or watersports enthusiasts. By acting as submerged breakwaters, artificial reefs are designed to cause large waves to break offshore, reducing nearshore wave energy and erosion. They could potentially be used to change the direction of waves, directing them away from the beach. Additional purposes range from geo-textile reefs designed for watersports, to reefs designed to provide an environment for fish and crustaceans [16].

\subsection{Objectives}

The primary objective of this research is to develop and validate an accurate and efficient wave, storm surge, and sediment transport model for southern Rhode Island for assessing erosion and also mitigation measures. Two models will be developed to predict waves, water elevation, and nearshore sediment transport for the a region of coastline in southern Rhode Island. SWAN+ADCIRC, a hydrodynamic model developed by UNC (University of North Carolina) and Notre Dame will be used to calculate the wave heights and storm surge on a regional scale. XBeach, a sediment transport model developed by Deltares, TU Delft, and UNESCO-IHE, will be nested in the SWAN+ADCIRC model. Waves and water levels from the SWAN+ADCIRC model will be used as forcing for sediment transport. Bed level changes will be analyzed along dune transects, and throughout the nearshore model domain over the duration of the storm. This model will be 
used to analyze the potential impact of a 100-year storm, without assuming any changes of bathymetry due to sea level rise or receding shoreline. The focus will be on storm-scale analysis, with sediment transport simulations lasting a few days.

Hurricanes Irene (2011) and Sandy (2012) will be simulated to validate the model. The wave heights and storm surge within SWAN+ADCIRC will be compared to NOAA tidal and wave stations within the domain. Volume of beach erosion will be analyzed along three transects within the XBeach domain. Along each of the transects, which are measured bi-monthly, the measurements directly

proceeding and following the event of interest are used. For the 100-year storm, the sediment transport will be analyzed along each of these transects.

Once the model was validated, the bathymetry in the XBeach model is altered to represent an artificial reef directly offshore from Charlestown beach. The accumulated erosion/accretion along the beach and dunes is compared to simulated results with and without the artificial reef present.

\subsection{Methods}

\subsubsection{Numerical Models}

This study uses ADCIRC, SWAN, and XBeach to estimate water levels, waves, and erosion, respectively, for a stretch of beach in southern Rhode Island. The boundary conditions for the sediment transport model are produced using SWAN+ADCIRC.

SWAN is a third-generation wave model, developed by the Delft University of Technology [5]. It uses the spectral wave action balance equation to solve for the 2-Dimensional wave spectrum over the computational domain. It was coupled with ADCIRC, developed by the University of North Carolina, is an ocean model that uses the finite element method to solve for time dependent tidal and surge equations across an unstructured grid [7]. The numerical formulation of these 
models are summarized in Appendix A.

SWAN+ADCIRC was used to estimate the regional wave heights and water levels, and provide forcing for XBeach. XBeach, developed by Deltares, TU Delft, and UNESCO-IHE, is a sediment transport model developed for analysis of beach erosion in small domains [31]. It is a fully integrated sediment transport model, comprised of short wave, hydrodynamic or long wave, sediment transport, and morphologic modules. Appendix B contains further description and the mathematical formulation of XBeach.

\subsubsection{Area of Study}

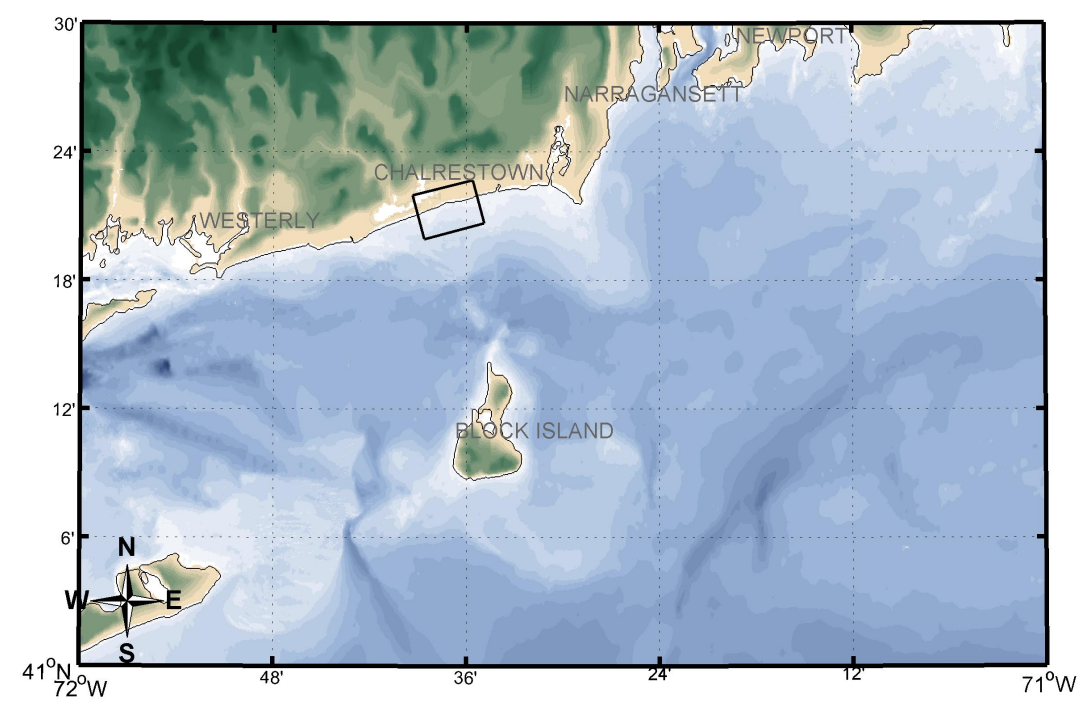

Figure 1: The study area for the nearshore sediment transport model.

The primary focus of this study is on the sediment transport along a 3.5 km section of coastline in southern Rhode Island, shown in Figure 1. The area of interest is located between Green Hill beach and Charlestown Breachway and serves as a barrier beach protecting the Eastern portion of Ningret Pond Coastal 
Lagoon. An XBeach model covering this domain is used for analysis of sediment transport during storms. In order to provide accurate input for this region, waves and tide need to be modeled on a much larger scale. Two computational domains were used for this research. Torres et al. (2017) [9] produced a high resolution regional ADCIRC mesh based on the Northeast Coastal Ocean Forecast System (NECOFS) Gulf of Maine (GOM4) [7]. The mesh resolution along the southern coast of Rhode Island has been increased from 1000 to 200 meters (with 100 meter resolution near inlets). Figure 2 shows the regional domain, and the nesting of the nearshore domain over the mesh.
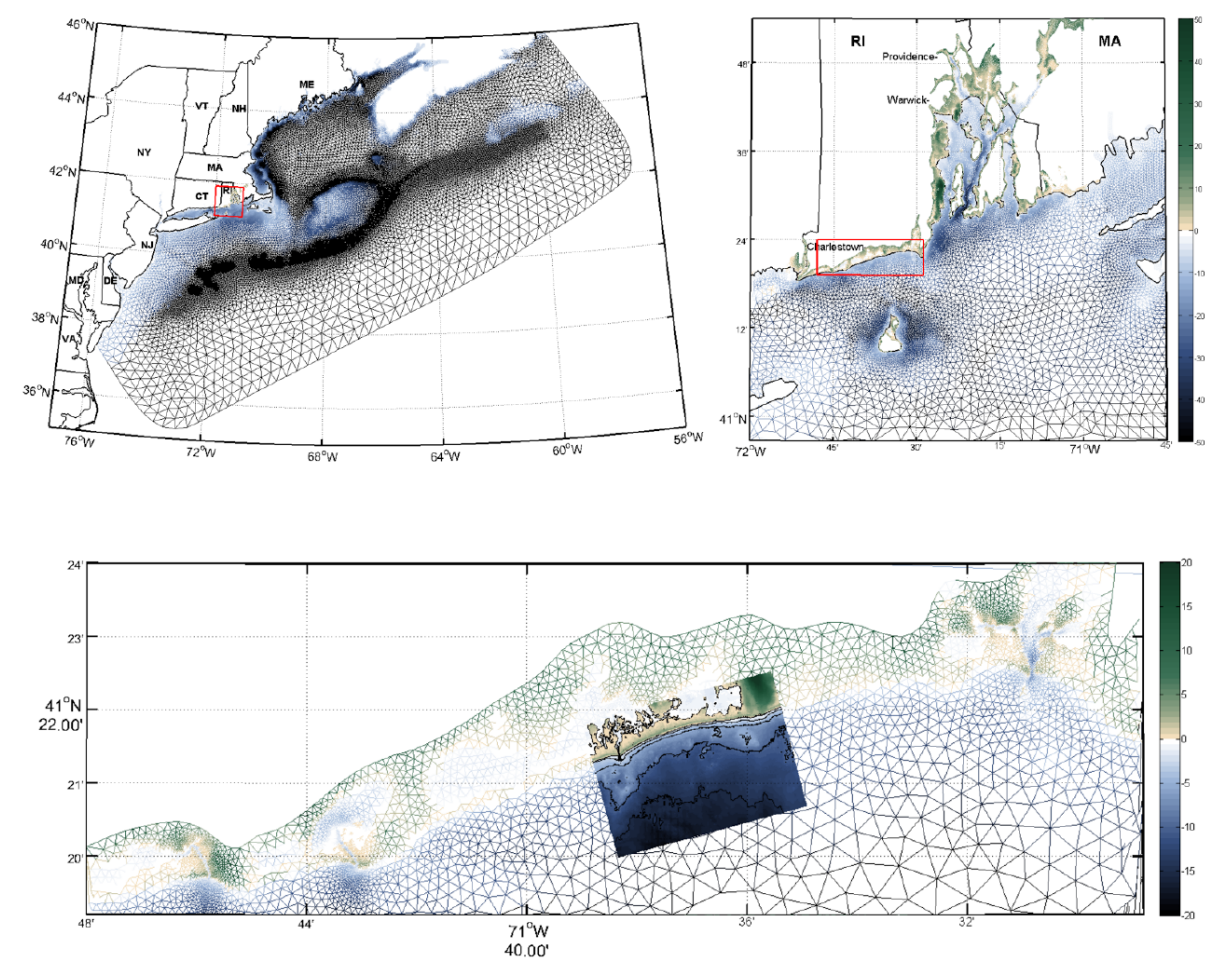

Figure 2: SWAN+ADCIRC computational domain (top), and the nested XBeach grid (bottom)

The nearshore domain was chosen for a number of reasons. First, it is representative of much of the southern Rhode Island barrier systems, as the dunes are low lying, and could easily be breached during a significant storm. Dune crests 
through this region have a maximum elevation between 3 and 5 meters in reference to NAVD88. The 100-year return period water elevation of 3.46 meters would inundate much of the region, even without the consideration of wave runup or erosion. The Charlestown Breachway, and Green Hill create a natural basin, sediment flux within this region would be considerably less than an exposed strip of beach. This reduces unrealistic sediment accretion near boundaries, as sediment should be preserved between Green Hill and the breachway.

The domain chosen extends beyond the area of interest, to prevent additional erosion or accretion due to the presence of the boundaries from affecting the results. Obliquely incident wave directions tend to artificially accelerate erosion along the exposed boundary, and reduce erosion along the shadowed boundary in the XBeach model. To correct these issues, the domain size was increased using increasing grid spacing in these shadow zones. The resulting domain, shown in Figure 3 was 5000 by 3500 meters in the longshore and cross-shore directions, respectively.

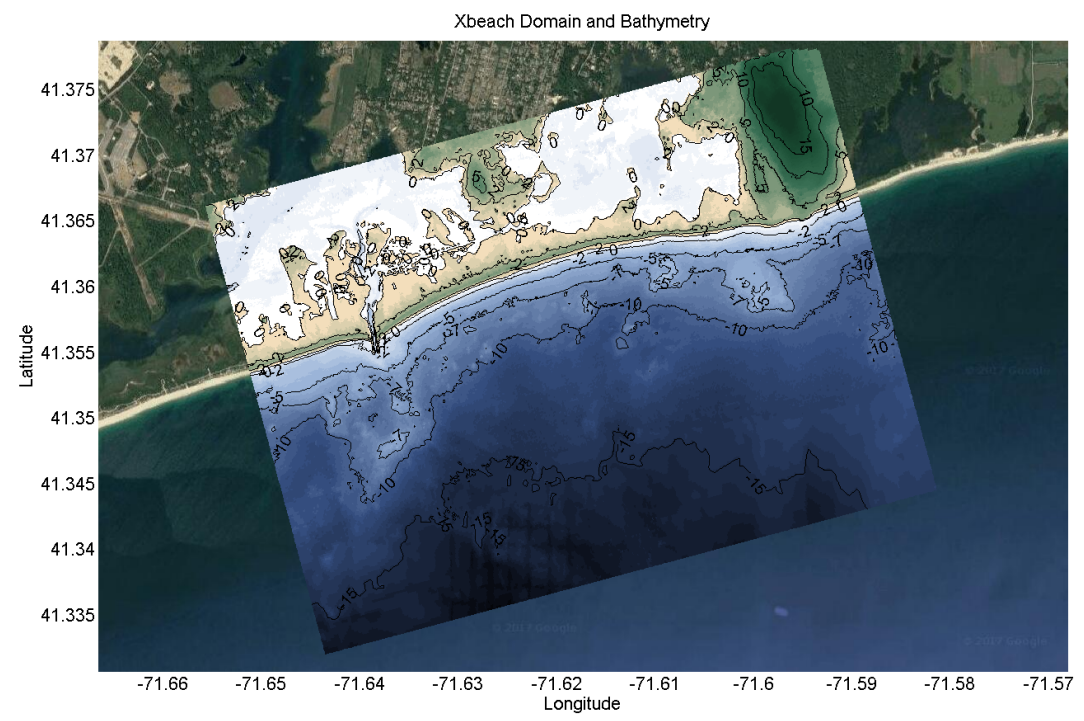

Figure 3: Google Maps image of Charlestown, with XBeach domain overlay. Elevation shown by contours in meters 


\subsubsection{Historic and Synthetic Storms}

Four simulations of tropical storms were performed, which are shown in Figure 4. Hurricanes Irene (2011) and Sandy (2014) were used as validation for the SWAN+ADCIRC and XBeach models. Using save points from the NACCS study, two synthetic storms with peak water elevations close to the 100-year return period water elevation in Newport were chosen. The tropical storm parameters from these storms were applied to a symmetric Holland parametric wind field, and used to force the wave, surge, and sediment transport model.

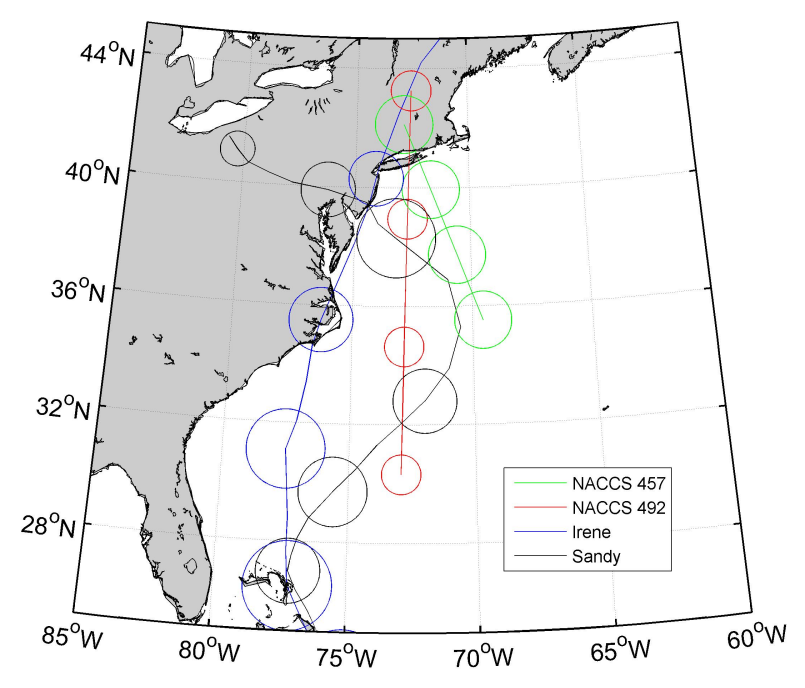

Figure 4: Hurriucane tracks and Radii of Maximum Winds (RMW) for Hurricanes Irene (blue) and Sandy (black), along with NACCS synthetic storms 457 (green) and 492(red). The RMW are shown in 24-hour increments to illustrate forward velocity.

Hurricane Irene was the costliest hurricane of the 2011 tropical storm season [26]. It formed on August 21, 2011, and reached Category 3, before making landfall in North Carolina as a Category 1. Irene affected many states in the northeast United States, surge reached 2.16 meters above mean sea level in North Carolina. As Irene continued north, it made landfall again as a tropical storm in New York, New Jersey, and Connecticut, again bringing significant surge and waves. The 
storm passed through the state of Vermont until it dissipated on August 30, 2011 [1]. Off the coast of Rhode Island, wave heights reached $9 \mathrm{~m}$ during the peak of the storm at the CDIP 154 buoy. Although large waves affected much of Rhode Island, the maximum surge along the southern coast was less than 1 meter [26].

Hurricane Sandy, also known as 'Superstorm Sandy' was the second costliest hurricane of all time in the United States (second to Katrina, 2005) ${ }^{1}$. It formed on October 22, 2012 in the Caribbean, and interacted with another storm system before making landfall as a tropical storm in New Jersey on October 29th. New Jersey and New York took the biggest hit from the storm, where severe waves and surge resulted in significant erosion and damage to and around shoreline structures[2]. Rhode Island experienced 1.5 meters of storm surge in Providence, while Newport and the southern beaches experienced approximately $1 \mathrm{~m}$ of surge. The combination of waves and tide resulted in statewide damage to the southern beaches. Dune over-topping and overwash fans were common in low points of many of the dunes, such as the portion of Misquamicuit beach shown in Figure 5.

To model the erosion due to a 100-year storm, two storms from the NACCS database were chosen. The peak water elevation from two storms closely matched the upper 95 percent confidence interval of the $1 \%$ annual water elevation plus mean high high water (MHHW) in Newport [5] (3.46 meters NAVD88). At save point 8741 (Closest to the Newport tidal gauge), storms 457 and 492 had maximum surges of 3.48 and 3.50 meters, respectively.

Storm 457 is representative of a landfalling Category 2 Hurricane, with a heading of $-20^{\circ}$, the eye of the storm passes through the tip of Long Island. The radius of maximum winds is 58 nautical miles, and travels directly up the Narragansett Bay. The forward velocity of the storm is $54 \mathrm{kmh}$, and a pressure deficit of -88 millibars. The duration of the time-series data at NACCS save point 9136

\footnotetext{
${ }^{1}$ The recent estimated cost of hurricanes within the 2017 season are considered.
} 


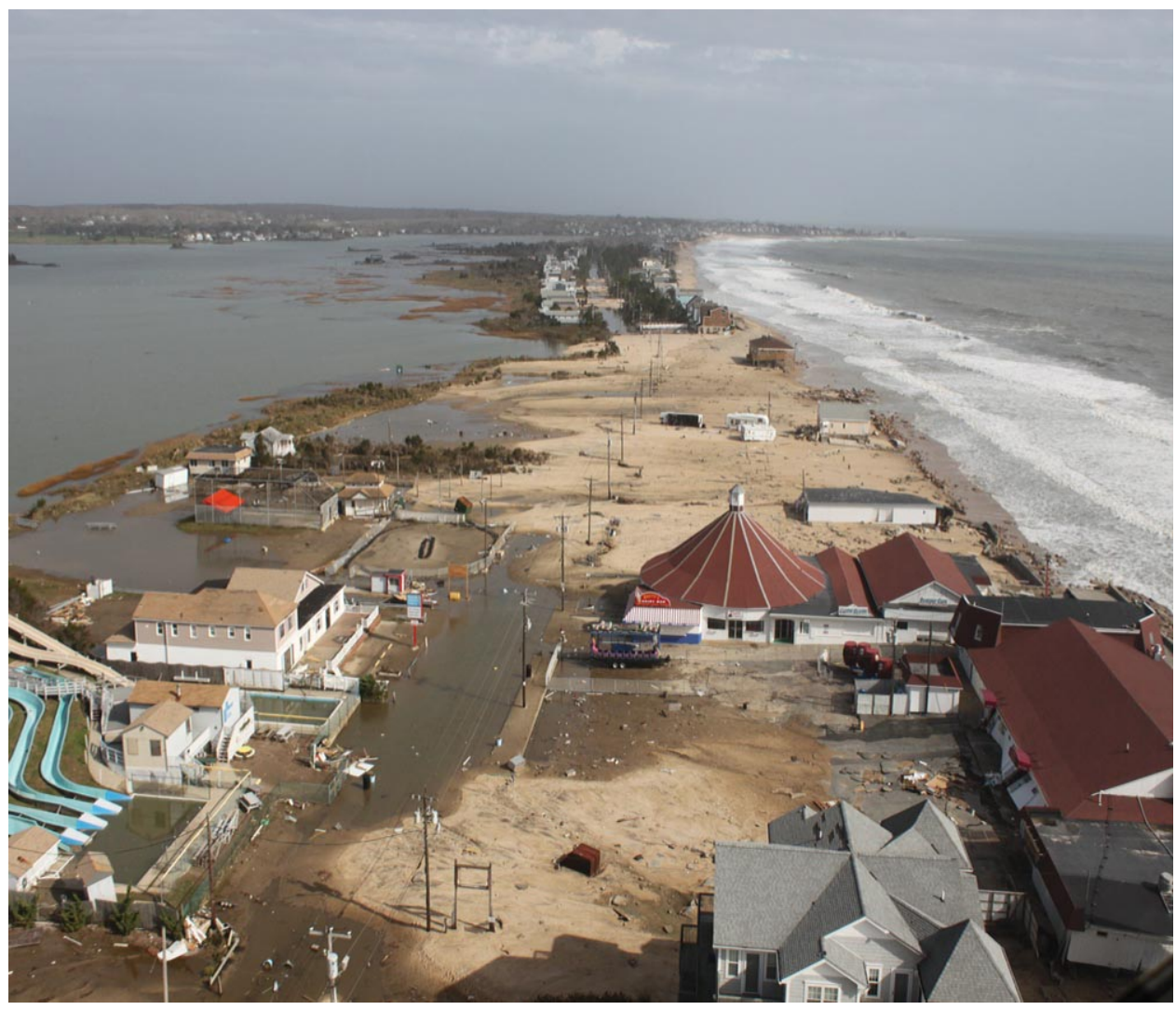

Figure 5: Overwash in Misquamicuit, Rhode Island after hurricane Sandy. Photo: Rhode Island Department of Transportation 
(Charlestown, Rhode Island) is 120 hours.

The Radius of maximum winds for storm 492 is 34 nautical miles, it's heading is $0^{\circ}$, and the eye passes through Long Island. The size and velocity is similar to that of hurricane Bob (1991), as it has a forward velocity of $99 \mathrm{kmh}$. The entire time-series duration of the storm at save point 9136 is 48 hours.

\subsubsection{Data}

Model Forcing and Bathymetric Data

The topographic data used for the XBeach domain is 1 meter resolution, on the state plane coordinate system, the $\mathrm{z}$ datum is in feet, and referenced to NAVD88. Topographic data was taken using LIDAR, the data was made available online by the Rhode Island Geographic Information System [30].

Three meteorological forcing products were used to force the SWAN+ADCIRC model, and were chosen based on availability. NECOFS Weather Research and Forecasting (WRF) atmosperic forcing uses three nested domains of increasing resolution from $27 \mathrm{~km}$ to $3 \mathrm{~km}$, and provides a 3 -day hindcast and 3-day forecast of atmospheric data. A WRF hindcast of Hurricane Sandy includes a synthetic (bogus) vortex to improve hindcast accuracy near the storm center [2]. Because the WRF data was unavailable for hurricane Irene, the European Centre for Medium Range Weather Forecast (ECMWF) ERA-interim model was used. ECMWF's ERA-interim model is a global hindcast dataset, publicly available for weather re-analysis [4]. The model utilizes data assimilation to improve the hindcast accuracy. The highest available resolution is $1 / 8$ degree spatial resolution, 6 hours increments.

A python script was used to create a Holland model over the computational domain using NACCS storm parameters [24]. For storms 457 and 492, the 10 meter $\mathrm{U} \& \mathrm{~V}$ velocity components, and sea level pressure are applied to the 
SWAN+ADCIRC domain. The meteorological forcing is in hourly increments, and is applied at each of the nodes within the domain.

\subsubsection{Numerical Model Setup and Physical Processes Regional tidal and surge model}

For extreme event wave and storm surge modeling in Rhode Island, a coupled SWAN+ADCIRC model was set-up and validated. The unstructured mesh used for SWAN and ADCIRC has greater spacing offshore, which reduces the total number of nodes compared with a structured cartesian grid over the same domain. This also allows for high resolution computation without the use of grid nesting. The nodal spacing at the boundaries is approximately $100 \mathrm{~km}$, while the nearshore resolution varies from 30-100 m. During a storm, tidal forcing is applied to each of the boundary nodes, and atmospheric forcing is applied across the entire domain.

The SWAN+ADCIRC model utilized two different global wind models for atmospheric forcing, based on availability. The Northeast Coastal Ocean Forecasting System (NECOFS), and the European Center for Medium Range Forecasts (ECMWF). Torres et al. (2017) [9] showed that if available, the WRF wind forcing provides the most accurate results for both waves and storm surge in the state of Rhode Island. Figure 6 shows a snapshot of the WRF forcing over the SWAN+ADCIRC domain. WRF was used as forcing for Sandy, and because it was unavailable, ECMWF was used for Irene.

The 10-meter U, V components, and surface pressure were applied to SWAN+ADCIRC by interpolating onto each node in the domain in hourly increments. ADCIRC interpolates these values internally for each computational time step (0.5 seconds), and the coupled SWAN model reads wind, water levels, and friction from ADCIRC and uses these to compute the wave conditions every 10 minutes. 


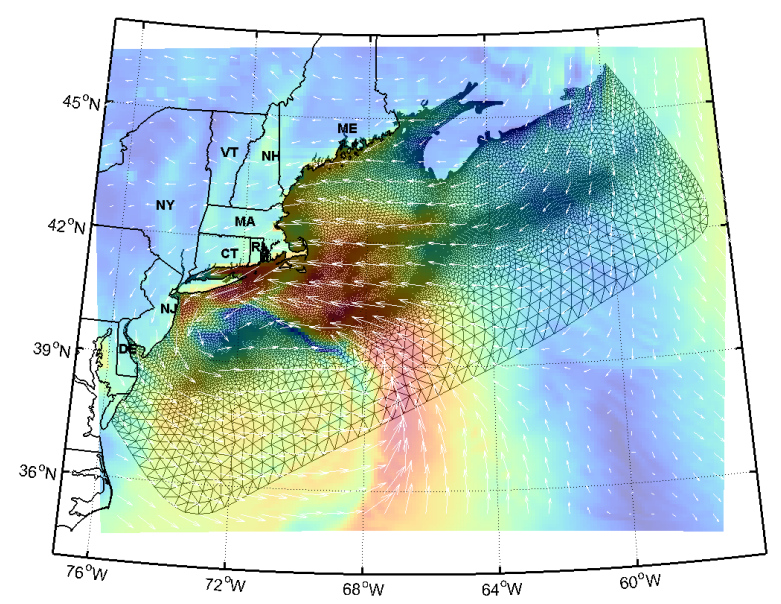

Figure 6: WRF forcing over SWAN+ADCIRC computational domain, snapshot from NorEaster Stella, March 14, 2017 6:00am

In SWAN, the wave energy domain was discretized into 36 directional bins over 40 frequencies ranging from .0314 to $1.4204 \mathrm{~Hz}$. By default, SWAN uses logarithmic spacing for the frequency bins. This increases the accuracy in lower frequencies, where the spectral peak usually is during a storm. Third-Generation whitecapping was used, with the whitecapping coefficient $=2.36 \mathrm{E}-5$, the value for wave steepness $=3.02 \mathrm{E}-3$, power of normalized steepness $=2.0$, whitecapping dependency $=1.0$ and power of wave number normalized with wave number $=1.0$. Triplets, quadruplets, and depth induced breaking was also activated. Under the numerics option, a CFL (Couriant-Friedrichs-Lewy) condition of 0.5 were applied to the refraction to prevent unrealistic focusing of waves due to coarse meshing $[12]$.

The SWAN+ADCIRC model provides global water elevations, depth averaged $\mathrm{U}$ and $\mathrm{V}$ current velocities, significant wave height (Hs), Peak Period (Tp) and mean wave Direction $\left(\theta_{m}\right)$ every hour. For validation, water elevation outputs were generated every 30 minutes in Newport and Providence, and the spectral output was extracted at the nearest node to CDIP 154 station. To force the 
XBeach model during storm conditions, the two-dimensional spectrum and water levels were extracted at the location of the XBeach domain origin.

\section{Nearshore sediment transport and erosion model}

A high resolution XBeach model was set up to model the effects of storms on barrier beaches. The domain, shown in Figure 3, was used to calculate waves, water elevation, water velocities, and sediment transport to analyze the dune erosion, and overtopping due to storm conditions. To set up the model, sediment samples were taken at a number of locations along the beach. The grain size distribution was used as input for XBeach by providing the diameters at which 50\% and $90 \%$ of the sediment sample's mass was comprised of smaller sediment (D50 and D90, respectively). Topography for the domain is $1 \mathrm{~m}$ resolution, and the bathymetry was interpolated into $1 \mathrm{~m}$ resolution. The bathymetry/topography was interpolated onto the computational grid. The domain was approximately $5 \times 4 \mathrm{~km}$, and was rotated 15 degrees counter-clockwise to ensure the coast is parallel to the offshore boundary. The domain was on an irregular cartesian grid, optimized for high resolution across the dunes. The grid resolution was $5 \times 10 \mathrm{~m}$ in the cross-shore and longshore directions, respectively, and decreases to $25 \times 25 \mathrm{~m}$ resolution at the boundary. The nodal spacing can be seen in Figure 7. This reduces computational cost in relation to a uniform grid, without sacrificing resolution across the dunes.

All XBeach sediment computations are made in what is defined as "morphological time". To increase the speed of computation, the morphological acceleration factor morfac(MF in bottom-updating formulation), can be used to decrease computational cost. A morfac value of 5 is used to decrease the computation time for the XBeach model. All input time steps are divided by morfac for the duration of the run, speeding up all processes in XBeach. The conversion from real-time to morphological time basically causes XBeach to run all processes in fast-forward. 
Table 1: XBeach variables and descriptions

\begin{tabular}{|c|c|c|}
\hline Variable & $\begin{array}{l}\text { Value } \\
\text { Used }\end{array}$ & Description \\
\hline nx, ny & $400 \times 500$ & $\begin{array}{l}\text { Number of nodes in } \mathrm{x} \text { and } \mathrm{y} \text { directions, } \\
\text { respectively. }\end{array}$ \\
\hline $\begin{array}{l}\text { Wave } \\
\text { Hydrody- } \\
\text { namics }\end{array}$ & Surf-Beat & Wave forcing option \\
\hline morfac & 5 & $\begin{array}{l}\text { Morphological acceleration factor, used } \\
\text { to decrease computation time by reduc- } \\
\text { ing frequency of bottom-updating. }\end{array}$ \\
\hline dtbc & 2 & $\begin{array}{l}\text { Frequency at which the wave flux at the } \\
\text { boundary is randomized and updated } \\
\text { (seconds). }\end{array}$ \\
\hline rt & 3600 & $\begin{array}{l}\text { Frequency XBeach reads a new bound- } \\
\text { ary condition file and re-compute wave } \\
\text { energy spectrum (seconds). }\end{array}$ \\
\hline facua & $0.25-0.3$ & $\begin{array}{l}\text { Asymmetric onshore sediment trans- } \\
\text { port to counteract wave asymmetry. }\end{array}$ \\
\hline tsmin & 0.1 & $\begin{array}{l}\text { Minimum time step in advection- } \\
\text { diffusion equation. }\end{array}$ \\
\hline tintg & 600 & $\begin{array}{l}\text { global variable output timestep (sec- } \\
\text { onds). }\end{array}$ \\
\hline globalvar & $\begin{array}{l}\mathrm{zs}, \mathrm{zb}, \mathrm{H}, \\
\mathrm{u}, \mathrm{v}, \text { sedero, } \\
\mathrm{Qb}, \text { urms }\end{array}$ & $\begin{array}{l}\text { global variables output every tintg sec- } \\
\text { onds. }\end{array}$ \\
\hline $\begin{array}{l}\text { Boundary } \\
\text { Forcing }\end{array}$ & $\begin{array}{l}\text { SWAN+ } \\
\text { ADCIRC } \\
2 \mathrm{D} \quad \text { Spec- } \\
\text { trum }\end{array}$ & $\begin{array}{l}\text { Method for providing wave boundary } \\
\text { conditions }\end{array}$ \\
\hline Friction & $\begin{array}{l}\text { Manning } \\
0.02\end{array}$ & Bottom friction formulation \\
\hline
\end{tabular}




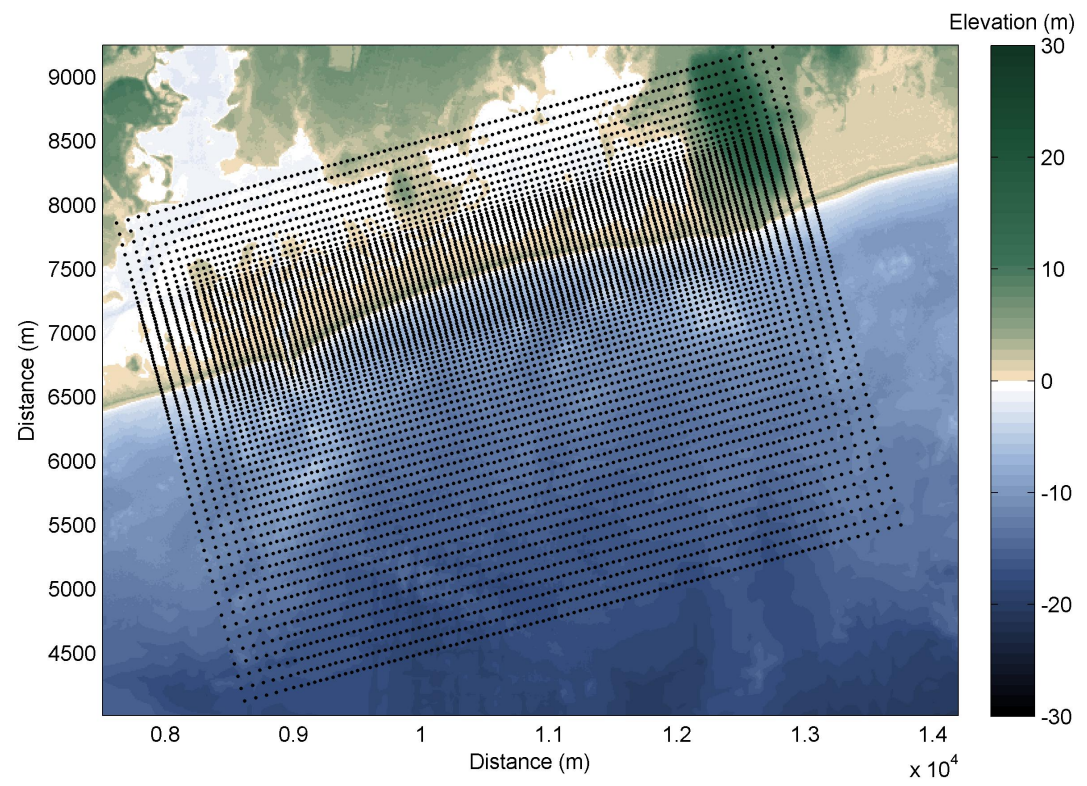

Figure 7: Grid spacing of XBeach domain over bathymetry (every 10th node shown), resolution is highest across the barrier beach in the middle of the domain

Using $m o r f a c=5$ means Xbeach runs for 12 minutes each hour, dividing all time inputs by morfac, and multiplying each resulting bed level change by 5 . Upon completion, the results are converted back to real-time by multiplying the morphological time by the morfac value. Trouw et al. (2012) [40] showed that morfac values between 1 and 10 provide only minor differences.

Because the XBeach model was originally calibrated for beaches in the North Sea, changes need to be made within the model to accurately predict sediment transport in the northeastern United States. In most cases, XBeach tends to overestimate the erosion under extreme waves and storm surge. McCall et al. (2010) [23] were able to improve performance of an XBeach model in the Gulf of Mexico by changing shields parameter values, along with storm duration. De Vet et al. (2015) [9] and Nederhoff et. al (2015) [29] showed that a facua parameter of 0.25 was best to simulate the erosion during hurricane sandy in Fire Island NY 
and Bay Head NJ, respectively. Additionally, Schambach (2016) [33] used a facua of 0.3 for the best agreement in southern Rhode Island during tropical storm Irene. Values of 0.3 and 0.25 were both used, in order to calibrate the XBeach model. Table 1 summarizes the parameters used for the sediment transport model.

\subsection{Results}

\subsubsection{Development of Beach Erosion Model Validation of the regional model}

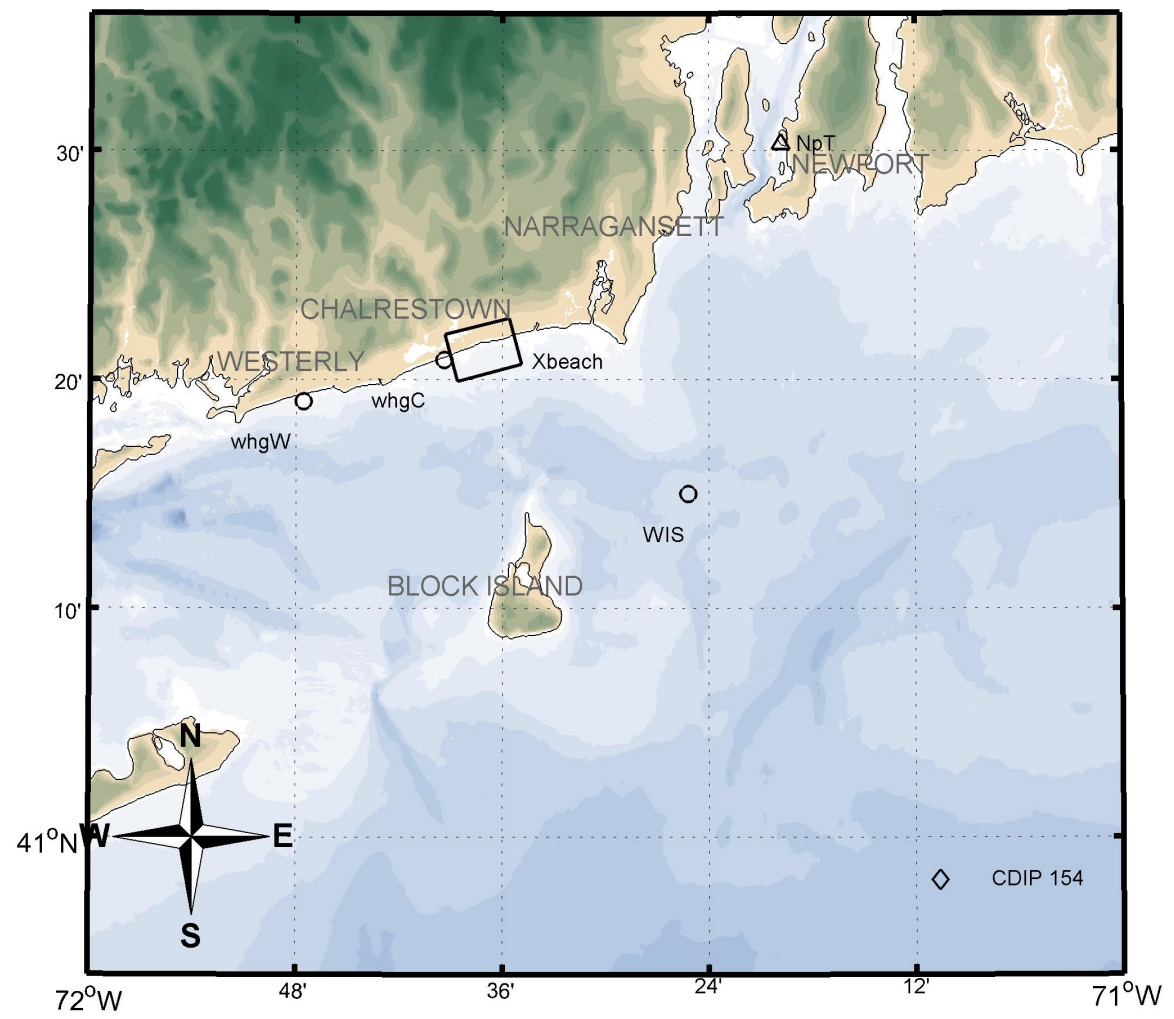

Figure 8: Locations of data used for validation of SWAN+ADCIRC. Spectral Wave Buoys (diamond), Tidal Stations (triangle), other wave data (circle), and the location of the XBeach domain (rectangle) are shown.

To validate the SWAN+ADCIRC model, wave data was compared offshore with measurements taken from the Scripps CDIP 154 buoy historical database [42]. Water elevations were compared to the Newport water elevation station in 6 minute increments, referenced to mean sea level, elevation in meters [5]. Addition- 
ally, three Acoustic Doppler Current Profilers that had been installed by Woods Hole Group from August 2010-October 2011 were used to validate nearshore wave heights during hurricane Irene (whgC, whgW in Figure 8). A hindcast of Hurricane Sandy was modeled to validate wave heights, and water levels within the domain. First, the SWAN+ADCIRC model was run in order to compute the boundary inputs for XBeach. NECOFS WRF hindcast winds were obtained from UMASS Dartmouth $^{2}$, and used to force the model. A comparison of the time series at the Newport water elevation station and CDIP 154 wave buoy can be seen in Figure 9 .

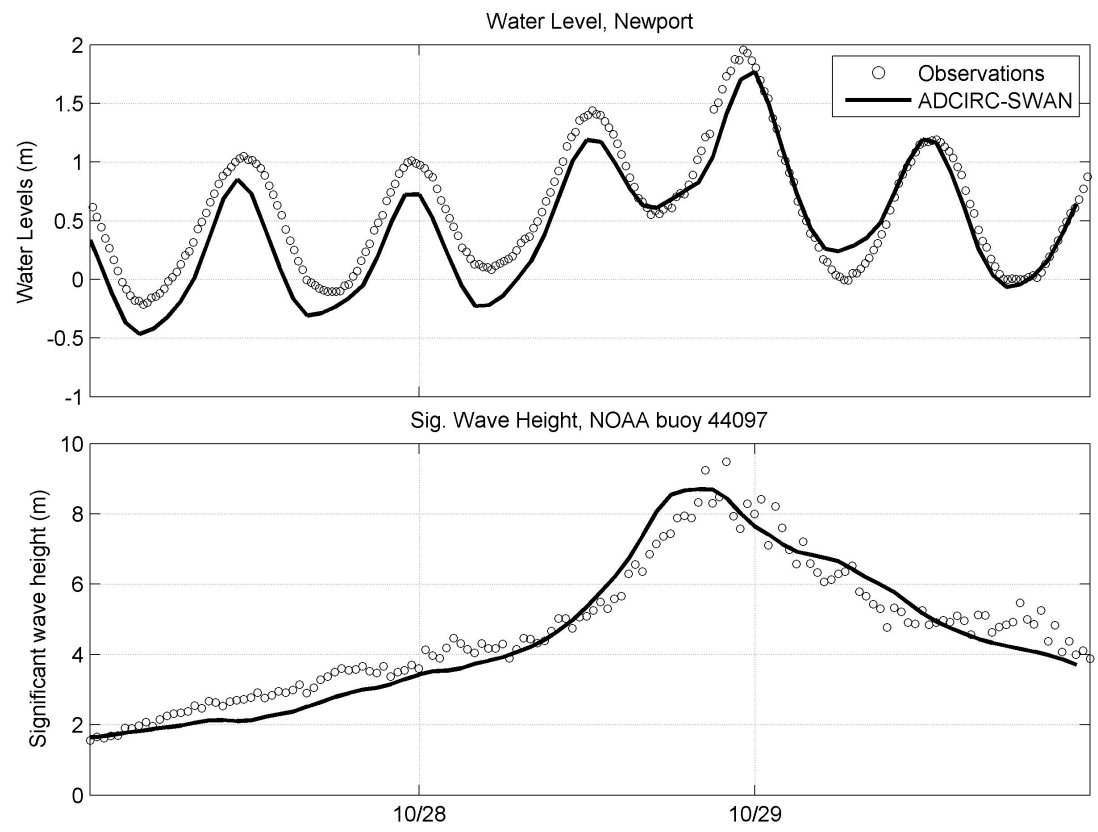

Figure 9: Time series of water levels measured at the Newport tidal gauge (top) and waves measured at CDIP buoy 154 (bottom) during hurricane sandy, compared to modeled data. Water level RMSE: 0.21, Significant Wave height RMSE: $0.15 \mathrm{~m}$

As shown in Figures 9 and 10, the SWAN+ADCIRC model shows relatively good agreement with measured data during the peak of the Storm for both water

\footnotetext{
${ }^{2}$ http://fvcom.smast.umassd.edu/
} 

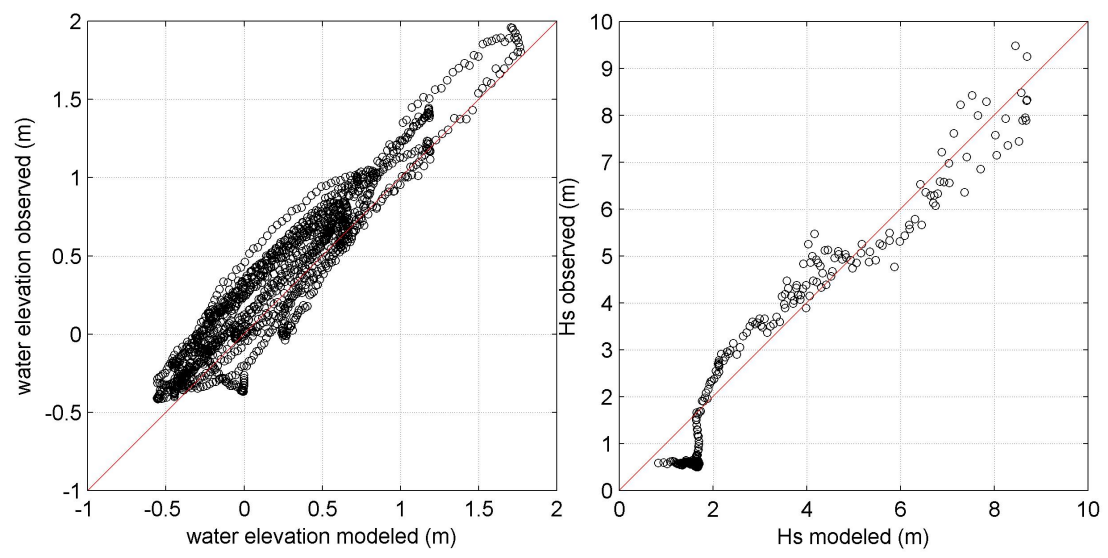

Figure 10: $\mathrm{r}^{2}$ for water elevation at the Newport gauge (left) and waves at the CDIP 154 buoy (right) during Hurricane Sandy SWAN+ADCIRC simulation.

levels and significant wave heights. Because the SWAN+ADCIRC model was used to provide spectral input to XBeach, a spectral analysis of the conditions during Sandy was performed to further analyze the accuracy of the model. During the simulation, the 2-D wave spectrum was extracted from the node nearest to CDIP 154 buoy, and was compared with the measured 9-band spectra.

Figure 11 compares the observed energy in 9 frequency bins with the corresponding wave spectrum in SWAN+ADCIRC. Table 2 shows the RMSE of the water levels from the NOAA Newport water level station, along with significant wave height, and 1-Dimensional spectrum from the CDIP 154 buoy. By breaking down the observed energy spectrum, the performance of the model can be further assessed. The greatest error was located in the bins between 12 and 16 seconds, these bins also contained the largest observed energy. The SWAN+ADCIRC model overestimates energy in the lower frequencies $(16 \mathrm{~s}<\mathrm{Tp}<22 \mathrm{~s})$, and tends underes- 
timate the high frequency tail $(\mathrm{Tp}<5 \mathrm{~s})$. However, the total energy of the model is close to the observations.

Table 2: RMSE of water levels, waves, and 1-Dimensional spectrum during Hurricane Sandy.

\begin{tabular}{|l|c|}
\hline Variable & RMSE \\
\hline \hline Water Level & $0.21 \mathrm{~m}$ \\
\hline Sig. Wave Height & $0.15 \mathrm{~m}$ \\
\hline \hline Spectrum band E(22+seconds) & $0.003 \mathrm{~m}^{2} / \mathrm{Hz}$ \\
\hline Spectrum band E(18-22seconds) & $0.057 \mathrm{~m}^{2} / \mathrm{Hz}$ \\
\hline Spectrum band E(16-18seconds) & $0.173 \mathrm{~m}^{2} / \mathrm{Hz}$ \\
\hline Spectrum band E(14-16seconds) & $0.240 \mathrm{~m}^{2} / \mathrm{Hz}$ \\
\hline Spectrum band E(12-14seconds) & $0.209 \mathrm{~m}^{2} / \mathrm{Hz}$ \\
\hline Spectrum band E(10-12seconds) & $0.110 \mathrm{~m}^{2} / \mathrm{Hz}$ \\
\hline Spectrum band E(8-10seconds) & $0.990 \mathrm{~m}^{2} / \mathrm{Hz}$ \\
\hline Spectrum band E(6-8seconds) & $0.104 \mathrm{~m}^{2} / \mathrm{Hz}$ \\
\hline Spectrum band E(0-6seconds) & $0.127 \mathrm{~m}^{2} / \mathrm{Hz}$ \\
\hline
\end{tabular}

\section{Hurricane Irene Simulation}

Torres et al. (2017) [9] validated the significant wave height and water levels for Hurricane Irene on the SWAN+ADCIRC domain. Based on all available meterological forcing datasets, it was shown that ECMWF interim meterological dataset provided satisfactory results for both waves and surge. The error of peak significant wave heights offshore was $-6.2 \%$, and maximum water level error at the Newport tidal guage was $22 \%$. Nearshore, the error for the peak significant wave heights observed in Charelstown, and Westerly, Rhode Island (whgW and whgC in Figure 8) were 10 and 13 percent, respectively. The nearshore model forcing for Irene was extracted from this model at the location of the XBeach domain origin.

\subsubsection{Calibration and validation of the nearshore model}

The XBeach model was calibrated/validated by comparing the volume of eroded sediment $\left(\mathrm{m}^{3}\right)$ along three transects within the domain, shown in Figure 

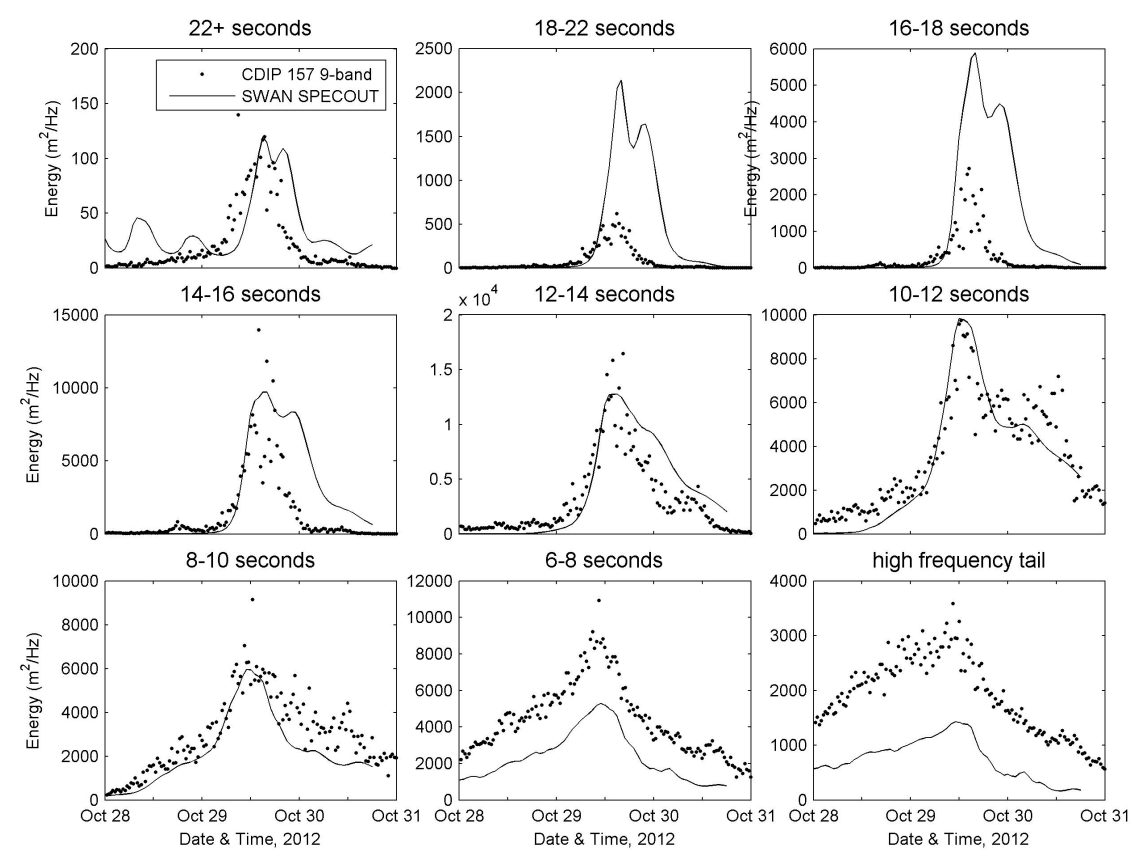

Figure 11: 9-band spectral validation of SWAN results for Hurricane Sandy. The energy in each of the 9 observed frequency bins (dotted) are compared to the swan spectral output (solid). Y-axes are scaled for clarity. 


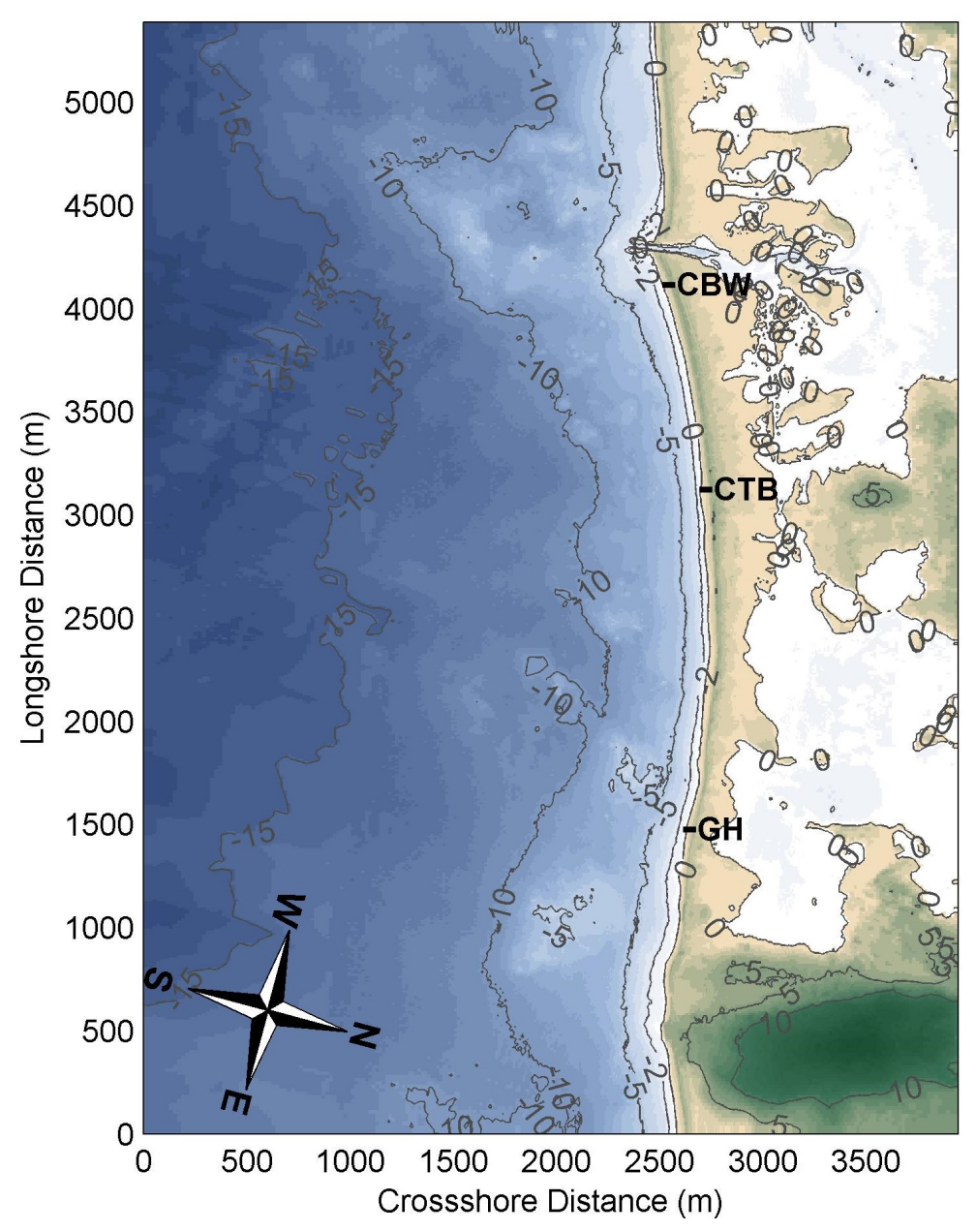

Figure 12: Locations of transects used for validation of the XBeach model: Charlestown Breachway (CBW), Charlestown Beach (CTB), and Green Hill beach (GH) 
12. The transects are measured by referencing a stake behind the normal dune crest, every local minimum and maximum is measured along a designated heading, perpendicular to the shoreline. The data is recorded bi-monthly, or immediately following storms [21]. For each case, the transects directly preceding and following the storms were used.

Hurricanes Sandy and Irene were used to force the XBeach model. Water elevations, and waves from the SWAN+ADCIRC simulation were used as boundary conditions for the XBeach model. The duration of simulation varied from 32 to 48 hours, and erosion was compared to measured transects within the domain shown in Figure 12. The available transect data from before and after hurricanes Sandy and Irene are shown in blue, in Figures 15 and 20, respectively. The hourly input of water levels, and wave conditions corresponding the 2-Dimensional spectrum can be seen in Figures 13 and 17.

\section{Calibration of XBeach}

Waves and water level were taken from the regional model during hurricane Sandy and used to force and calibrate the nearshore model. During hurricane Sandy, the Green Hill and Charlestown Breachway (GH and CBW in Figure 12) stakes were washed away. The Green hill stake was replaced, while the Charlestown Breachway transect was not. The reference change at Green Hill (approximately 10 m North of the previous measurement) was accounted for by shifting the reference points of the post-storm observations. Because the Charlestown Breachway stake was not replaced, there is no post-Sandy data along that transect, and data was not compared at this location during calibration.

Sandy resulted in minor dune over-topping throughout the domain. Figure 14 shows the simulated erosion throughout the XBeach domain during hurricane Sandy. A low-lying region between Green Hill and Charlestown experienced the 

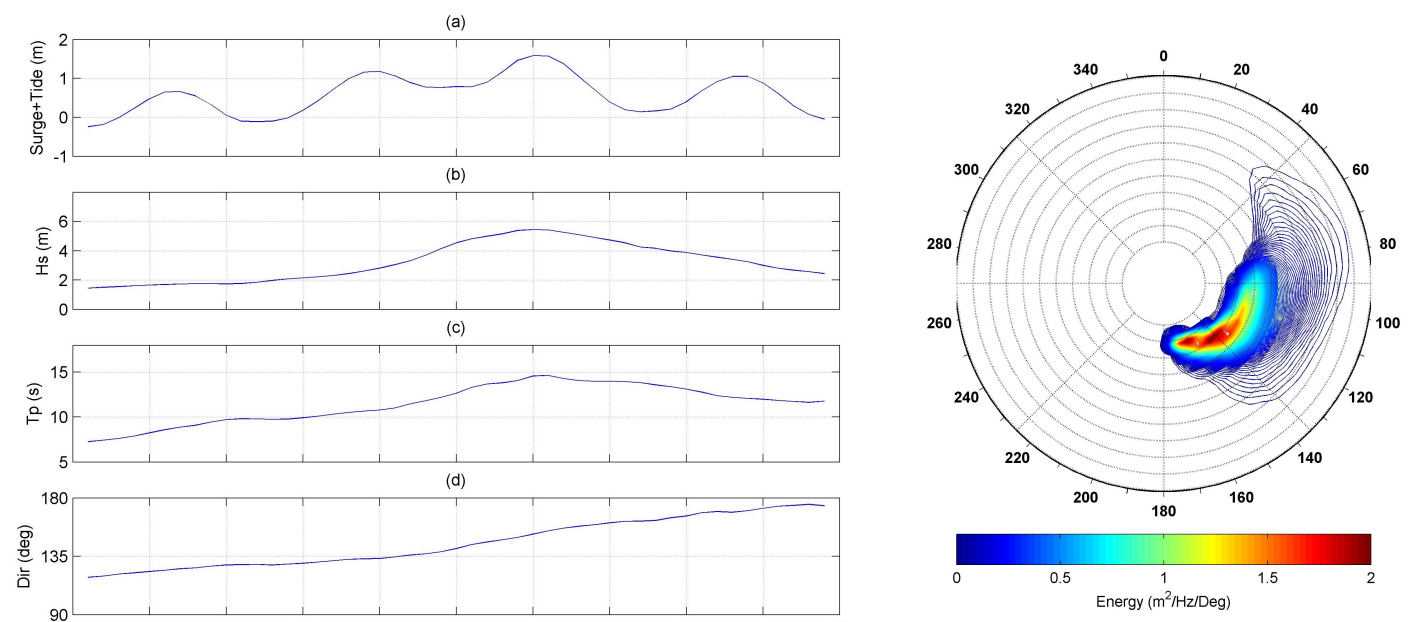

Figure 13: Left: XBeach hourly input for Hurricane Sandy along the seaward boundary. Water elevation due to tide and surge (a) is applied in hourly increments, along with the 2-dimensional wave spectrum. The significant wave height (b), peak period (c), and peak direction (d) corresponding to the wave spectrum are shown for clarity. Right: The 2-dimensional wave spectrum applied to the boundary, during the peak of the storm.
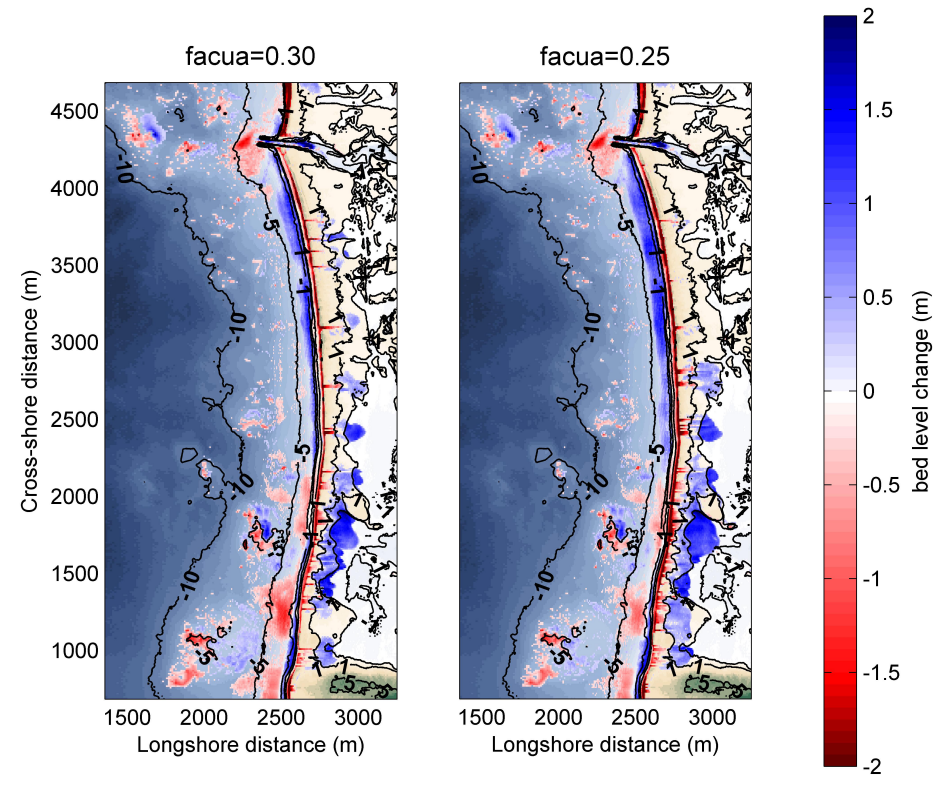

Figure 14: Comparison of accumulated erosion/accretion due to Hurricane sandy with fua value ranging from 0.25 to 0.3 

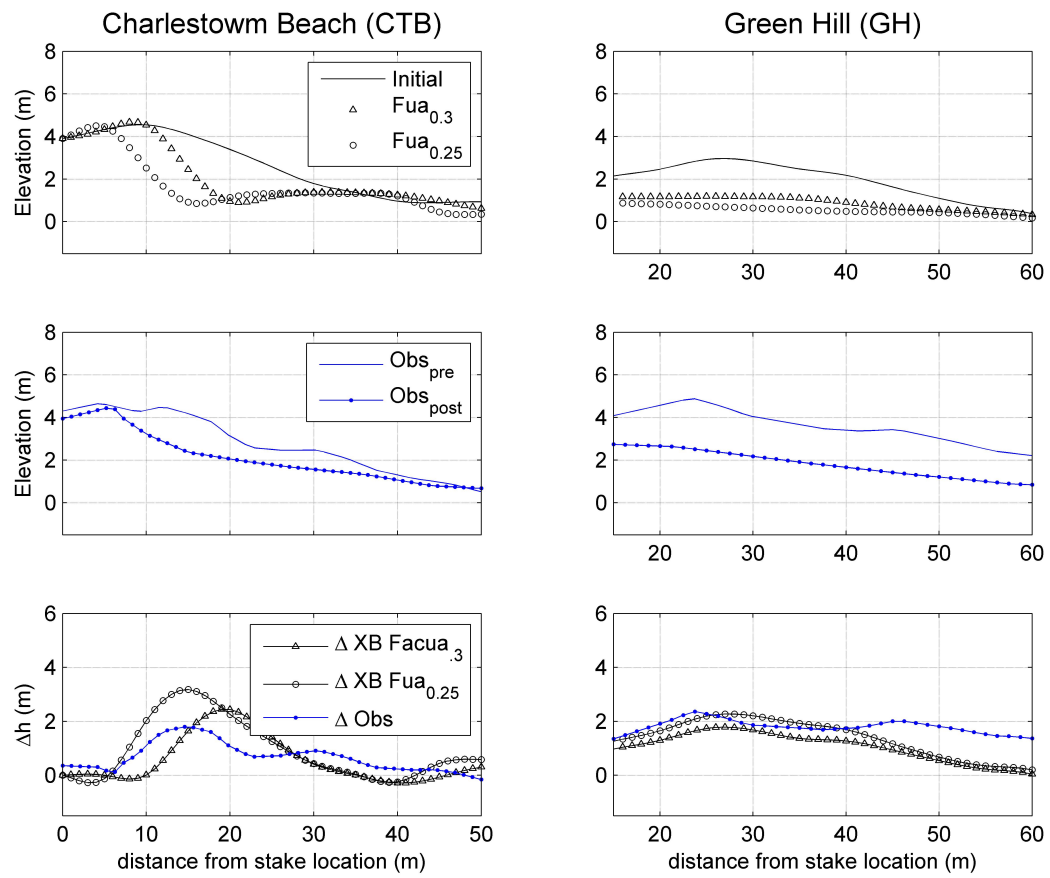

Figure 15: Modeled (top) and measured (middle) elevation before and after Hurricane Sandy are shown along Charlestown Beach (CTB) and Green Hill (GH) transects. The change in elevation along these transects (bottom) are compared for facua values of 0.3 and 0.25

Table 3: Comparison of volume of dune eroded during hurricane Sandy (meters cubed per meter along the beach)

\begin{tabular}{|l|l|l|l|}
\hline location & Observed & Fua $=\mathbf{0 . 3}$ & Fua $=.25$ \\
\hline GH & $81.63 \mathrm{~m}^{3}$ & $49.96 \mathrm{~m}^{3}$ & $65.53 \mathrm{~m}^{3}$ \\
\hline CHTB & $32.72 \mathrm{~m}^{3}$ & $28.01 \mathrm{~m}^{3}$ & $44.40 \mathrm{~m}^{3}$ \\
\hline TOTAL & $114.35 \mathrm{~m}^{3}$ & $77.97 \mathrm{~m}^{3}$ & $109.93 \mathrm{~m}^{3}$ \\
\hline
\end{tabular}



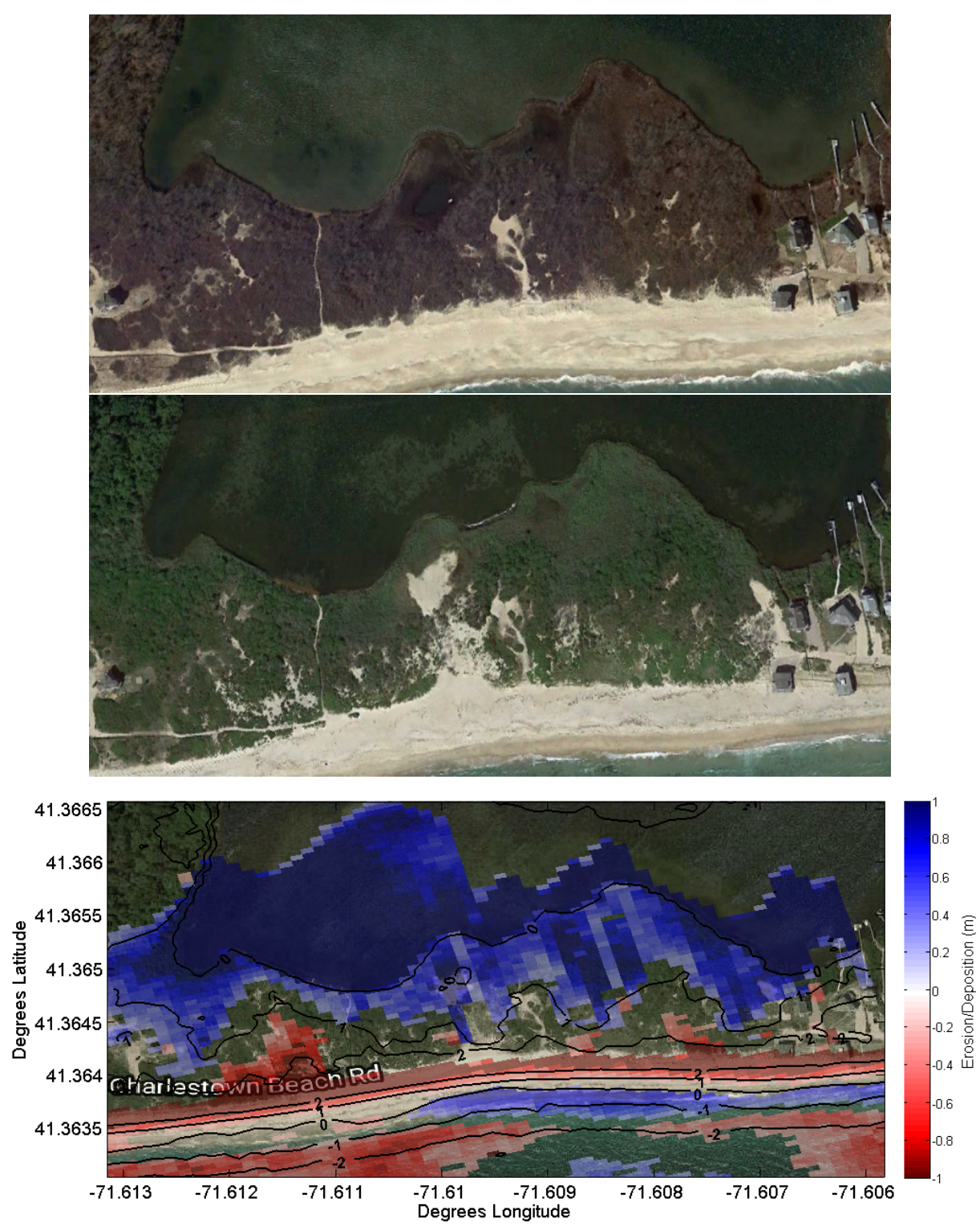

Figure 16: A stretch of barrier beach in May, 2012 (top) and September 2014 (middle) taken before and after Hurricane Sandy. Calculated bed level change in XBeach (bottom) shows sediment pushed over the dunes and created overwash fans. 
greatest damage during the event. Figure 16 compares observed Google Earth images (map Data 2017 google) from before and after Hurricane Sandy in the location mentioned above, and the modeled bed leveled change. Although the dunes had either been repaired or naturally recovered by the time the second image was taken, locations of overwash fans can be seen, vegetation was uprooted, and sediment was deposited behind the dunes. The most apparent region is along the Western boundary of the images shown, as much of the dunes were eroded. There is also a small pond in the center of the first image, filled with sediment during Sandy. Sediment was also deposited in these low-lying area during the XBeach simulations.

The percent error, shown in Eq. 1 was used to analyze results of the XBeach simulations. Both the mean of the percent error $(\overline{\% \text { Error }})$, and the absolute value of the percentage error (|\%Error $\mid)$ were compared to show the model performance along the transects.

$$
\operatorname{error}(\%)=\left(\frac{\text { Volume }_{\text {simulated }}-\text { Volume }_{\text {observed }}}{\text { Volume }_{\text {observed }}}\right) 100
$$

Table 4: Percent error along the observed transects during hurricane Sandy.

\begin{tabular}{|l|l|l|}
\hline Transect & Sandy Fua $=\mathbf{0 . 3}$ & Sandy Fua $=\mathbf{0 . 2 5}$ \\
\hline \hline GH & $-38.7 \%$ & $-19.7 \%$ \\
\hline CHTB & $5.8 \%$ & $20.1 \%$ \\
\hline error $(\%)$ & $-16.8 \%$ & $0.195 \%$ \\
\hline $\mid$ error $(\%) \mid$ & $22.3 \%$ & $19.9 \%$ \\
\hline
\end{tabular}

In Table 3, the eroded volume along transects during hurricane Sandy simulations for facua of 0.25 and 0.30 are compared. The percent error for both facua values compared in Table 4. The calibration of the model to hurricane Sandy showed that a facua of 0.25 provided the most accurate results in relation to a facua value of 0.30 . Although using a facua of 0.3 provided more accurate results 

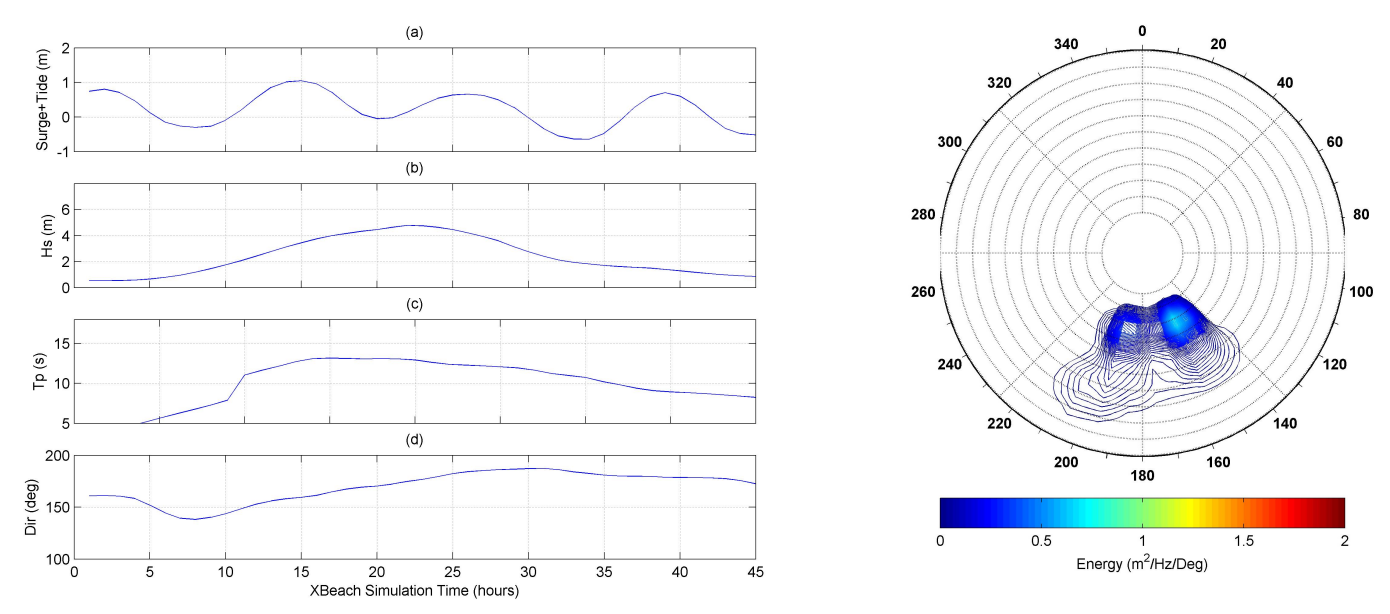

Figure 17: Left: XBeach hourly input for Hurricane Sandy along the seaward boundary, from 00:00 Oct 28, 2012. Water elevation due to tide and surge (a) is applied in hourly increments, along with the 2-dimensional wave spectrum. The significant wave height (b), peak period (c), and peak direction (d) corresponding to the wave spectrum are shown for clarity. Right: The 2-dimensional wave spectrum applied to the boundary, during the peak of the storm.

along the CHTB transect, both the mean percent error, and mean of the magnitude of percent error were lower for a facua value of 0.25 . Therefore, it was determined that using a facua value of 0.25 would provide better results throughout the entire domain.

\section{Validation}

Tropical storm Irene was used to validate the nearshore sediment transport model. All three transects had data available for comparison to modeled results for this storm. Although Irene produced large waves measured at CDIP 154 buoy, the southerly direction resulted in a significant amount of swell shadowing by Block Island. The peak surge from Irene was also significantly less in relation to Hurricane Sandy. The storm did not cause any dune over-topping within the domain. Because of this, all three stakes used as reference for transect measurement remained intact. Figures 18 and 19 compare the modeled erosion and inundation 

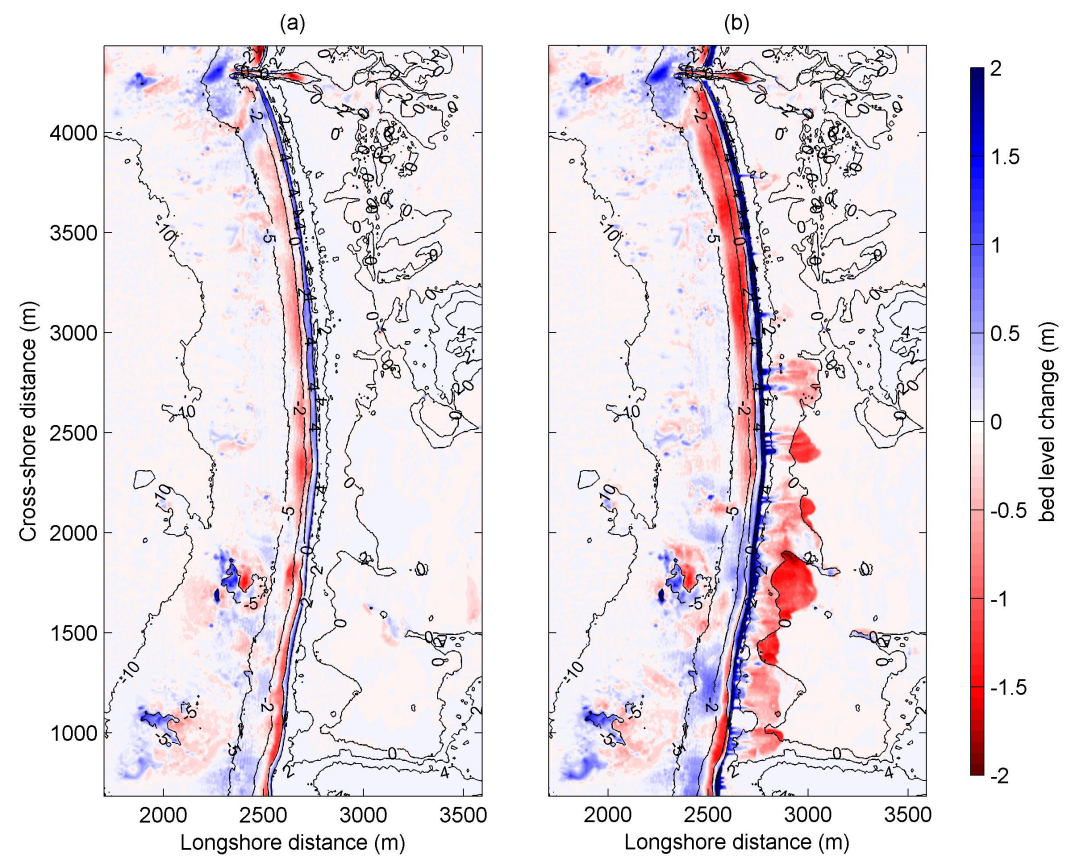

Figure 18: Simulated bed level change for Irene(a) in relation to Sandy (b). Initial bottom contours are shown for reference (black).
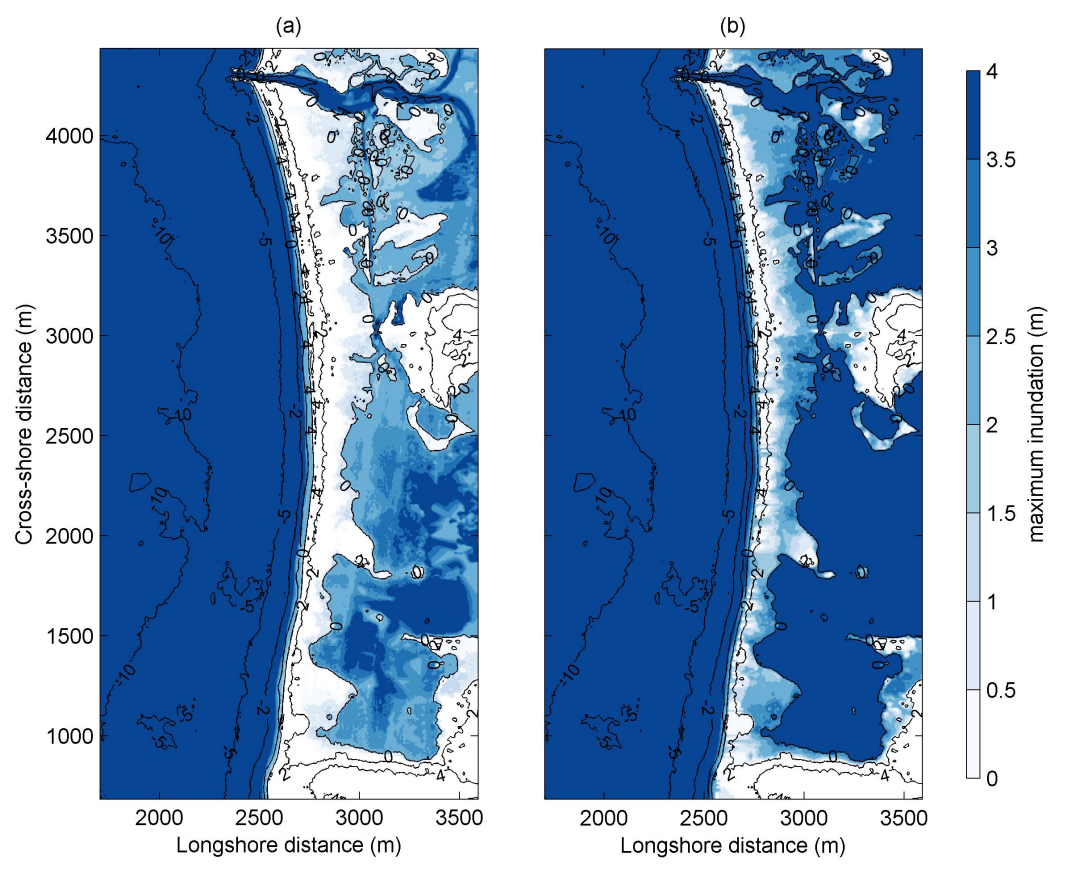

Figure 19: Maximum inundation during Irene (a), compared to Sandy (b), with initial bottom contours (black). 
during the simulations of hurricanes Irene and Sandy. The simulated erosion for hurricane Irene is compared to the measured data in Figure 20, the percent error along each of these transects are in Table 5.
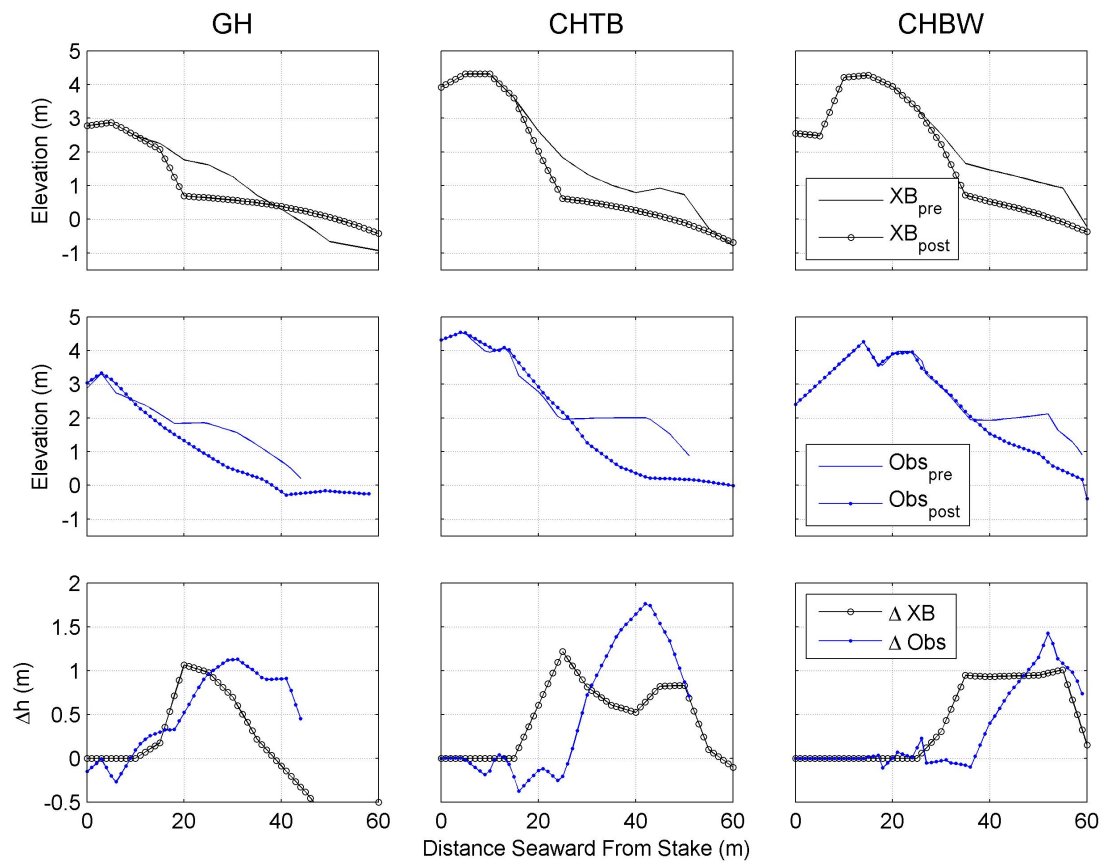

Figure 20: Modeled (top) vs. measured (middle) dune transects from before and after Hurricane Irene along Charlestown Breachway CHBW), Charlestown Beach (CHTB) and Green Hill (GH) transects. Bottom: the simulated elevation change (black) along these transects is compared to the observations (blue).

Table 5: Percent error for eroded volume along the observed transects during Hurricane Irene.

\begin{tabular}{|l|l|}
\hline Transect & Irene \\
\hline \hline GH & $-32 \%$ \\
\hline CHTB & $-3.3 \%$ \\
\hline CHBW & $37.5 \%$ \\
\hline error $(\%)$ & $0.75 \%$ \\
\hline$\overline{\mid \text { error }(\%) \mid}$ & $24.26 \%$ \\
\hline
\end{tabular}




\subsubsection{Modeling synthetic storms from the NACCS dataset}

NACCS synthetic storm 457 was simulated without tides, using an uncoupled ADCIRC model. The results were compared to the NACCS results at three save points. Figures 21 and 22 shows a comparison of the NACCS 457 winds and surge in relation to the ADCIRC model. Although the wind magnitude was similar, the higher resolution model predicted slightly smaller magnitude of surge in relation to the NACCS results at save points 8605, 8742, and 9136.

(A)

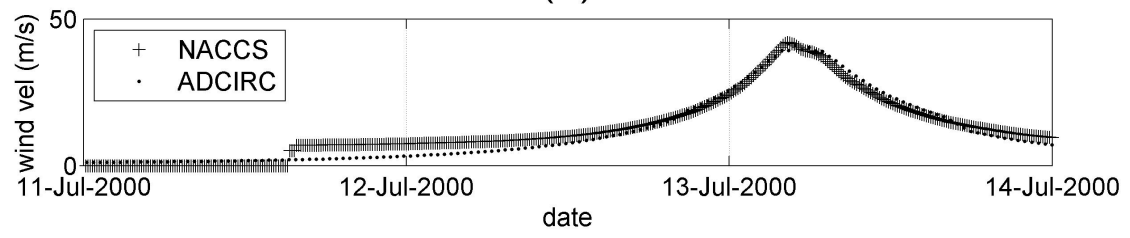

(B)

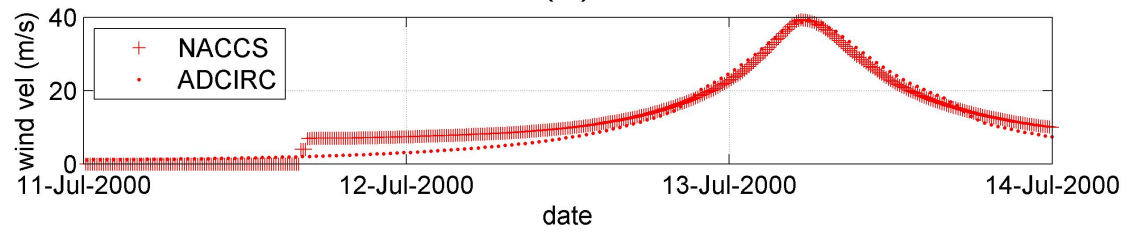

(C)

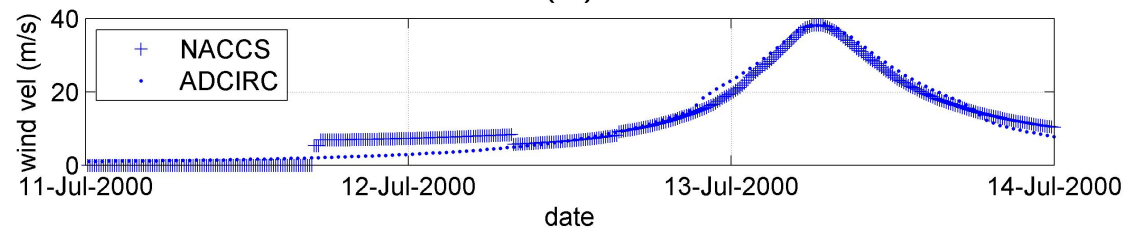

Figure 21: Comparison of the recreated synthetic hurricane wind field at the location of NACCS save points in Charlestown (A), Newport (B), Providence (C).

After the comparison of surge with NACCS, and validation of the XBeach model, the potential sediment transport during a 100-year storm was modeled over the XBeach domain. For two storms, NACCS 457 and 492, the parametric wind was applied to the regional model, and the modeled surge and wave spectrum from the two storms were applied as boundary forcing to the XBeach model. During the simulation, storm surge greatly exceeded $2 \mathrm{~m}$ above Mean Sea Level for multiple 
(A)

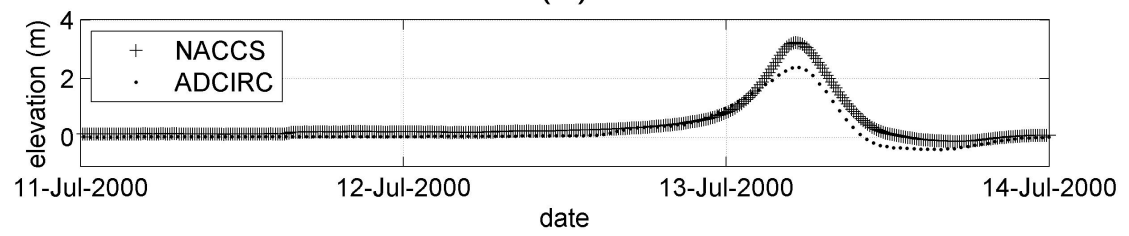

(B)

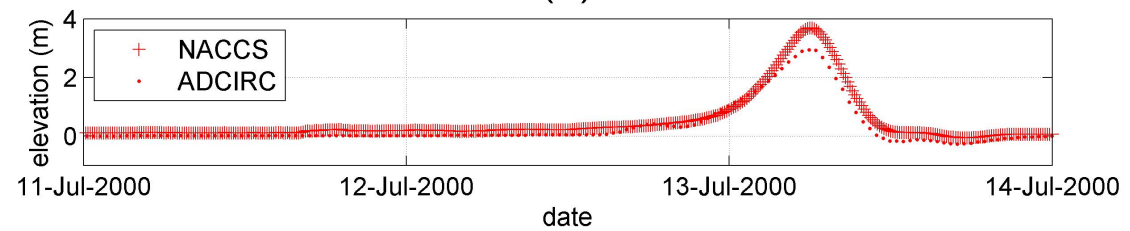

(C)

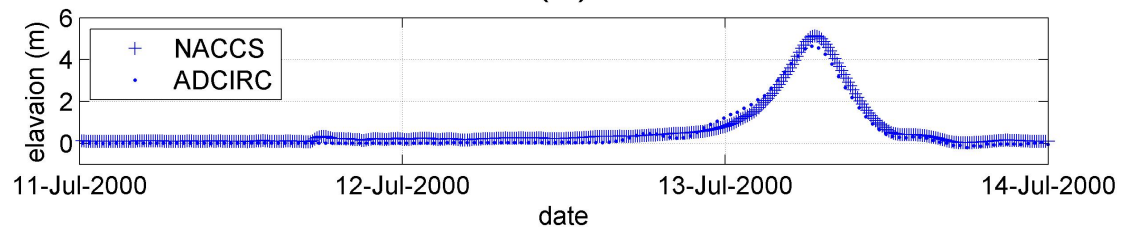

Figure 22: Time series water elevation over the high-resolution mesh, near NACCS save points in Charlestown (A), Newport (B), Providence (C).

hours in both cases. The significant wave height at the XBeach boundary exceeds 7 meters in both cases, and the combined water levels due to waves and surge completely inundated the barrier beach.

Figures 23 and 24 show the water levels, significant wave height, peak period, and peak direction at the XBeach boundary for storms 457 and 492, respectively. The wave conditions are input as a 2-dimensional spectrum, shown on the right, and water elevation is applied uniformly across the seaward boundary. The duration of the XBeach simulation of storm 457 is 48 hours, while the simulation of 492 is only 24 hours. Figure 25 shows the bed level change for the two synthetic storm simulations, and Figure 26 shows the maximum inundation during the storm.

The track of synthetic storm 457 was similar to Hurricane Sandy, as the storm heading is towards the Northwest at landfall. However, the storm makes landfall in Rhode Island, and the RMW of the synthetic storm passes through Providence. 

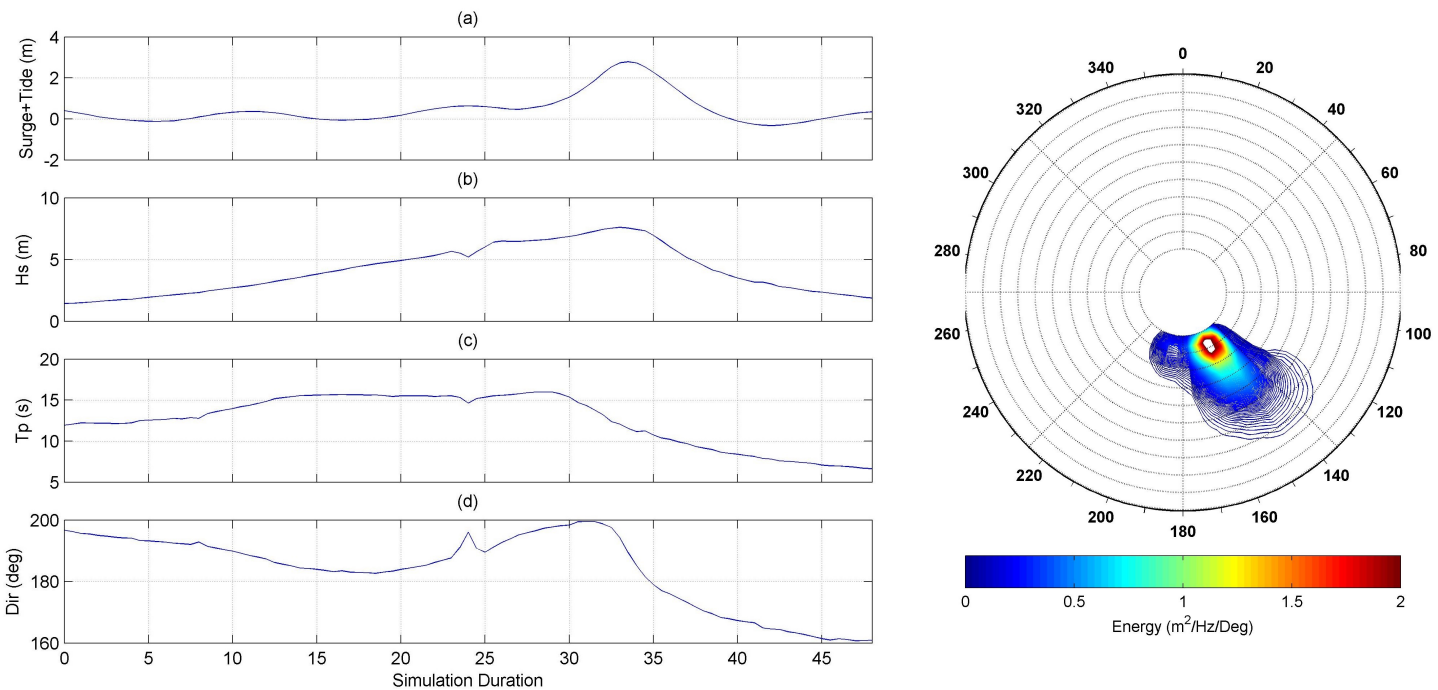

Figure 23: Left: XBeach hourly input for NACCS 457 along the seaward boundary. Water elevation due to tide and surge (a) is applied in hourly increments, along with the 2-dimensional wave spectrum. The significant wave height (b), peak period (c), and peak direction (d) corresponding to the wave spectrum are shown for clarity. Right: The 2-dimensional wave spectrum applied to the boundary, during the peak of the storm.
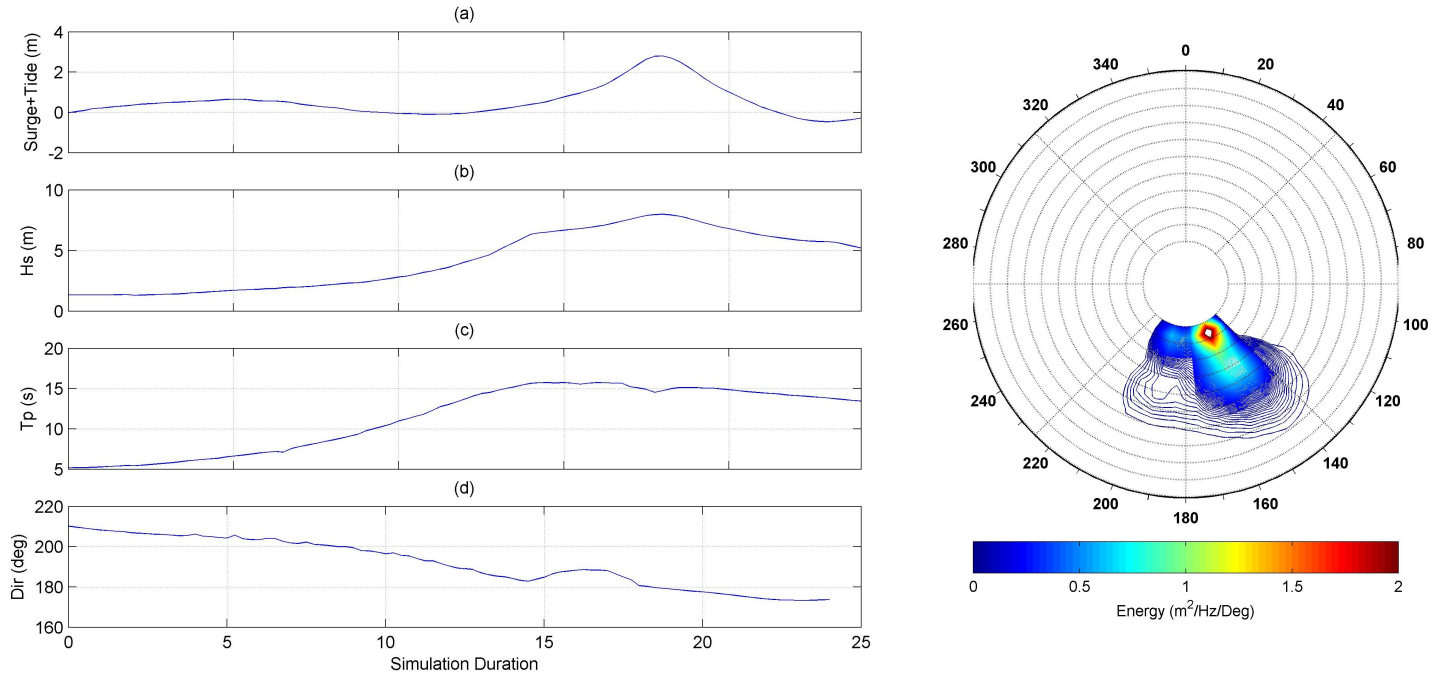

Figure 24: Left: XBeach hourly input for NACCS 492 along the seaward boundary. Water elevation due to tide and surge (a) is applied in hourly increments, along with the 2-dimensional wave spectrum. The significant wave height (b), peak period (c), and peak direction (d) corresponding to the wave spectrum are shown for clarity. Right: The 2-dimensional wave spectrum applied to the boundary, during the peak of the storm. 

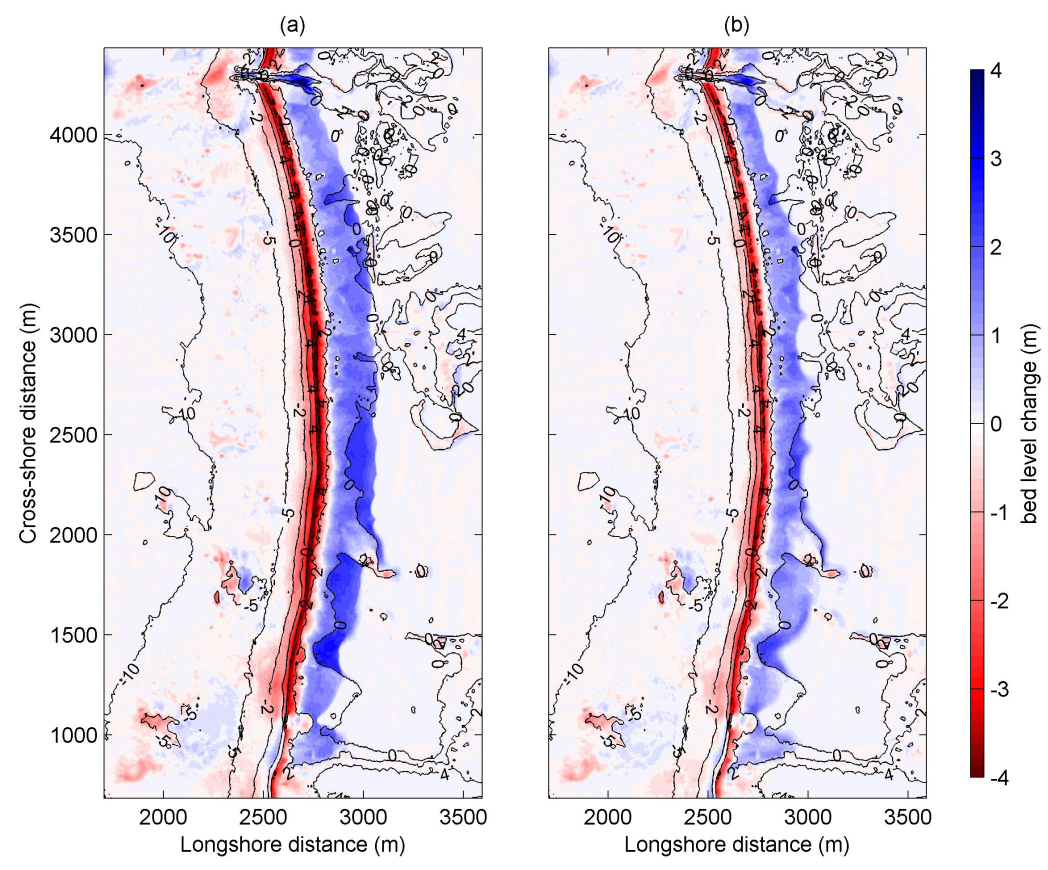

Figure 25: Simulated bed level change for NACCS 457 (a) and NACCS 492 (b), with initial bottom contours (black).
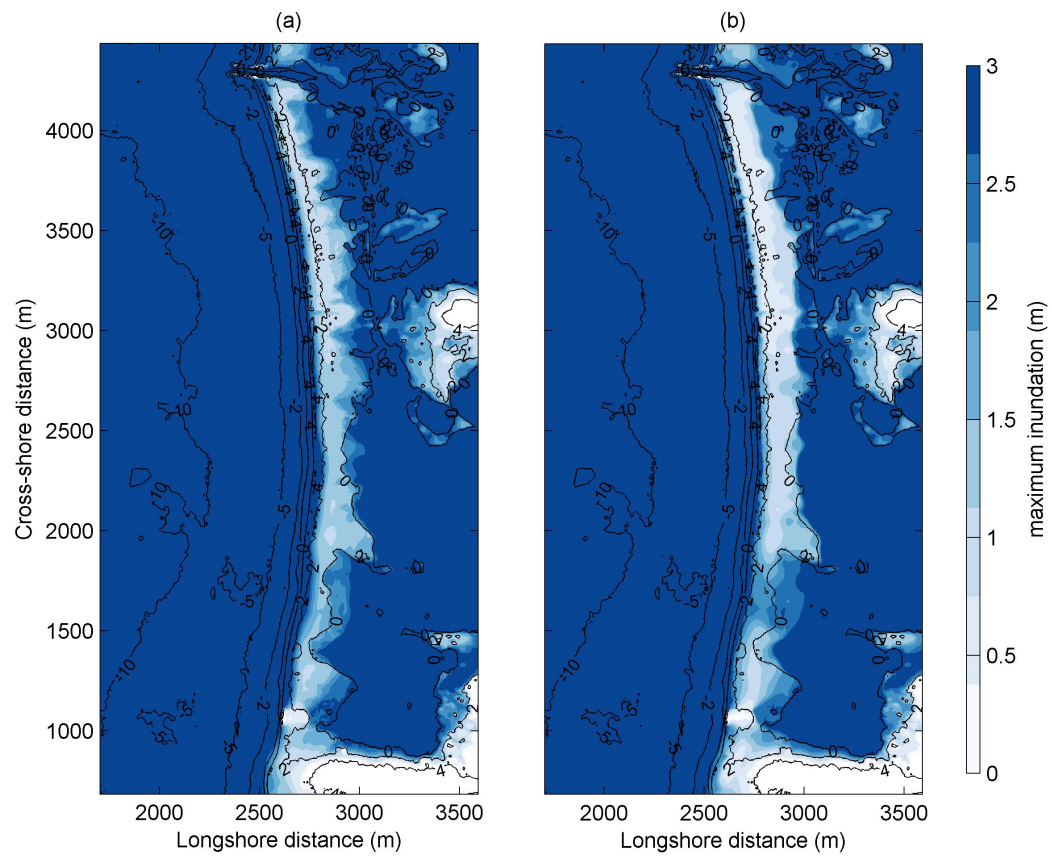

Figure 26: Maximum inundation over bed level (meters) during NACCS 457 (a) and 492 (b). 
NACCS 457 fully erodes the dune crest across the XBeach domain. As shown in Figure 24, the entire crest of the dunes along the barrier beach is eroded landward, and as much as $4 \mathrm{~m}$ of sediment is transported from the dune crest into the coastal pond. In comparison, NACCS 492 resulted in significantly less erosion. It's much higher forward velocity reduced the duration of peak waves and surge. The period of surge greater than 2 meters was 5.25 hours for NACCS 457, while only 2 hours for NACCS 492.

\subsubsection{Assesment of a hypothetical beach erosion mitigation: artificial reef}

After the XBeach model is validated, an artificial reef is implemented into the computational domain. Artificial reefs meant for erosion mitigation are often designed to dissipate wave energy through breaking. Research on submerged breakwaters using both wave flumes and numerical models have shown that the reduction of wave energy transmission through breakwaters is most sensitive to the ratio of breakwater crest depth and incident wave height $d / H[15,36]$. Crest width is also an important feature when considering submerged breakwater design, as waves are dissipated from both breaking and bottom friction [15, 36, 34]. The effectiveness of artificial reefs depends greatly on water depth, and reefs would not be as efficient regions with large tidal ranges, or during events with large storm surge. Small tidal ranges $(\approx 1 m)$ in Rhode Island would result in minimal variability of crest depth.

Previous studies of multi-purpose surfing reefs have proposed triangular geometries for both resilience towards storms, and functionality as a recreational surfing reef $[4,38]$. Mendona et. al (2012) proposed an artificial reef with an angle of $45^{\circ}$ would be suited towards advanced surfers. The reef, shown in Figure 27, has a crest depth of $1 \mathrm{~m}$ NAVD88, and dimensions of $100 \mathrm{~m}$ and $50 \mathrm{~m}$ in the longshore 

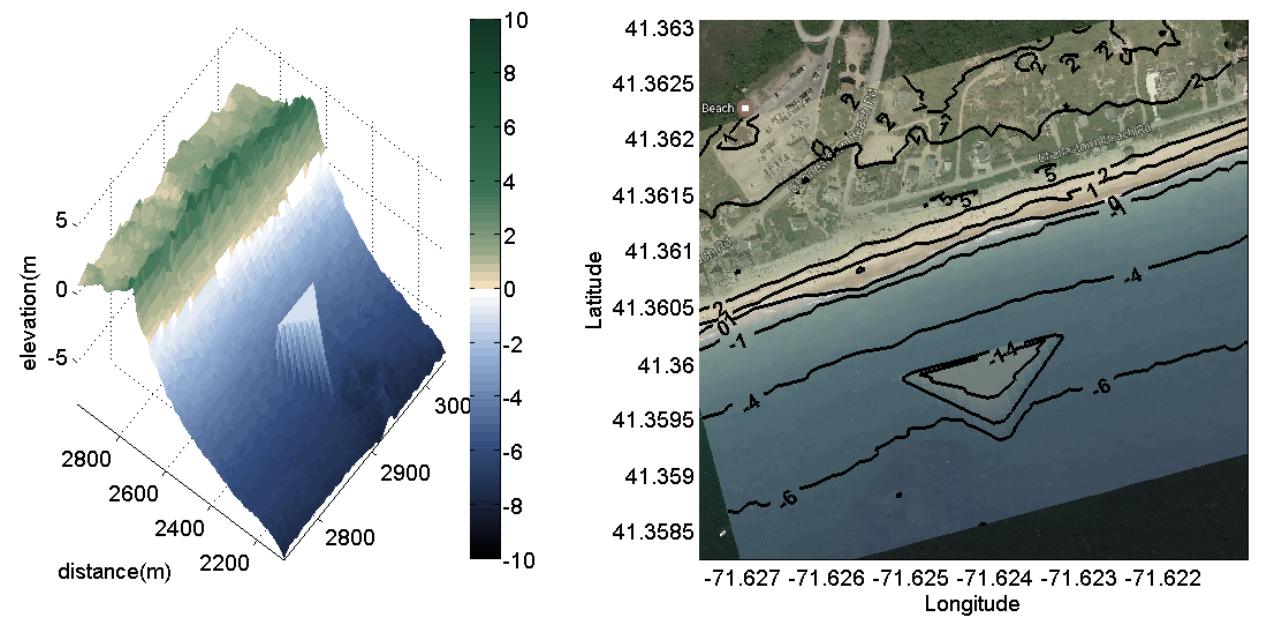

Figure 27: Artificial reef geometry, and location within the domain

and cross-shore directions, respectively. The reef is centered approximately 200 $\mathrm{m}$ from the shoreline. The base of the reef extends $100 \mathrm{~m}$ further longshore and seaward, the sides have a slope of $-3 / 50$, and decrease to a depth of $7 \mathrm{~m}$, or until the local bathymetry is greater than the depth of the reef.

\section{Effect of reef on erosion}

Because the sediment transport was validated in the collision and overtopping regime, Sandy and Irene were simulated again, over an altered bathymetry in order to analyze the impact of an artificial reef on beach erosion during storm conditions. The impact of the reef was compared by comparing the accumulated erosion with and without the artificial reef present. This was done in both 2-dimensions across the entire domain, and along a series of ten theoretical transects behind the reef, shown on the right in Figure 28. A cross-shore transect, $500 \mathrm{~m}$ in length, was created along the dune crest to analyze the effect of the artificial reef on overwash (plot a in Figure 29). Three $200 \mathrm{~m}$ long cross-shore transects span from the surf zone over the dune crest(plots b-d in in Fig. 29).

The presence of the artificial reef provided protection for the beach and dune face directly leeward of the reef. However, increased erosion occurred in the wake 

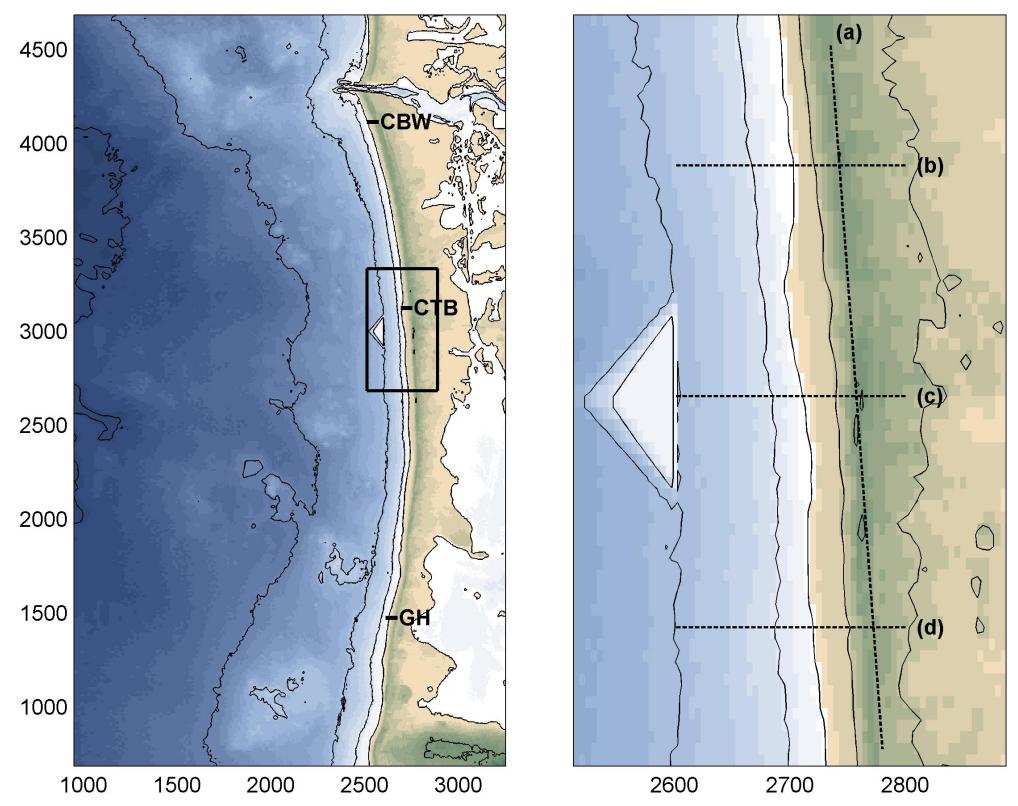

Figure 28: Location of artificial reef within domain (right), and location of transects for analysis of sediment transport in the wake of the reef (left). Units in meters. 
of the reef, and was dependant on the predominant wave direction. For hurricane Sandy, the majority of wave energy came from the southeast, accelerating erosion west of the reef. During Irene, a significant portion of the swell came out of the south, increasing erosion to the east of the reef.

Figure 29 compares the accumulated bed level change from the XBeach simulations with and without the reef globally, and along the four transects shown in Figure 28. Plots A and B show the difference between accumulated sediment with and without the reef. The magenta regions show where erosion was mitigated, and the cyan areas show where the reef increased the erosion. Plots a-d below compare the erosion during hurricanes Irene(red) and Sandy(blue), the solid black lines are the initial dune profiles, dashed lines represent results of the control simulations, while solid lines represent results with the reef present. 

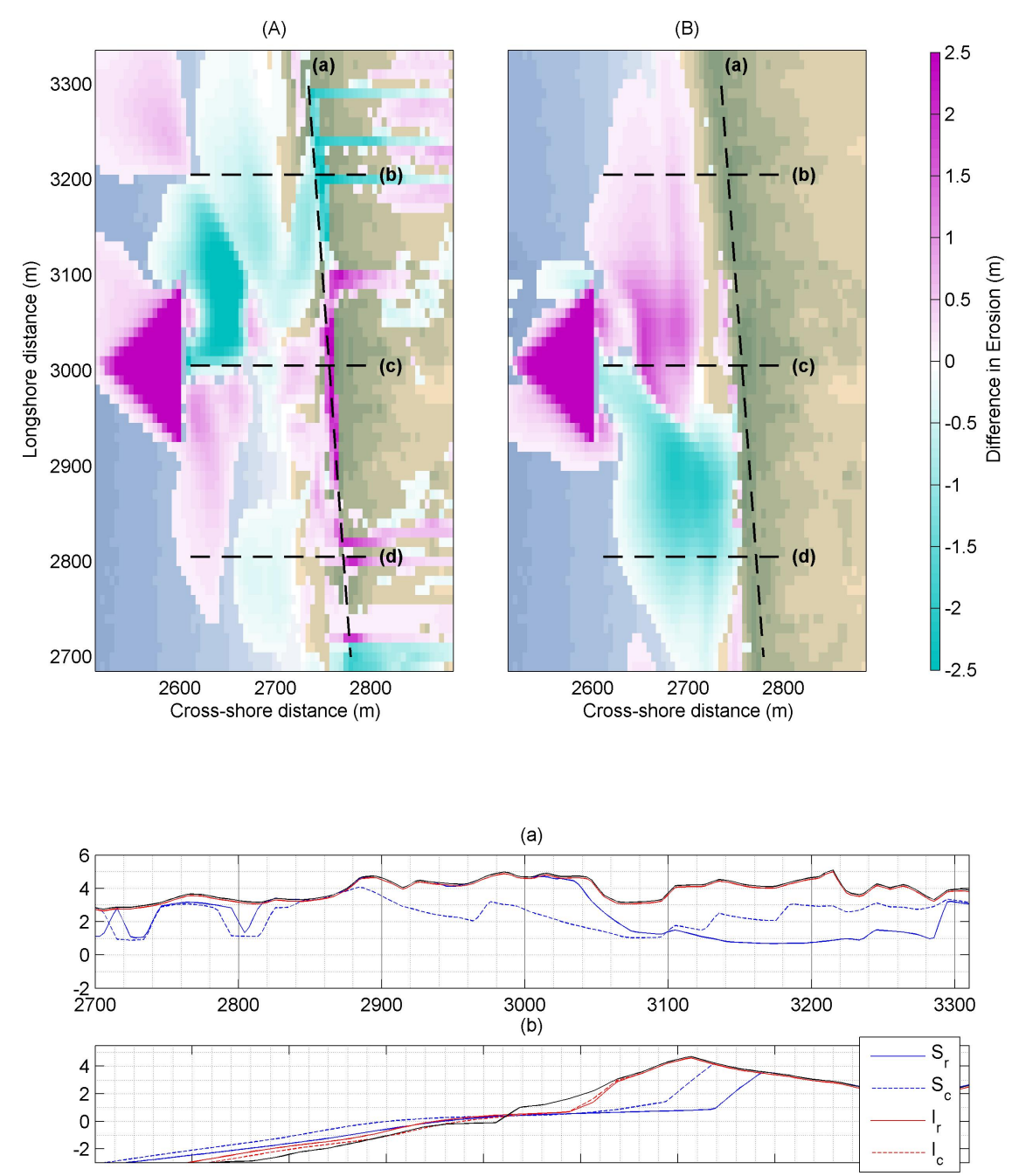

(c)
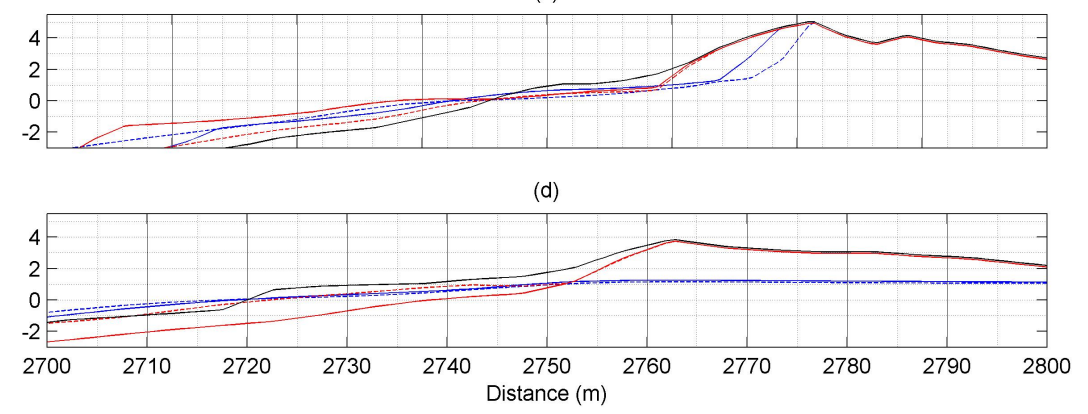

Figure 29: Above: Difference in accumulated bed level change $\left(h_{\text {reef }}-h_{\text {control }}\right)$ for Sandy (A) and Irene (B). Below: Comparison of sediment change for Irene (red) and Sandy (blue) without the artificial reef (dashed), and with the reef (solid) along the dune crest (a) and three cross-shore (b-d) transects 


\subsection{Discussion}

\subsubsection{Regional model Validation}

Torres et al. (2017) [9] showed the importance of accurate meteorological forcing while using SWAN+ADCIRC, and that wind models with less than $20 \%$ error can be used successfully for surge and wave predictions. For all runs, the most accurate meteorological data available were used.

The availability of validation locations for both nearshore wave heights and water levels during Hurricane Sandy was limited. This impacted the confidence in predictions of both the wave spectrum, and water elevation at the XBeach boundary. While the RMSE of the significant wave height and water elevations were reasonable (0.18 and 0.21 meters, respectively), it should be noted that both locations were far from the XBeach boundary. The spatial variance of storm surge in Rhode Island is much smaller between Newport and the southern coast in comparison to wave heights. Wave height validations made more than $50 \mathrm{~km}$ offshore provided little information on the accuracy of wave heights at the nearshore model boundary.

During Hurricane Irene, the two Woods Hole Group data provided nearshore wave height measurements. The 'Center' ADCP was near the XBeach domain, and provided a good idea of the accuracy of the performance SWAN+ADCIRC model's wave predictions. The error between the peak modeled and observed significant wave height during Irene was less than 10\% [9].

\section{Synthetic Storms}

A 100-year storm was modeled by generating a storm that matched the upper limit of the $95 \%$ confidence interval for the $1 \%$ annual recurrence water levels in Newport, Rhode Island (2.81 m NAD88)[5]. Two storms from the NACCS exceeded this value: 3.48 and 3.50 meters for storms 457 and 492, respectively. 
The atmospheric forcing from these storms were used to force the regional model. Shaw et al. (2016) [35] showed that the NACCS overestimated the water levels in Newport and Providence. Additionally, the low resolution in the southern coast of Rhode Island resulted in inaccuracies near coastal ponds. For storm number 457, the high resolution model showed good agreement for winds in relation to the NACCS study at the three save points shown in Figure 22. The peak water level in Newport in the regional model was 3.05 meters without tide.

Both storms were modeled in order to provide a comparison of time scale for the nearshore erosion model. Water elevations and waves are often used to classify the return period of storms, but time scale is often the determining factor when considering erosion. Munger et. al (2010) classified storm return period by erosion, and determined that these methods were unreliable. Rather, three other factors that take into account the storm duration, water levels, and wave height are more accurate methods for correlating the return period of storms. An improved method of classifying a 100-year storm based on erosion southern Rhode Island would take these factors into consideration.

\subsubsection{Nearshore model Calibration/Validation}

In the area of interest, a facua value of 0.25 provides results with the highest

accuracy. This is consistent with the tests by De Vet et al. (2015) [9] and Nederhoff et. al (2015). Without historical elevation data of dune overwash in Rhode Island, validation of the overwash regime in XBeach is extremely difficult. With historical satellite images, locations of overwash can be compared, but only serves as a qualitative comparison, and cannot provide information on total volume eroded. Additionally, the exclusion of the remainder of Ningret pond may adversely affect dune overwash in the study area. 


\section{Erosion Due to Synthetic 100-year Storms}

Water elevation due to storm surge, wave set-up, and total storm duration are the greatest factors to consider when identifying threats of beach erosion due to storms. Although the waves and water levels during the NACCS 492 storm were greater than that of 497, the much slower traveling NACCS 457 had a much longer duration, leading to a more significant amount of erosion. The direction of swell does not have as great an impact on the eroded beach volume in comparison to the surge, wave height, and duration[32]. Once the storm enters the overwash regime, longshore transport is no longer the dominating factor on erosion.

\section{Artificial Reef}

Based on the results from hurricanes Irene and Sandy, the response sediment behind the artificial reef was affected by swell direction, magnitude of surge, and storm duration. For both Sandy, and Irene, the presence of the reef reduced the total impact of waves on the dunes. During Irene, waves came from a more southerly direction, reducing erosion on the eastern side of the Reef, and increasing erosion on the western side. During Sandy, more erosion was observed east of the reef, while less was observed to the west. The Dunes directly in the wake of the reef are almost completely protected (see transects $a$ in Figure 28), but dunes towards the east are impacted slightly more.

To improve the impact of the artificial reef, building more reefs in series, as a segmented breakwater system would provide better protection from storms [41]. A larger region of coastline behind the reef would be protected, and reduce the impact of swell direction during storms. The structural integrity of a reef placed directly offshore should also be researched, as the assumption that the reef cannot be eroded is not realistic under extreme conditions. For hurricanes Irene, and Sandy, scour can be seen along the lee-side of the reef, and design changes may 
need to be made, in order to reduce erosion around the base.

\subsection{Conclusion}

In this work, SWAN+ADCIRC and XBeach models were calibrated using Hurricane Sandy, and validated using Irene. The sediment transport domain, spanning a small stretch of barrier beach in Rhode Island was used to measure the effectiveness of an artificial reef for beach and dune protection. Validations were made by comparing results to measured wave and tidal data, and by comparing sediment loss along three transects located in the domain. The combined models were then used to analyze the potential impacts of a 100-year storm on the dunes within the domain.

The surge prediction in the regional model had a root mean squared error (RSME) of $0.21 \mathrm{~m}$ at the Newport tidal gauge during Hurricane Sandy. The significant wave height had a RMSE of $0.18 \mathrm{~m}$ at the CDIP 154 Station. The distribution of spectral energy in SWAN was biased towards lower frequencies offshore, and underestimates higher frequencies. During hurricane Irene, the peak significant wave heights nearshore were predicted within $10 \%$ of observations. The XBeach model was forced using the 2-dimensional wave spectrum and water level output from SWAN+ADCIRC. The conditions from Hurricanes Irene and Sandy were compared along three measured transects within the domain. Using a Facua parameter of 0.25 resulted in the lowest percent error along transects within the domain. The greatest error along a transect was 20.1\% during Sandy, and 37.5\% during Irene. The mean magnitude of error along all available transects was $19.9 \%$ for Sandy, and $24.26 \%$ for Irene.

The above methodology was used for a mitigation study along a section of the barrier beach within the domain. Hurricanes Irene and Sandy were simulated again using an altered bathymetry file containing a non-erodible artificial reef, as an 
effort to protect the beach and dunes behind it. The model results were compared to the control test to determine the magnitude of shoreline and dune mitigation in the area behind the reef. During Hurricane Sandy, erosion was mitigated along the dune crest leeward of the reef, mitigating dune erosion by as much as 2 meters. Storms resulting in moderate overwash may be mitigated behind the reef, but events with severe surge and waves will not be mitigated. Neither of the NACCS storms were mitigated by the reef, as the magnitude of surge and tide during the peak reduced the frequency of wave breaking over the reef. Additionally, steep angled swells (i.e. large angle of incidence in relation to beach contours) will pass behind the reef, and erosion will not be mitigated.

Due to time restraints, variable friction was not considered in this study. Previous research suggests increasing friction over land would reduce the magnitude of erosion during the overwash regime [29, 33]. Further application of this model for erosion mitigation may include varying reef geometry, dune restoration, or the addition of vegetation to dunes. Combining erosion models with circulation models may provide better predictions of erosion during extreme events. The methods used in this study could be applied to a number of barrier beaches along Rhode Island's southern coast, and the results can be introduced as time-varying bathymetry input in SWAN+ADCIRC for improved flood mapping. 


\section{LIST OF REFERENCES}

[1] Avila, L.A., and Cangialosi, J., "Tropical Cyclone Report - Hurricane Irene" (PDF). National Hurricane Center. 2011-12-14. Retrieved 2017-06-22.

[2] Blake, E.S., Kimberlain, T.B., Berg, R.J., Cangialosi, J.P., and Beven J.L.II, "Tropical Cyclone Report - Hurricane Sandy" (PDF). National Hurricane Center. 2013-2-12. Retrieved 2017-06-22.

[3] Babanin, A. V., Young, I. R., \& Banner, M. L. (2001). Breaking probabilities for dominant surface waves on water of finite constant depth. Journal of Geophysical Research: Oceans, 106(C6), 11659-11676.

[4] Black, K. (2001). Artificial Surfing Reefs for Erosion Control and Amenity: Theory and Application. Journal Of Coastal Research, (34), 1-44.

[5] Booij, N., Ris, R.C. and Holthuijsen, L.H. (1999). A Third-Generation Wave Model for Coastal Regions, Part I, Model Description and Validation, Journal of Geophysical Research, C4, 104, 7649-7666.

[6] Chen, C. (2017). The hindcast wind data for Hurricane Sandy based on WRF output. Personal Communication (January 12, 2017).

[7] Chen, C., Beardsley, R. C., and Cowles, G. (2006). An unstructured grid, finitecolume coastal ocean model (FVCOM) system. Oceanography, 19(1), 7889.

[8] Corbella, S., \& Stretch, D. D. (2012). Predicting coastal erosion trends using non-stationary statistics and process-based models. Coastal Engineering, 70, 40-49. 10.1016/j.coastaleng.2012.06.004

[9] De Vet, P. L., Mccall, R. T., Bieman, J. P., Stive, M. J., \& Ormondt, M. V. (2015). Modelling Dune Erosion, Overwash And Breaching At Fire Island (Ny) During Hurricane Sandy. The Proceedings of the Coastal Sediments 2015. 10.1142/9789814689977-0006

[10] Dean, R. G., (1990) Equilibrium beach profiles: characteristics and applications. Journal of Coastal Research, 7(1), 53-84. Fort Lauderdale (Florida), ISSN 0749-0208.

[11] Dee, D. P., Uppala, S. M., Simmons, A. J., Berrisford, P., Poli, P., Kobayashi, S., Andrae, U., Balmaseda, M. A., Balsamo, G., Bauer, P., Bechtold, P., Beljaars, A. C. M., van de Berg, L., Bidlot, J., Bormann, N., Delsol, C., Dragani, R., Fuentes, M., Geer, A. J., Haimberger, L., Healy, S. B., Hersbach, H., Hlm, E. V., Isaksen, L., Kllberg, P., Khler, M., Matricardi, M., McNally, A. P., Monge-Sanz, B. M., Morcrette, J.-J., Park, B.-K., Peubey, C., de Rosnay, P., 
Tavolato, C., Thpaut, J.-N. and Vitart, F. (2011), The ERA-Interim reanalysis: configuration and performance of the data assimilation system. Q.J.R. Meteorol. Soc., 137: 553597. doi:10.1002/qj.828

[12] Deitrich, J. C. (2009, Oct 28). Wave Refractions on Coarse Meshes. Retrieved from https://ccht.ccee.ncsu.edu/wave-refraction-on-coarse-meshes/

[13] Dietrich, J. C., Zijlema, M., Westerink, J.J., Holthuijsen, L.H., Dawson, C., Luettich, R.A., Jensen, R., Smith, J.M., Stelling, G.S., and Stone, G.W. (2011). Modeling Hurricane Waves and Storm Surge using Integrally-Coupled, Scalable Computations, Coastal Engineering, 58, 45-65.

[14] Duarte, C. M., Losada, I. J., Hendriks, I. E., Mazarrasa, I., \& Marb, N. (2013). The role of coastal plant communities for climate change mitigation and adaptation. Nature Climate Change,3(11), 961-968. doi:10.1038/nclimate1970

[15] Grilli, S. T., Losada, M. A., Martin, F., (1994). Characteristics of Solitary Wave Breaking Induced by Breakwaters. Journal of Waterway, Port, Coastal, and Ocean Engineering. 74

[16] Harris \& Woodring, (2001). Artificial reefs for submerged and subaerial habitat protection, mitigation and restoration. 54th Institute of the Gulf and Caribbean Fisheries Institute (GCFI), Turks \& Caicos, Is., pp. 386-395

[17] Hashemi, M., Ghadampour, Z., \& Neill, S. (2010). Using an artificial neural network to model seasonal changes in beach profiles. Ocean Engineering, 37(1415), 1345-1356. doi:10.1016j.oceaneng.2010.07.004

[18] Hasselmann K., T.P. Barnett, E. Bouws, H. Carlson, D.E. Cartwright, K. Enke, J.A. Ewing, H. Gienapp, D.E. Hasselmann, P. Kruseman, A. Meerburg, P. Mller, D.J. Olbers, K. Richter, W. Sell, and H. Walden. (1975) Measurements of wind-wave growth and swell decay during the Joint North Sea Wave Project (JONSWAP)' Ergnzungsheft zur Deutschen Hydrographischen Zeitschrift Reihe, 95

[19] Holland, G. \& Bruyere, C.L. (2014). Recent intense hurriane response to global climate change. Climate Dynamics. 42(617). https://doi.org/10.1007/s00382013-1713-0

[20] Karambas, T. V. (2012). Design Of Detached Breakwaters For Coastal Protection: Development And Application Of An Advanced Numerical Model. Coastal Engineering Proceedings, 1(33). doi:10.9753/icce.v33.sediment.115

[21] King, J., (2017). Personal Communication, Shared beach transect observations from before and after hurricanes Irene and Sandy. 
[22] Luettich, R.A., Jr., Westerink, J.J., and Scheffner, N.W. 1992. ADCIRC: an Advanced Three-Dimensional Circulation Model for Shelves, Coasts, and Estuaries, Report 1: Theory and Methodology of ADCIRC-2DDI and ADCIRC03DL, Dredging Research Program Technical Report DRP-92-6, U.S. Army Engineers Waterways Experiment Station, Vicksburg, MS 137 p.

[23] Mccall, R., Vries, J. V., Plant, N., Dongeren, A. V., Roelvink, J., Thompson, D., \& Reniers, A. (2010). Two-dimensional time dependent hurricane overwash and erosion modeling at Santa Rosa Island. Coastal Engineering, 57(7), 668683. doi:10.1016/j.coastaleng.2010.02.006

[24] McKenna, Brian., (2016). Personal Communication, Shared Assateague.sh, a bash script, used to recreate wind fields based on parameters from the NACCS database.

[25] Mendona, A., Fortes, C. J., Capito, R., Neves, M. G., Carmo, J. S., \& Moura, T. (2012). Hydrodynamics around an Artificial Surfing Reef at Leirosa, Portugal. Journal of Waterway, Port, Coastal, and Ocean Engineering, 138(3), 226-235. doi:10.1061/(asce)ww.1943-5460.0000128

[26] Munger, s., and \& Kraus, N. C. (2010) Frequency of Extreme Storms Based on Beach Erosion at Northern Assateague Island, Maryland. Shore and Beach. 78(2),3-11.

[27] N.C. Nadal-Caraballo, J.A Melby, V.M. Gonzalez A.T. Cox,. (2014). North Atlantic Coast Comprehensive Study (NACCS): Coastal Storm Hazards from Virginia to Maine. U.S. Army Engineer Research and Development Center (ERDC), Technical Report. ERDC-CHL-TR-15-5, 2015.

[28] NOAA. (2017). CO-OPS., Tidal Data. Retrieved from: https://tidesandcurrents.noaa.gov/. (Last accessed: April, 2017)

[29] Nederhoff, C., Lodder, Q., Boers, M., Bieman, J. D., \& Miller, J. (2015). Modeling The Effects Of Hard Structures On Dune Erosion And Overwash. The Proceedings of the Coastal Sediments 2015. doi:10.1142/97898146899770219

[30] RIGIS. (2013). Digital Elevation Model, DEM11. Rhode Island Geographic Information System (RIGIS) Data distribution System. Retrieved from http://www.rigis.org/data/topo/2011, Environmental Data Center, University of Rhode Island (last date accessed: 8 December 2016).

[31] Roelvink, D., Reniers, A., Dongeren, A. V., Vries, J. V., Lescinski, J., \& Mccall, R. (2009). Modeling Storm Impacts On Beaches, Dunes And Barrier Islands. Coastal Engineering. doi:10.1142/9789814277426-0140 
[32] Sallenger, A. (2000). Storm impact scale for barrier islands. Journal of Coastal Research, 16(3), 890895.

[33] Schambach, L., Grilli, A. G., Grilli, S. T., Hashemi, M. R., King, J. (2017). Assessing the impact of extreme storms on barrier beaches along the Atlantic coastline: Application to the Southern Rhode Island coast. Submitted to Coastal Engineering. In review.

[34] Seabrook, Stuart R., Hall, Kevin R., (1998). Wave Transmission at Submerged Rubblemound Breakwaters. Coastal Engineering Proceedings, [S.1.], n. 26, jan. 2001. ISSN 2156-1028.

[35] Shaw, A., Hashemi, M., Spaulding, M., Oakley, B., \& Baxter, C. (2016). Effect of Coastal Erosion on Storm Surge: A Case Study in the Southern Coast of Rhode Island. Journal of Marine Science and Engineering, 4(4), 85. doi:10.3390/jmse4040085

[36] Soung, S., Kim, J., Yoon, H., Jung, T., Do K., \& Shin, S. (2017). An Observational and Numerical Study of Storm-Induced Morphologic Changes at Sanpo Beach, Korea. Journal of Coastal Research. 79

[37] Spaulding, M.L., Grilli, A.R., Damon, C., Fugate, G., Oakley, B.A., Isaji, T., and Schambach, L., (2016). Application of state of art modeling techniques to predict flooding and wave for an exposed coastal area.

[38] Ten Voorde, M., Neves, M. G., Antunes Do Carmo, J. S., (2008). Preliminary study of the geometry of an artificial Reef for Coastal Protection and Surfing along the west coast of Portugal. Journal of Intrgrated Coastal Zone Management. 8(1):6579

[39] Torres, M., Hashemi, M. R., Hayward, S., Ginis, I., Spaulding, M., (2017) Simulation of stormsurge in the northeast coast of the US; a closer look at the wind forcing.

[40] Trouw, K. J., Zimmermann, N., Mathys, M., Delgado, R., \& Roelvink, D. (2012). Numerical Modelling Of Hydrodynamics And Sediment Transport In The Surf Zone : A Sensitivity Study With Different Types Of Numerical Models. Coastal Engineering Proceedings, 1(33), 23. doi:10.9753/icce.v33.sediment.23

[41] U.S. Army Corps of Engineers. (2002). Coastal Engineering Manual (CEM). Engineer Manual 1110-2-1100. U.S. Army Corps of Engineers, Washington, D.C. (6 volumes).

[42] University of California, San Diego. (2017). CDIP., Wave Data. Retrieved from https://cdip.ucsd.edu/. (Last accessed: April, 2017) 
[43] Woods Hole Group (2012). Wave, Tide and Current Data Collection Contract No. W912WJ-09-D-588 0001-0026. US Army Corps of Engineers: New England District, MA, USA.

[44] Woods Hole Group. (2011). Narragansett Town Beach Replenishment Feasibility Project. Retrieved from http://www.narragansettri.gov/DocumentCenter/Home/View/782

[45] Zeitlin-Hale, L., Olsen, S. B., \& Grant, M. (2010). The State of Rhode Island Coastal Resources Management Program, as Revised. Providence, RI: Coastal Resources Management Council. 


\section{MANUSCRIPT 2}

\section{Development of a Realtime Wave and Storm Surge Forecasting Model}

For Rhode Island

by M. Reza Hashemi, Malcolm Spaulding, Marissa Torres, Scott Hayward \& Chris Small

This manuscript will serve as a portion of the final report for the University of Rhode Island's contribution to the NERACOOS Regional Resiliency project. Portions of this research are also being prepared for submission to Computers and Geosciences. 


\begin{abstract}
A set of MATLAB and bash programs were designed for preprocessing and automating the coupled wave and hydrodynamic model SWAN+ADCIRC for real time forecasting of waves and storm surge. The method allows the user to locally preprocess, package, and automate the system, while running the system externally using High Performance Computing (HPC). Each of the user input files are described, and the forecasting process is explained. The system is then applied to a SWAN+ADCIRC domain in Rhode Island, and tested during Stella, an extratropical event in March 2017, Nor'Easter Stella. The three day forecast system had a maximum offshore significant wave height Root Mean Squared Error (RMSE) of less than $1.2 \mathrm{~m}$, and a storm surge RMSE of less than 0.2 meters during simulation of NorEaster Stella. The system is shown to be conveniently activated and monitored in the event of an emergency.
\end{abstract}

\title{
2.1 Introduction
}

Damage due to storm surge and waves is one of the greatest threats to coastal communities in the United States, and worldwide. As methods of storm surge forecasting have improved over the years, different forecasting systems have been used to convey the threat of storm surge to either city officials, or the public. The National Oceanographic and Atmospheric Administration (NOAA) uses a number of operational grids, and the Sea Lake, and Overland Surges from Hurricanes (SLOSH)[3] to forecast surges due to hurricanes. These models are used by state government to make evacuation decisions.

The coupled wave and hydrodynamic model SWAN+ADCIRC is a 2 and 3dimensional ocean model that solves the wave-action, continuity and momentum equations over an unstructured grid [7, 1]. Fleming et al. (2008) [6] automated ADCIRC using the Adcirc Surge Guidance System (ASGS), by using the National 
Hurricane Center (NHC) forecast advisories to create a parametric Holland model. ASGS is capable of running ensemble models, by running multiple simulations by varying hurricane parameters. Although ensemble methods for predicting storm surge are able to take into account uncertainty of tropical storm trajectories, they cannot fully address the threat due to extratropical storms. Also, the resolution should be locally improved in each region.

In 2016, NERACOOS (with support from NOAA) began a project with the goal of better improving New England communities for the threats of coastal storms. This included creating an improved coastal flooding forecast system for the states of Connecticut, Rhode Island, Massachusetts, New Hampshire, and Maine. Torres et al. (2017) [9] highlighted the importance of the accuracy in meteorological forcing for coastal flooding and wave modeling using SWAN+ADCIRC. In their study, it was determined that the best model for Rhode Island was the NECOFS WRF wind model [2] in comparison to the both the ADCIRC parametric wind and ECMWF Era-Interim [4] meteorological forcing models.

The objective of this study was to develop a real time SWAN+ADCIRC storm surge and wave forecasting system capable of being used for a range of meteorological forcing products in Rhode Island coastal waters. The system should be managed on an external desktop, and run on a High or Performance Computing (HPC) cluster. It should be capable of predicting both waves and storm surge due to both tropical and extra-tropical systems. Additionally, the system should be applicable over a wide range of regions, and should be scalable for small or large domains. This paper will describe all the requirements to set up and run the described forecasting system. A test case in the state of Rhode Island is also presented, and the results were discussed. 


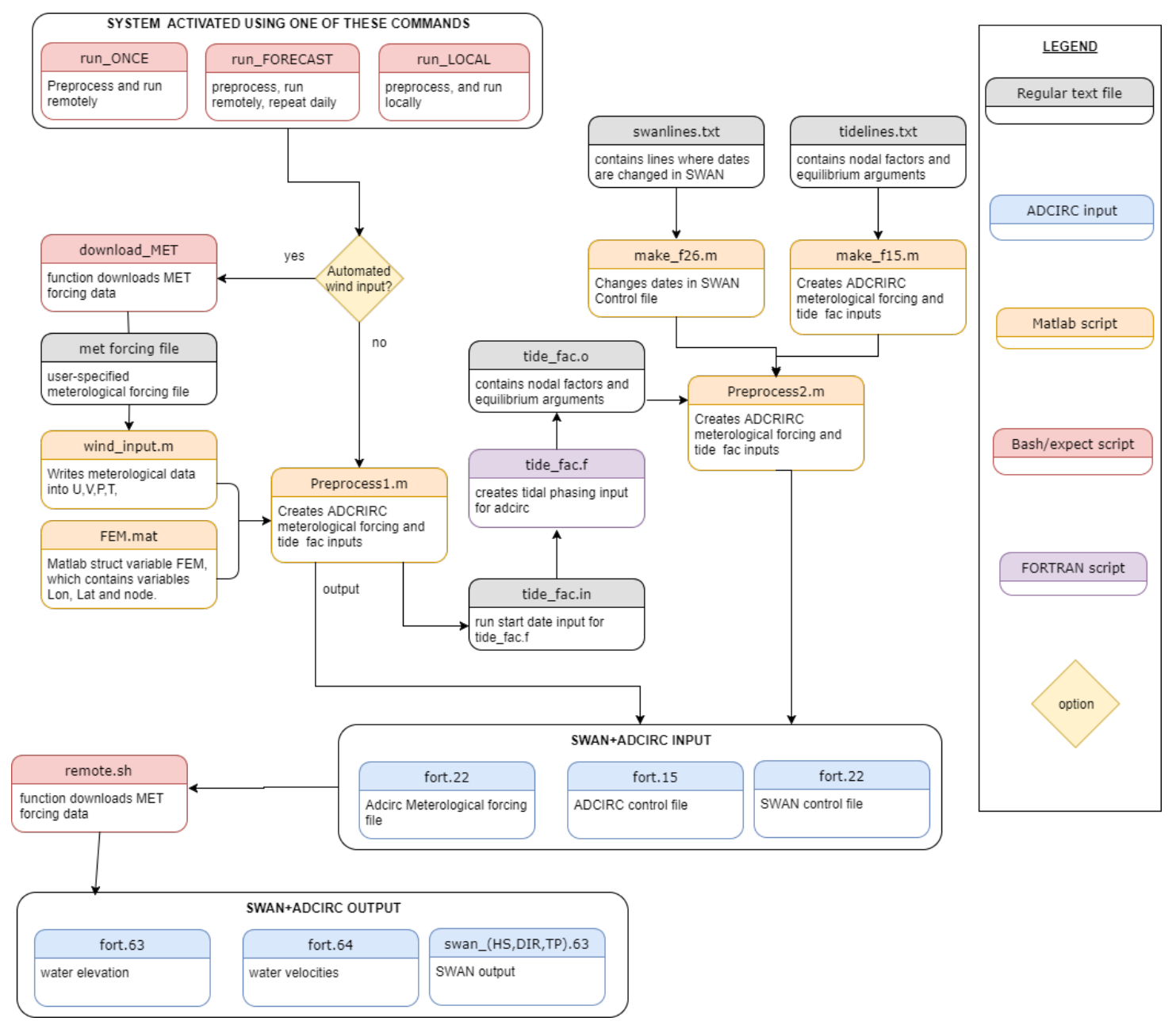

Figure 30: Flow chart of process for Rhode Island real-time forecasting system. Summaries of these codes are located in Table 7, and full codes are listed in Appendix D.

\subsection{Methods}

The presented Matlab and Bash scripts are designed to be distributed freely, and altered for the needs of the user. With the exception of Matlab, all software requirements for implementation are open source, and free. Upon activation, the system will download wind from the outside source specified by the user. In the case of this study, NECOFS (Northeast Coastal Ocean Forecasting System) [2] forcing was used ${ }^{1}$. The meteorological forcing will be used in the ADCIRC-SWAN

\footnotetext{
${ }^{1}$ http://fvcom.smast.umassd.edu/necofs/
} 
model. Dates and tidal constituents in the SWAN and ADCIRC control files will be changed based on the dates corresponding to the meteorological forcing. The new input files will be moved into a folder, and sent to an external computer cluster for computation. Figure 30 summarizes these forecasting processes in a flow chart. The functionality of these codes are explained in the following sections.

\subsubsection{Bash and MATLAB Codes Requirements}

A complete SWAN+ADCIRC model should be used in the required input explained below. Additionally, the user should have the software listed in Table 6 downloaded on the system.

Table 6: Required Software and Codes

\begin{tabular}{ll} 
PreProcessing: & \\
\hline MATLAB & https://www.mathworks.com/ \\
Fortran compiler & \\
linux/bash & https://www.gnu.org/software/bash/ \\
Expect & http://expect.sourceforge.net/ \\
Computation: & \\
\hline ADCIRC & http://adcirc.org/ \\
SWAN & http://swanmodel.sourceforge.net/
\end{tabular}

\section{Nodal Attributes in ADCIRC}

The locations of each node from the ADCIRC grid and boundary information file (fort.14) are required. The nodal number, and corresponding longitude and latitude points should be saved in variable names node, $x$, and $y$, respectively within a file named FEM.mat. By saving the data into a .mat file, the fort.14 does not need to be executed every iteration, thus, saving computation time.

\section{Meteorological Forcing}

The meteorological forcing must be on a cartesian grid, as the global 10-meter wind velocities, and pressure are interpolated onto each of the nodes. It is advised 
Table 7: List and description of Files and Scripts within the Master Directory, refer to Appendix D for full codes.

\begin{tabular}{|c|c|c|}
\hline Subdirectory & Filename & Description \\
\hline \multirow[t]{6}{*}{ Matlab } & preprocess1.m & "executes met_inputs.m, and tf2_input.m \\
\hline & met_inputs.m & $\begin{array}{l}\text { Function provides meteorological in the } \\
\text { correct format for make_fort22. } m \text { and } \\
\text { tf2_inputs.m }\end{array}$ \\
\hline & tf2_inputs.m & Prepares input for tide_fac.f \\
\hline & preprocess $2 . \mathrm{m}$ & $\begin{array}{l}\text { executes make_fort15.m and } \\
\text { make_fort26.m }\end{array}$ \\
\hline & make_fort15.m & Changes tidal constituents in fort.15 \\
\hline & make_fort $26 . \mathrm{m}$ & Changes dates in fort. 26 \\
\hline \multirow[t]{5}{*}{ Bash } & forecast & $\begin{array}{l}\text { bash function file, contains automation } \\
\text { functions. }\end{array}$ \\
\hline & remote.sh & $\begin{array}{l}\text { Bash file that executes upload.sh, } \\
\text { prep.sh, and run.sh. Enter Login cre- } \\
\text { dentials here. }\end{array}$ \\
\hline & upload.sh & $\begin{array}{l}\text { Expect function uploads pre-processed } \\
\text { data. }\end{array}$ \\
\hline & $\operatorname{login} . \mathrm{sh}$ & $\begin{array}{l}\text { Expect function logs in and executes } \\
\text { ADCIRC prep executables, and sub- } \\
\text { mits batch file. }\end{array}$ \\
\hline & run.sh & $\begin{array}{l}\text { Expect function logs in and submits } \\
\text { ADCIRC run in queue. }\end{array}$ \\
\hline \multirow[t]{6}{*}{ input } & FEM & .mat file with finite element mesh data. \\
\hline & fort. 15 & ADCIRC control file \\
\hline & fort. 26 & SWAN control file \\
\hline & tide_input.txt & $\begin{array}{l}\text { Contains lines where ADCIRC tidal } \\
\text { factors are changed. }\end{array}$ \\
\hline & swan_lines.txt & $\begin{array}{l}\text { Contains lines where SWAN dates are } \\
\text { changed. }\end{array}$ \\
\hline & met_input.m & $\begin{array}{l}\text { Meterological forcing file to be used in } \\
\text { ADCIRC. }\end{array}$ \\
\hline
\end{tabular}

that the meteorological forcing covers the entire grid, although it is not required. The wind variables should be in units of meters per second $(\mathrm{m} / \mathrm{s})$, and pressure should be in meters of water $\left(\mathrm{mH}_{2} \mathrm{O}\right)$. As wind forcing sources vary significantly from one another, the user should edit the function metinput.m so the Lon, Lat, $U, V, P, t$, and $d t$ are properly generated for each time step. The format of each of 
these variables are described in the provided metimput.m file, in Appendix D.3.1.

If the nodal attributes file domain is larger than the meteorological forcing, the boundary will be extended, a wind velocity of zero, and pressure of $10.332 \mathrm{mH} 20$ (1013.25 mbar) will be applied to a new outermost boundary to prevent instabilities along this boundary. It should be noted that if the meteorological forcing does not cover the computational domain, results near the uncovered boundaries may have high uncertainties.

\section{Tidal Forcing}

Table 8: Format of the tidal constituent input file tideinput.txt

M2 5071
S2 5172
M1 5373
S1 x x
O1 x x

TideFac, available on the ADCIRC website, computes the nodal factors and equilibrium arguments for the ADCIRC control file, which are used for tidal forcing. An altered version of this code reads from a text file rather than prompting the user to manually enter the run date, duration and nodal factors. This information is provided in the tide_fac.in file, and is automatically changed in preprocess $1 . m$ based on the date given in met_inputs.m. The line numbers that correspond to each of the tidal constituents are included in tidelines.txt file, shown in Table 8. These specify the lines what will be changed by preprocess2.m, and which constituents will not be included.

\section{Automation of SWAN control file}

The SWAN control file (fort.26) does not need to be changed once an ADCIRC model has been configured. However, the reference dates within the file should be changed to prevent confusion when analyzing the output from multiple runs. The 
Table 9: Format of swanlines.txt

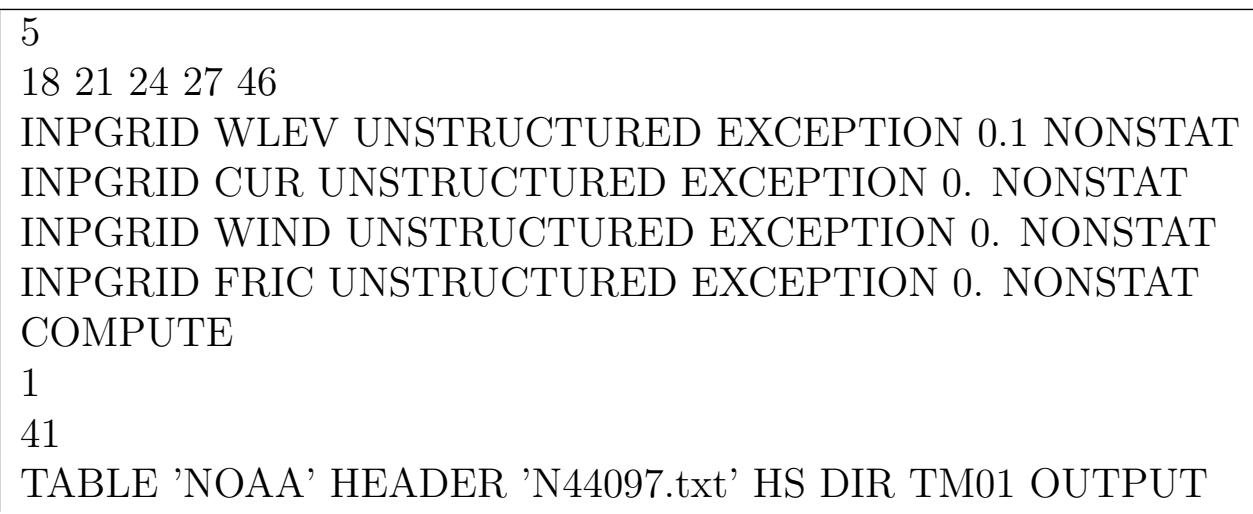

lines where these dates need to be changed in SWAN should be listed in the first line of swanlines.txt, as shown in Table 9. This should be followed by the strings that normally precede the input lines. Next, any custom lines can be added. The example model pulls output at the node on the grid near the NOAA 44097/CDIP 154 buoy, and uses the output for validation.

\subsubsection{Automation}

In order for the system to run properly, the location of the working folder, containing all the ADCIRC input, should be assigned to the HOMEdir variable. The lines at the beginning of the forecast script should also be changed to download the files used for meteorological forcing (refer to comments in Appendix D.2.1). To remotely access the system where ADCIRC will be executed, a series of expect scripts are controlled by the bash script remote.sh. Enter the IP, and login credentials, along with strings the system returns while logging in. prep.sh will automatically login/run/logout the necessary ADCIRC prep functions. run.sh will execute the batch file on your system, which must be made separately based on user specifications.

After changing the user inputs, the functions within forecast can be added the environment by executing the following commands from the home directory of the 
forecasting system.

user@computer $\$$ source forecast

This will add all the bash functions within the script named forecast into the local environment.

$$
\text { user@computer \$ runONCE }
$$

Should be used to run the entire process once

$$
\text { user@computer \$ runLOOP }
$$

Should be used to begin an infinite loop. This terminal window will run and submit a run. Upon completion, it will wait until the specified time in forecast, and continue to execute daily until terminated by the user.

$$
\text { user@computer \$ runLOCAL }
$$

Can be used to run the system locally.

\subsubsection{Application of Forecasting System in Rhode Island}

The forecasting system was applied to a SWAN+ADCRIC model focused in Rhode Island during Nor'Easter Stella, which was the most significant extratropical event of the 2016-2017 winter season. The storm resulted in coastal flooding in

New Jersey and as much as 5 feet of snow $(1.5 \mathrm{~m})$ to some areas [10] across the Northeast United States. This Storm provided an opportunity to test the accuracy of the described forecast system for both waves and surge. WRF wind model provided by NECOFS was applied to a mesh tested and validated by URI [9]. The atmospheric forcing and computational domain are shown in Figure 31. The mesh has a resolution of 100 m nearshore, and was merged into GOM4 [2] to provide higher resolution in Rhode Island.

The forecast was executed two days before the arrival of Nor'Easter Stella. As shown in Figures 32 and 33, the forecasting system more accurately predicts 


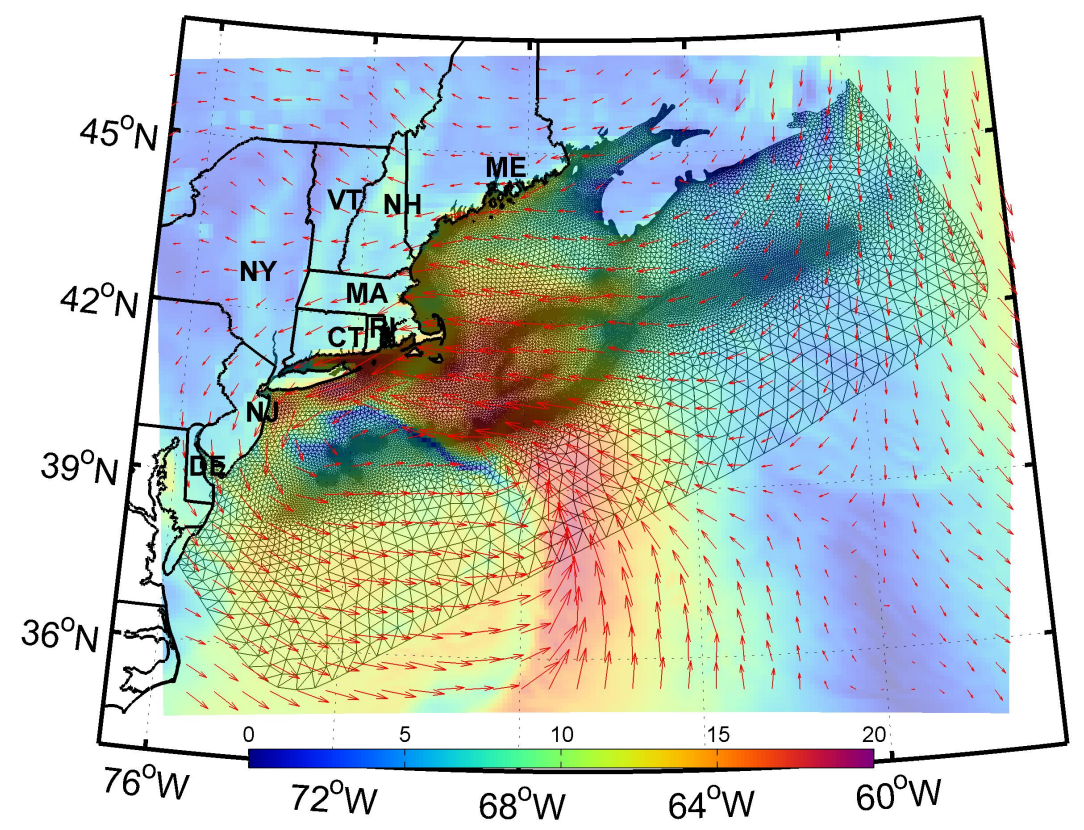

Figure 31: Wind Velocity and Direction Vectors during Nor'Easter Stella over the computational grid.

water levels and surge nearing days three and four of the model simulation. The Significant wave height is under-predicted by approximately $1 \mathrm{~m}$ at the peak of the storm. Figure 33 shows the Root Mean Squared Error (RMSE) for both water level and waves during the duration of the forecast. The magnitude of error is greatest at the start of the simulation for water level, as the ramp function takes a number of days to bring tides up to phase. There was also a slight bump in error during the peak of the storm. The error of wave heights got larger as the forecasting period approached the peak of the storm.

\subsubsection{Modeling Synthetic Storms Representing the 100-year Event}

After hurricane Sandy, the USACE performed the North Atlantic Coastal Comprehensive Study [8], a coastal hazard study for resilience adaptation towards an increased risk to ports, coastal communities, and businesses. The study ad- 

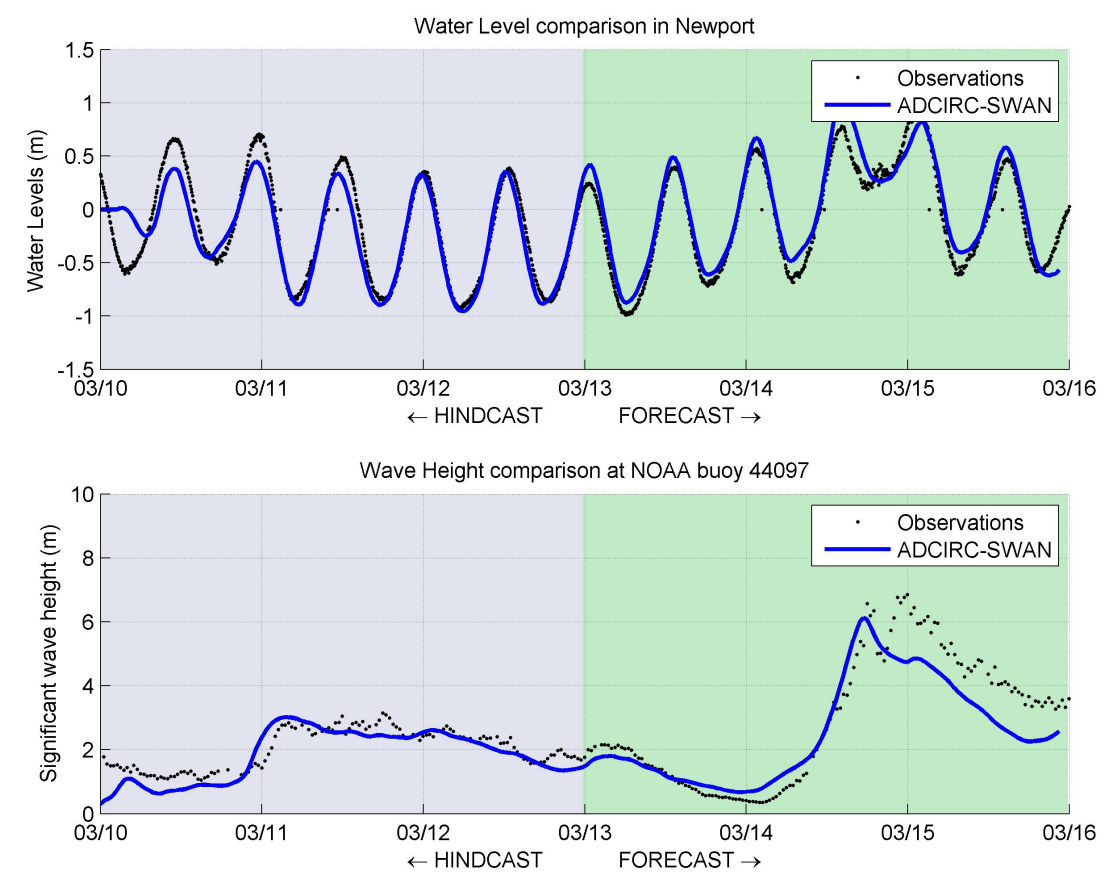

Figure 32: Comparison of measured and modeled data, taken on 3/13/2017. The blue region represents the hindcast period, used as to ensure the model is running properly. The forecast period is shown in green.

dressed the threats of storms to the northeastern United States by modeling the surge and waves during 1050 synthetic tropical and 100 historic extra-tropical storms, and provided the data in a number of save points across the northeast. The peak water elevation from two storms closely matched the upper 95 percent confidence interval of the $1 \%$ annual water elevation plus mean high high water (MHHW) in Newport [5] (3.46 m NAVD88). At NACCS save point 8741 (closest to the Newport tidal gauge), storms 457 and 492 had maximum surges of 3.48 and 3.50 meters, respectively.

If tides are added to the simulation, the peak water elevations during each of the NACCS storm 457 would be greater than NOAA's expected 100-year return period water elevation in Newport. The track of this storm can be seen in Figure 34. Figures 35 and 36 compare the time series wind and water elevation in Charlestown, 

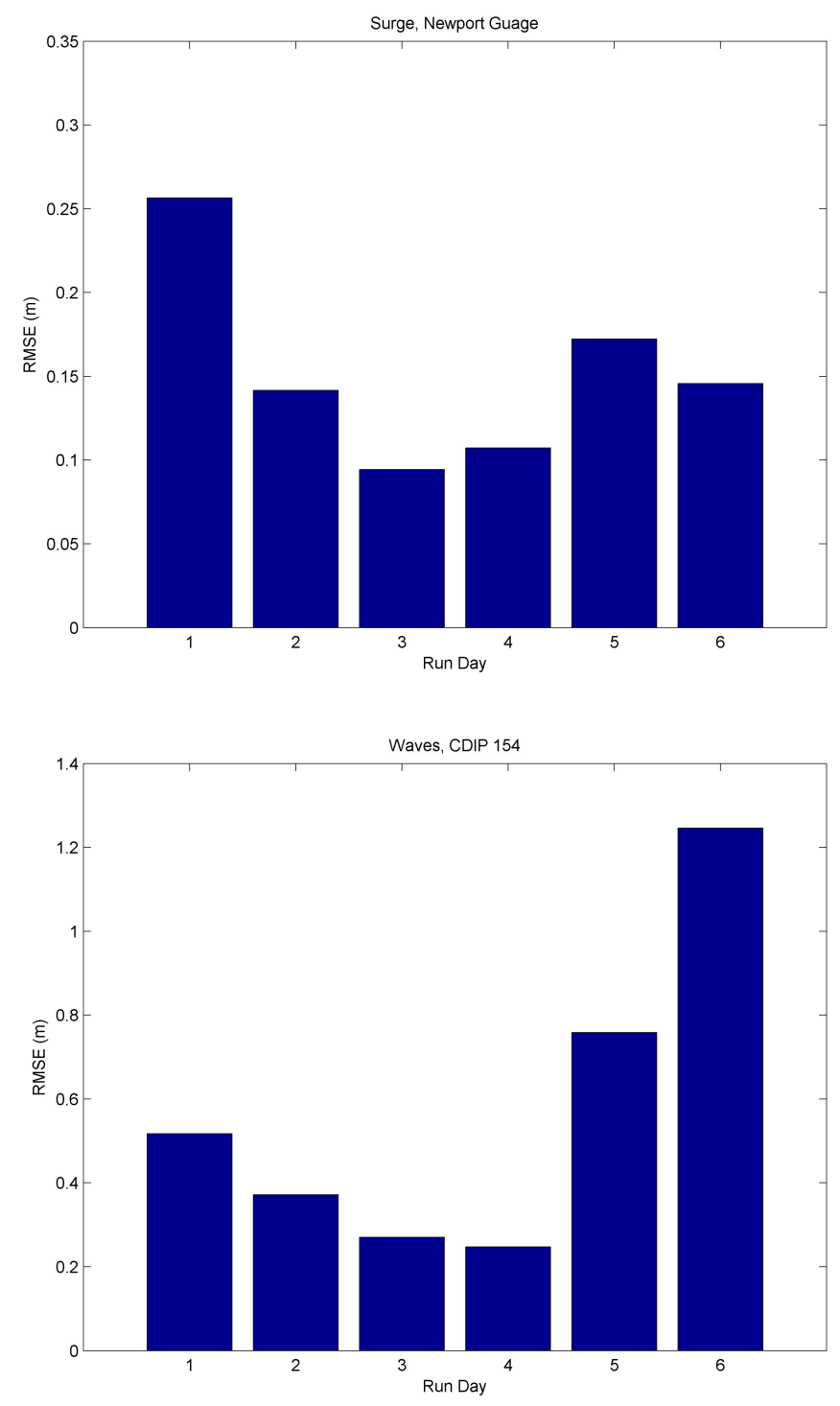

Figure 33: Daily root-mean squared error (RMSE) for the surge at NOAA Newport tidal gauge in Newport (top) and daily RMSE of waves at CDIP 157 buoy(bottom).

Newport, and Providence. Results of the high resolution model were used for 2Dimensional wave and flood maps for the state of Rhode Island, maximum water elevations are shown in Figure 37. 


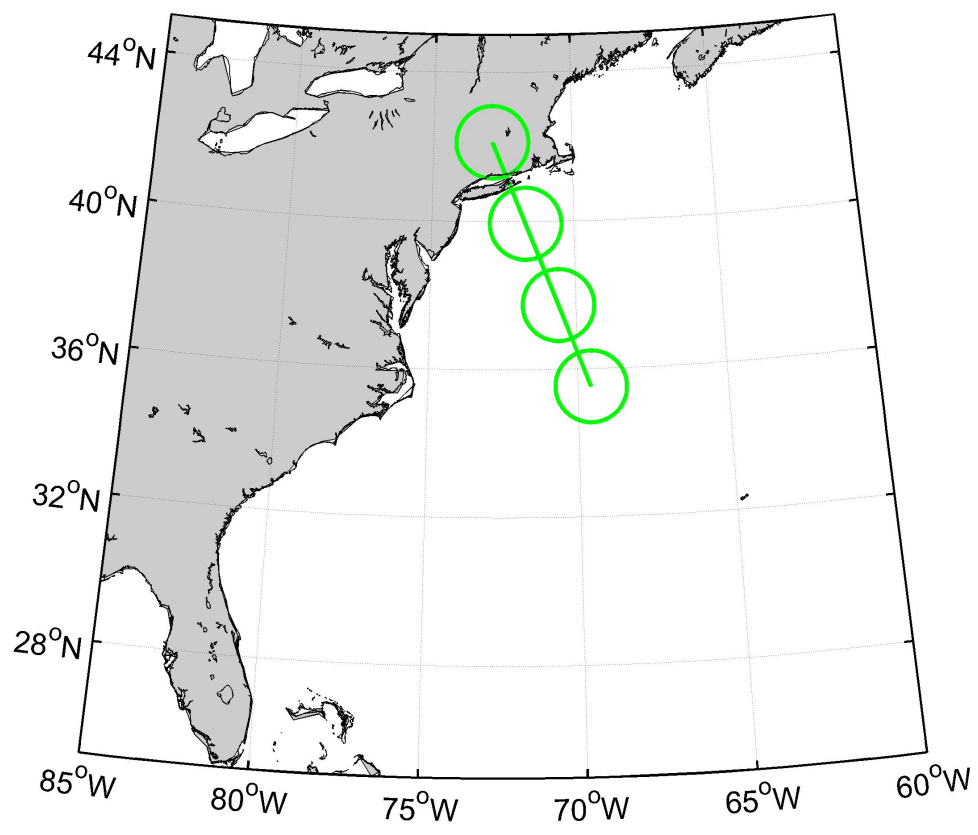

Figure 34: Track of NACCS storm ID 457, with radius of maximum wind (RMW) plotted every 24 hours.

(A)

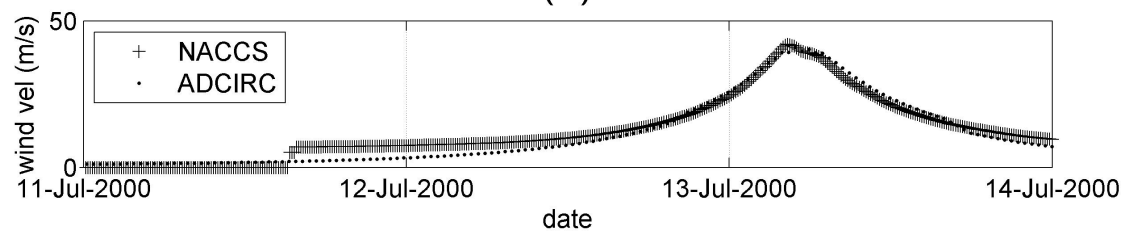

(B)

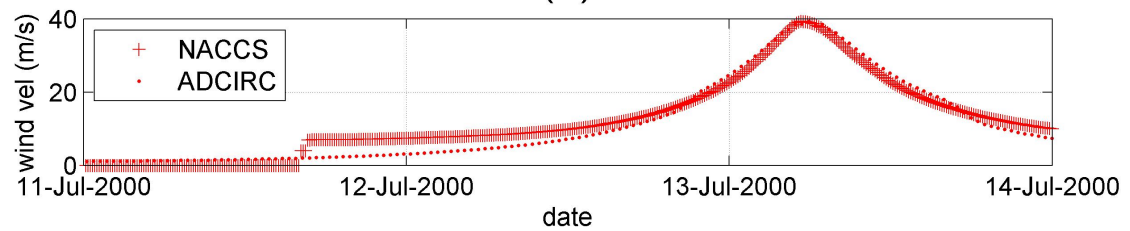

(C)

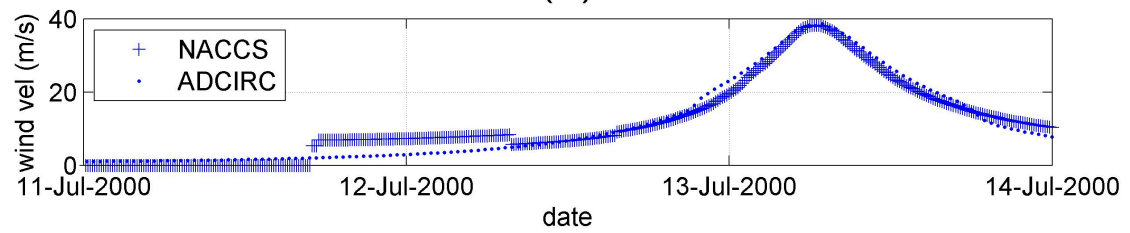

Figure 35: Comparison of the recreated synthetic hurricane wind field at the location of NACCS save points in Charlestown (A), Newport (B), Providence (C). 
(A)

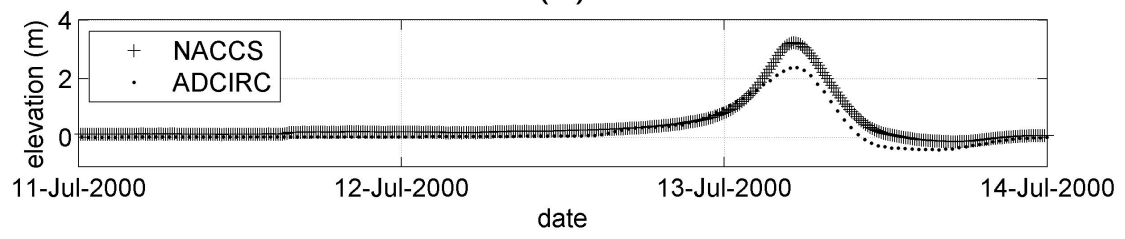

(B)

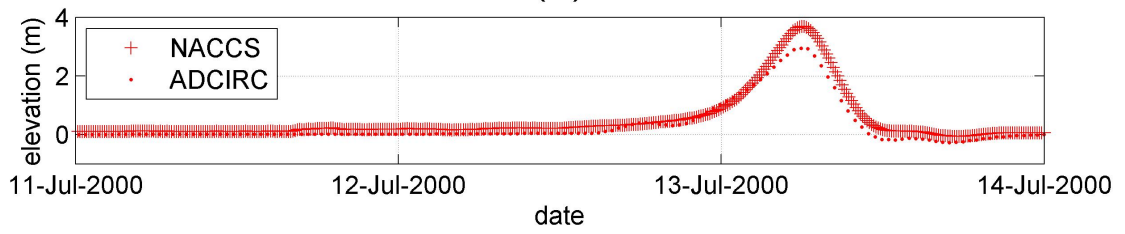

(C)

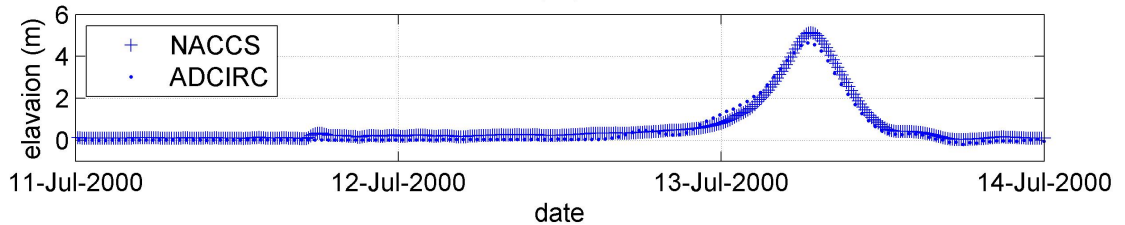

Figure 36: Time series water elevation over the high-resolution mesh, near NACCS save points in Charlestown (A), Newport (B), Providence (C). 


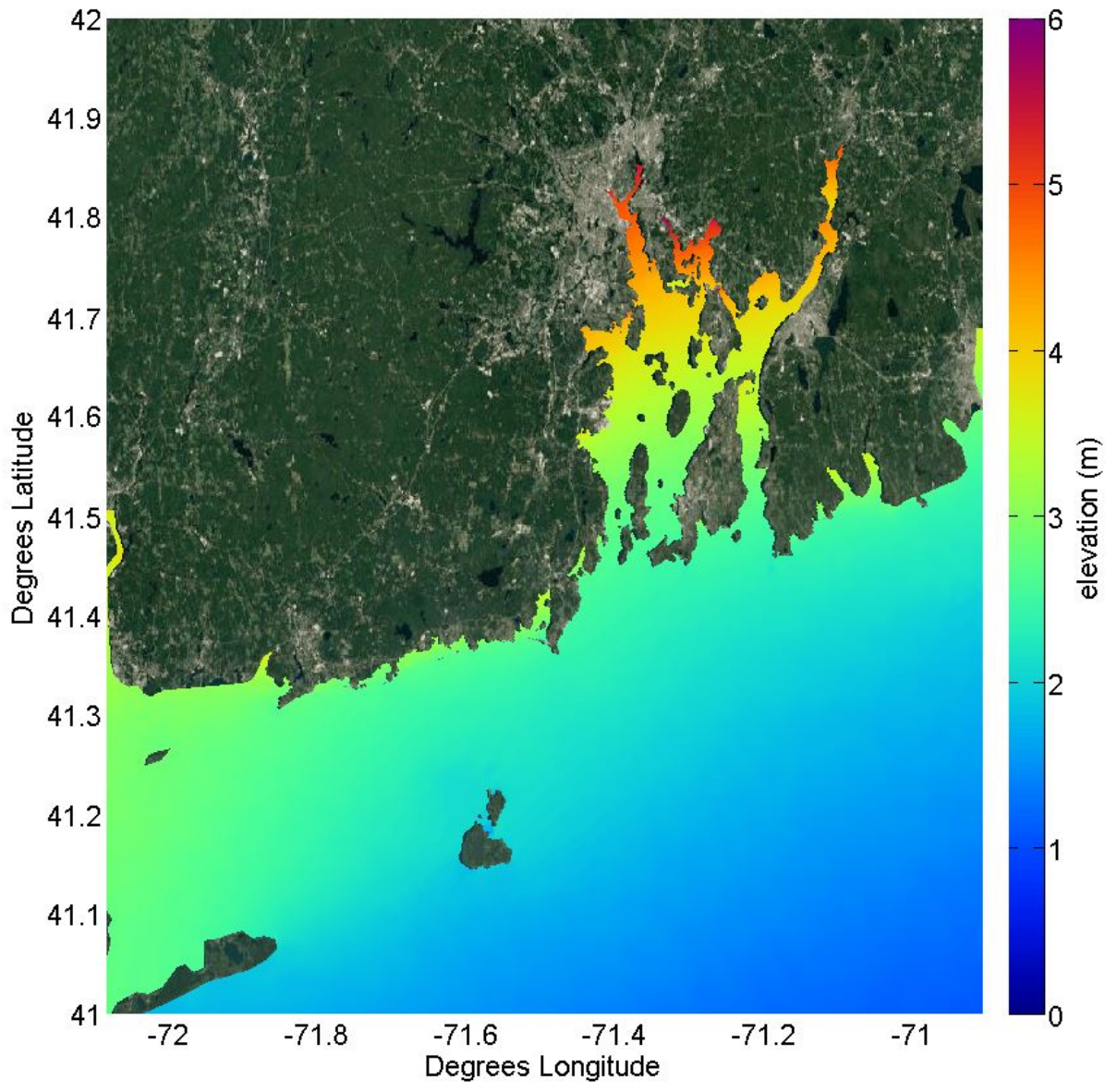

Figure 37: Maximum water elevation over the high-resolution mesh during the synthetic 100 year storm. 


\subsection{Discussion and Conclusion}

A set of MATLAB and bash programs were designed for preprocessing and automating the coupled wave and hydrodynamic model SWAN+ADCIRC for real time forecasting of waves and storm surge. Simulations are preprocessed and packaged locally, before being sent to run externally using High Performance Computing (HPC). During Nor'Easter Stella, the forecast system was able to perform a 3-day forecast for the state of Rhode Island in with a simulation time of 6 hours using 64 processors. The meteorological forcing was published at 10:00 GMT, computation is set to start at 10:30 GMT, meaning the simulation is complete and ready to be available for the public at 16:30 GMT, or 12:30 EST. With this information, the public can be alerted by nightfall if a coastal storm were approaching.

The real-time forecasting system allows the user to automate the preprocessing and running of a SWAN+ADCIRC model using parametric wind fields. Control files allow for user input, and easy implementation with new ADCIRC models. The model was tested during Noreaster Stella, using NECOFS WRF atmospheric forcing. The maximum RMSE during the forecast period was $1.2 \mathrm{~m}$ for waves at the CDIP 154 buoy, and $0.2 \mathrm{~m}$ for surge in Newport. Therefore, the system is been tested and is read for future applications. 


\section{LIST OF REFERENCES}

[1] Booij, N., Ris, R.C. and Holthuijsen, L.H. (1999). A Third-Generation Wave Model for Coastal Regions, Part I, Model Description and Validation, Journal of Geophysical Research, C4, 104, 7649-7666.

[2] Chen, C. (2017). The hindcast wind data for Hurricane Sandy based on WRF output. Personal Communication (January 12, 2017).

[3] Chen, J., Shaffer, W. A., and Gilad, A. J., (1984): SLOSH- ahurricane storm surge forecasting model. Preprints, Oceans 84, Washington, D.C., Marine Technology Society and IEEE/Oceanic Engineering Society, 314-317.

[4] Dee, D. P., Uppala, S. M., Simmons, A. J., Berrisford, P., Poli, P., Kobayashi, S., Andrae, U., Balmaseda, M. A., Balsamo, G., Bauer, P., Bechtold, P., Beljaars, A. C. M., van de Berg, L., Bidlot, J., Bormann, N., Delsol, C., Dragani, R., Fuentes, M., Geer, A. J., Haimberger, L., Healy, S. B., Hersbach, H., Hlm, E. V., Isaksen, L., Kllberg, P., Khler, M., Matricardi, M., McNally, A. P., Monge-Sanz, B. M., Morcrette, J.-J., Park, B.-K., Peubey, C., de Rosnay, P., Tavolato, C., Thpaut, J.-N. and Vitart, F. (2011), The ERA-Interim reanalysis: configuration and performance of the data assimilation system. Q.J.R. Meteorol. Soc., 137: 553597. doi:10.1002/qj.828

[5] Extreme Water Levels - Newport. (2013). Retrieved July 2, 2017, from https : //tidesandcurrents.noaa.gov/est/est_station.shtml?stnid $=8452660$

[6] Fleming, J.G., Fulcher, C.W., Luettich, R. a., Estrade, B.D., Allen, G.D., Winer, H.S., (2008). A real time Storm surge forecasting System using ADCIRC. Estuar. Coast.Model 40990, 893912. http://dx.doi.org/10.1061/40990(324)48

[7] Luettich, R.A., Jr., Westerink, J.J., and Scheffner, N.W. (1992). ADCIRC: an Advanced Three-Dimensional Circulation Model for Shelves, Coasts, and Estuaries, Report 1: Theory and Methodology of ADCIRC-2DDI and ADCIRC03DL, Dredging Research Program Technical Report DRP-92-6, U.S. Army Engineers Waterways Experiment Station, Vicksburg, MS 137 p.

[8] N.C. Nadal-Caraballo, J.A Melby, V.M. Gonzalez A.T. Cox,. (2014). North Atlantic Coast Comprehensive Study (NACCS): Coastal Storm Hazards from Virginia to Maine. U.S. Army Engineer Research and Development Center (ERDC), Technical Report. ERDC-CHL-TR-15-5, 2015.

[9] Torres, M., Hashemi, M. R., Hayward, S., Ginis, I., Spaulding, M., (2017) Simulation of stormsurge in the northeast coast of the US; a closer look at the wind forcing. 
[10] Wright, P., \& Carr, A. (2016, January 04). Winter Storm Stella Dumps Nearly 5 Feet of Snow In Some Areas, Leads to At Least 16 Deaths. Retrieved July 12, 2017, from https://weather.com/storms/winter/news/snow-winter-stormstella-news-updates 


\section{APPENDIX A \\ Introduction to SWAN and ADCIRC models}

\section{A.1 SWAN}

SWAN is a third-generation wave model, developed by the Delft University of Technology. It uses the spectral wave action balance equation to solve for the 2-Dimensional wave spectrum over the computational domain.

$$
\frac{\partial N}{\partial t}+\frac{\partial c_{x} N}{\partial x}+\frac{\partial c_{y} N}{\partial y}+\frac{\partial c_{\sigma} N}{\partial \sigma}+\frac{\partial c_{\theta} N}{\partial \theta}=\frac{S_{t o t}}{\sigma}
$$

where:

$N=E / \sigma, E(\sigma, \theta)$ is the 2-dimensional wave spectrum.

$c_{x}, c_{y}$ are the wave celerity in $\mathrm{x}$ and $\mathrm{y}$ directions

$c_{\sigma}$ accounts for shift in frequancy

$c_{\theta}$ accounts for wave refraction

$S_{\text {tot }}$ describes all the activated sources and sinks within the model

$$
S_{t o t}=S_{i n}+S_{n 13}+S_{n l 4}+S_{d s, w}+S_{d s, b}+S_{d s, b r}
$$

Where each of the terms represent wind growth $\left(S_{i n}\right)$, nonlinear triplet $\left(S_{n 13}\right)$, and quadruplet $\left(S_{n 14}\right)$ wave-wave interactions, whitecapping $\left(S_{d s, w}\right)$, bottom friction $\left(S_{d s, b}\right)$, and breaking $\left(S_{d s, b r}\right)$. Each of these terms may be altered within the SWAN control file. SWAN uses the Crank-Nicholson scheme, and is unconditionally stable.

\section{A.2 ADCIRC}

ADCIRC, Developed by the University of North Carolia, is an ocean model that uses the finite element method to solve for time dependent tidal and surge equations across an unstructured grid. It uses the vertically-integrated continuity 
and momentum equations over an unstructured mesh. The continuity equation can be written as:

$$
\frac{\partial H}{\partial t}+\frac{\partial}{\partial x}(U H)+\frac{\partial}{\partial y}(V H)=0
$$

where $U$ and $V$ are the depth averaged velocities. $H$ is water column depth.

$$
\begin{gathered}
U, V=\frac{1}{H} \int_{-h}^{\eta} u, v d z \\
H=\eta+h
\end{gathered}
$$

Unlike SWAN, ADCIRC is conditionally stable, and is subject to CFL criterion. While SWAN can have a computational time step of a matter of minutes, most ADCIRC models use a time step in the order of fractions of a second to a few seconds.

\section{A.3 SWAN+ADCIRC coupling}

Coupling SWAN+ADCIRC allows for computation of water levels, currents, and waves in a non-stationary timeframe. SWAN also has the ability to compute wave-induced set-up in addition to storm surge. When coupled, SWAN reads timevarying water elevation, friction, currents, and meteorological forcing directly from ADCIRC. ADCIRC reads the wave stresses computed by the SWAN model. The use of an unstructured grid allows for increased resolution in the areas of interest without sacrificing computational cost.

Message Passing Interface (MPI) allows SWAN+ADCIRC runs to be distributed across multiple processors, decreasing total computational time. When running a coupled SWAN+ADCIRC model on multiple processors, the unstructured domain is broken up into a number of smaller domains during preprocessing. 


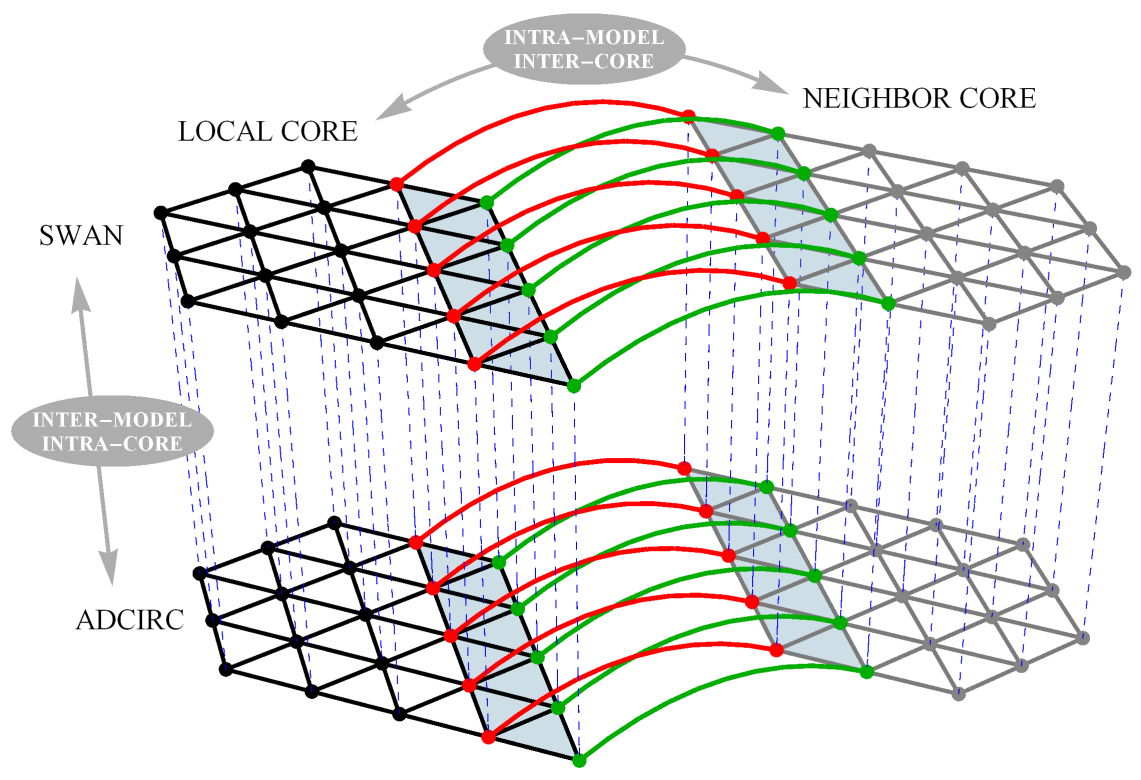

Figure A.38: SWAN+ADCIRC coupling schematic, https://ccht.ccee.ncsu.edu

Each processor contains it's own model, As illustreated by Figure A.38. The boundary nodes for each model are shared with another domains during computation. An example of the breakdown of the SWAN+ADCIRC domain can be seen in Figure A.39 


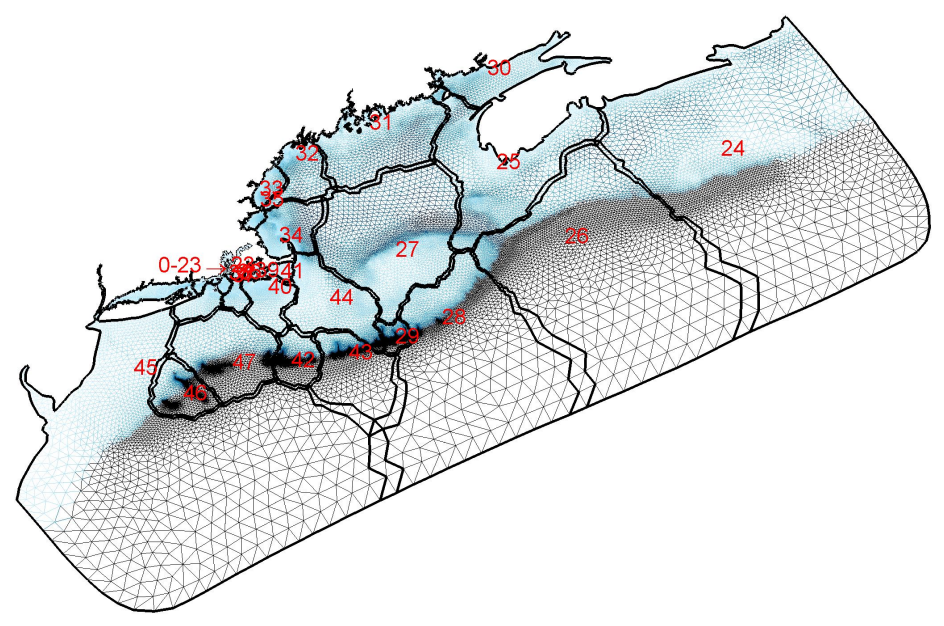

Figure A.39: Breakdown of regional model on 48 processors 


\section{APPENDIX B}

\section{Introduction to XBeach}

Table B.10: List of Variables

\begin{tabular}{|l|l|}
\hline Variable & Description \\
\hline$N$ & the spectral energy density \\
\hline$c_{g}$ & Group Velocity \\
\hline$c_{\theta}$ & Refraction \\
\hline$\sigma$ & wave frequency \\
\hline$\theta_{m}$ & mean wave direction \\
\hline$S$ & Radiation Stress \\
\hline$S_{\text {roller }}$ & roller dissipation \\
\hline$D_{\text {waves }}$ & wave dissipation \\
\hline$D_{\text {roller }}$ & roller dissipation \\
\hline$u^{L}, v^{L}$ & lagrangian flow velocities \\
\hline$u^{E}, v^{E}$ & eulerian flow velocities \\
\hline$f$ & coriolis force \\
\hline$z_{s}$ & water level \\
\hline$F$ & wave force \\
\hline$\tau_{b}$ & bed shear stress \\
\hline$\tau_{z}$ & wind shear stress \\
\hline$C$ & depth-averaged concentration of suspended sediment. \\
\hline$h$ & the water depth \\
\hline$u_{A}$ & the facua parameter \\
\hline$D_{s}$ & the sediment diffusion coefficient. \\
\hline$T_{s}$ & the current time step \\
\hline$z_{b}$ & the bed level \\
\hline$m_{c r}$ & critical bed slope \\
\hline$\rho$ & the density of salt water \\
\hline$S_{x}, S_{y}$ & x and y components of sediment transport \\
\hline
\end{tabular}

XBeach, developed by Deltares, TU Delft, and UNESCO-IHE, is a sediment transport model developed for analysis of beach erosion in small domains. Xbeach uses the advection-diffusion equation to calculate changes in bathymetry due to wave energy, and currents. Unlike many third generation wave models, it is not designed for wave generation due to winds, and default settings do not take into 
account changes in $\sigma$ space, meaning energy cannot shift between frequencies. Because of this, the boundary conditions will be created using wave and water level conditions produced by the SWAN+ADCIRC models. During computation, four different modules are used to calculate erosion. Hydrodynamics consist of a short-wave modeule, and a flow module, which both recieve boundary conditions to calulate waves, currents, and surface elevations. The Morphodynamic modules calculate sediment transport and changes in bed level based on the hydrodynamics.

\section{B.1 Hydrodynamics}

The XBeach hydrodynamic modules consist of a short wave module, and a flow module.

\section{B.1.1 Short wave module}

The stationary mode wave action balance equation used by XBeach is shown below:

$$
\begin{gathered}
\frac{\partial N}{\partial t}+\frac{\partial c_{x} N}{\partial x}+\frac{\partial c_{y} N}{\partial y}+\frac{\partial c_{\theta} N}{\partial \theta}=-\frac{D_{\omega}+D_{f}+D_{v}}{\sigma} \\
N(x, y, t, \theta)=\frac{E_{\omega}(x, y, t, \theta)}{\sigma(x, y)}
\end{gathered}
$$

The difference can be seen here in relation to SWAN's spectral wave action

balance equation, $\frac{\partial c_{\sigma} N}{\partial \sigma}$ is absent in Xbeach wave formulation. When using surfbeat (instationary) mode, XBeach propagates wave packets over the calculated phase-averaged wave conditions.

XBeach uses a roller concept to model wave breaking.

$$
\frac{\partial S_{\text {roller }}}{\partial t}+\frac{\partial c_{x} S_{\text {roller }}}{\partial x}+\frac{\partial c_{y} S_{\text {roller }}}{\partial y}+\frac{\partial c_{\theta} S_{\text {roller }}}{\partial \theta}=D_{\text {waves }}-D_{\text {roller }}
$$


Where $D_{\text {waves }}$ and $D_{\text {roller }}$ are the wave dissipation, and roller dissipation, respectively.

$$
D_{\text {waves }}=\frac{a}{4} \rho g f_{\text {rep }} \frac{H_{\text {rms }}^{3}}{h} Q_{\text {break }}, \quad D_{\text {roller }}=\frac{S_{\text {roller }}}{E_{\text {roller }}} \bar{D}_{\text {roller }}
$$

\section{B.1.2 Flow module}

The flow module calculates the water elevations, and depth averaged water velocities over the domain, based on boundary conditions. It provides surface elevation and lagrangian particle velocities to the short wave and sediment transport modules.

Shallow water equations:

$$
\begin{gathered}
u^{L}=u^{E}+u^{s} v^{L}=v^{E}+v^{s} \\
u^{s}=\frac{\left(S_{\text {waves }}+2 S_{\text {roller }}\right) \cos \theta}{C \rho h} v^{s}=\frac{\left(S_{\text {waves }}+2 S_{\text {roller }}\right) \sin \theta}{C \rho h}
\end{gathered}
$$

GLM shallow water equations:

$$
\frac{\partial u^{L}}{\partial t}+u^{L} \frac{\partial u^{L}}{\partial x}+u^{L} \frac{\partial u^{L}}{\partial y}-f v^{L}-h_{h}\left(\frac{\partial^{2} u^{L}}{\partial x^{2}}+\frac{\partial^{2} u^{L}}{\partial y^{2}}\right)=\frac{\tau_{s} x}{\rho h}-g \frac{\tau_{b}^{E} x}{\rho h}-g \frac{\partial z_{s}}{\partial x}+\frac{F_{x}}{\rho h}
$$

\section{B.2 Morphodynamics}

The morphodynamics in XBeach include sediment transport and morphology modules.

\section{B.2.1 Sediment transport module}

Advection diffusion equation: 


$$
\frac{\partial C}{\partial t}+\frac{\partial h C\left(u^{E}+u_{a} \sin \theta_{m}\right)}{\partial x}+\frac{\partial h C\left(v^{E}+u_{a} \cos \theta_{m}\right)}{\partial y}+\frac{\partial}{\partial x}\left[D_{s} h \frac{\partial C}{\partial x}\right]+\frac{\partial}{\partial y}\left[D_{s} h \frac{\partial C}{\partial y}\right]=\frac{h C_{e q}-h C}{T_{s}}
$$

Sediment equilibrium equation:

$$
C_{e q}=\frac{A_{s b}}{h}\left(\sqrt{\left(u^{E}\right)^{2}+0.64 u_{r m s, 2}^{2}}-u_{c r}\right)^{1.5}+\frac{A_{s s}}{h}\left(\sqrt{\left(u^{E}\right)^{2}+0.64 u_{r m s, 2}^{2}}-u_{c r}\right)^{2.4}
$$

Sediment transport equation:

$$
\begin{aligned}
& S_{x}=h C\left(u^{E}+u_{A} \sin \theta\right)+\frac{\partial}{\partial x}+\frac{\partial}{\partial x}\left(D_{s} h \frac{\partial C}{\partial x}\right) \\
& S_{y}=h C\left(v^{E}+u_{A} \sin \theta\right)+\frac{\partial}{\partial x}+\frac{\partial}{\partial x}\left(D_{s} h \frac{\partial C}{\partial y}\right)
\end{aligned}
$$

\section{B.2.2 Morphology module}

The bed updating equation is determined by gradient of sediment transport:

$$
\frac{\partial z_{b}}{\partial t}=f_{m o r}\left(\frac{\partial S_{x}}{\partial y}+\frac{\partial S_{b}}{\partial y}\right)
$$

To simulate erosion and collapsing of dunes, the avalanching formulation is included in XBeach formulation.

$$
\begin{array}{cc}
\Delta z_{b}=\left(\left[\frac{\partial z_{b}}{\partial x}\right]-m_{c r}\right) \Delta x & \text { for } \frac{\partial z_{b}}{\partial x}>0 \\
\Delta z_{b}=-\left(\left[\frac{\partial z_{b}}{\partial x}\right]-m_{c r}\right) \Delta x & \text { for } \frac{\partial z_{b}}{\partial x}<0
\end{array}
$$




\section{APPENDIX C}

\section{An Efficient Method to Study Long-Term Sediment Transport}

\section{C.1 Introduction}

In manuscript 1, a wave, surge, and sediment transport model for storm-scale analysis of beach erosion was developed, and used to analyze the feasibility of using artificial reefs for erosion mitigation. While storms pose the greatest threat to dunes and coastal communities, long-term analysis of sediment transport is needed when considering the installation of any shoreline structure, such as an artificial reef in this case. It is likely that the natural beach equilibrium will be affected, over the course of a matter of months, or years. The following methodology presents a simplified method for providing boundary forcing for the nearshore sediment transport model. A simplified sediment transport model was used to analyze beach profile response due to the installation of an artificial reef.

\section{C.2 Wave climate look-up table}

A look-up table method was developed to correlate wave conditions at an offshore buoy with the boundary of the sediment transport model. A stationary SWAN model, illustrated by the black box in Figure C.40 is forced using the wave climate at the CDIP 154 buoy. Based on the wave conditions at the CDIP 154 buoy, a library is created, comprised of the 2-dimensional SWAN output for the significant wave height, peak period, and direction. This library is used to create a look-up table for a desired location within the domain.

The wave climate information from WIS shows the majority of offshore swells near the boundary come from a directions between 115 and 225 degrees $\mathrm{N}$, and the 100-year return period Hmo is between 10 and 12 meters. To estimate the majority of wave climates, a combination of these conditions should be analyzed. The origin 


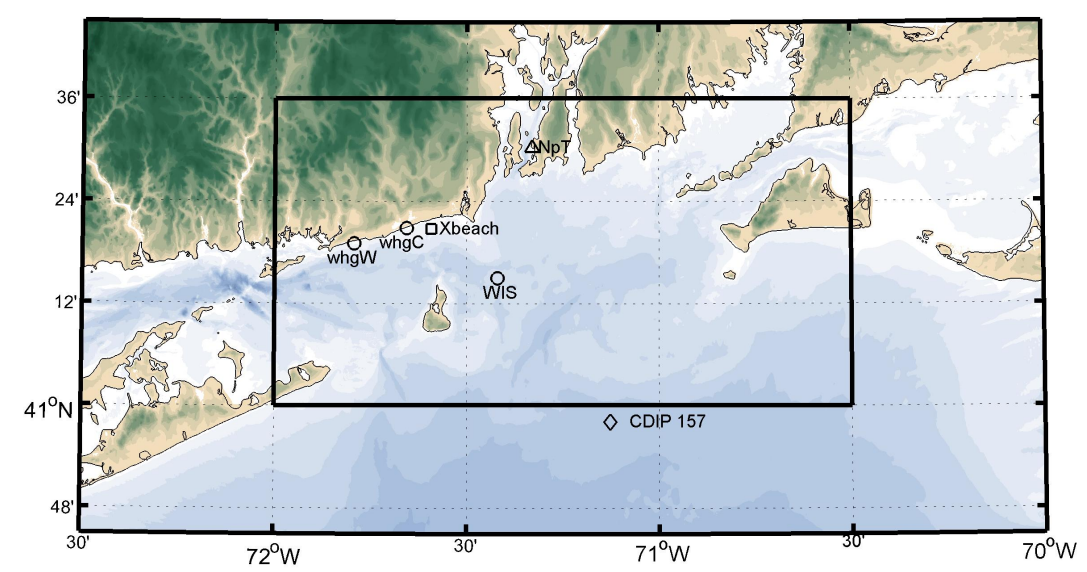

Figure C.40: Stationary SWAN model domain, and validation locations for boundary forcing method.

of the SWAN model domain is located at $41 \mathrm{~N}, 72 \mathrm{~W}$, and is $1.5^{\circ} \mathrm{W}$ by $0.6^{\circ} \mathrm{N}$. The grid spacing is approximately 150 meters, and the domain is $450 \times 180$ grid points. 420 separate SWAN runs were performed, with every possible permutation of significant wave heights (Hs) of 1, 2, 5, 9, and 12 meters with peak directions ranging from $90,110,130,140,150,160,170,180,190,200,210,230,250$, and 270 degrees, and peak periods of 4, 7, 10, 12, 15, and 20s were computed throughout the domain.

Hurricane Irene was used to calibrate the model. Two ADCPs deployed by Woods Hole Group[44], (whgW, and wghC in Figure C.40) were used to compare the Hs, Tp, Dp for the month of August 2011. Using the default model settings, SWAN overpredicted the wave height at both locations during hurricane Irene. Two parameters were adjusted to increase dissipation from the boundary to shore. The Jonswap peak enhancement gamma was changed from its default value of 
3.3 to 2.0 [21]. Additionally, whitecapping was increased in order to improve the dissipation from the boundary towards shore [3]. Comparison of these parameters scan be seen in Figure C.41

The dissipation due to whitecapping from the sources/sinks equation described in section 2.3.1 is defined as the term $S_{d s, \omega}$, and is calculated using the following equation:

$$
S_{d s, w}(\sigma, \theta)=-\Gamma \sigma \frac{k}{k} E(\sigma \theta)
$$

where $\gamma$ is related to wave steepness

$$
\gamma=C_{d s}\left((1-\partial)+\partial \frac{k}{k}\right)\left(\frac{s}{s_{P} M}\right)^{p}
$$
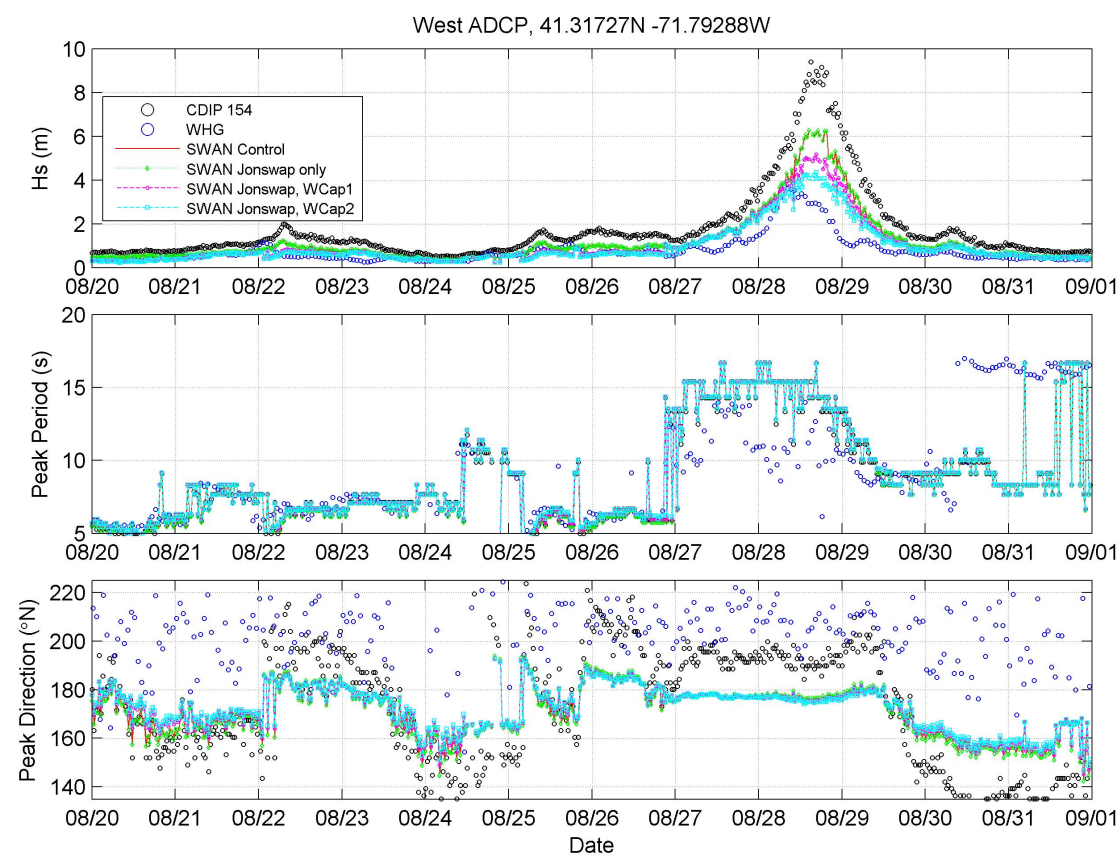

Figure C.41: Stationary SWAN model sensitivity test for Jonswap Gamma, and Whitecapping at Woods Hole West ADCP. Time-series of significant wave height(top), peak period(center), and peak direction (bottom) from 08/20/2011 to 09/01/2011. 
Table C.11: Root Mean Squared Error (RMSE) of Significant wave height, period, and direction at West ADCP, from 08/20/2011 to 09/01/2011

\begin{tabular}{|l|l|l|l|}
\hline Model set-up & Hs RMSE & Per RMSE & Dir RMSE \\
\hline Control & $0.4106 \mathrm{~m}$ & $0.2114 \mathrm{sec}$ & $34.3828^{\circ}$ \\
\hline Jonswap Gamma $=2.0$ & $0.4125 \mathrm{~m}$ & $0.2114 \mathrm{sec}$ & $34.4729^{\circ}$ \\
\hline$C_{d s}=2.36 e-4$ & $0.2438 \mathrm{~m}$ & $0.2809 \mathrm{sec}$ & $33.4709^{\circ}$ \\
\hline$C_{d s}=2.36 e-3$ & $0.1157 \mathrm{~m}$ & $0.2993 \mathrm{sec}$ & $33.1274^{\circ}$ \\
\hline
\end{tabular}

Table C.12: Root Mean Squared Error (RMSE) of Significant wave height, period, and direction at Center ADCP, from 08/20/2011 to 09/01/2011

\begin{tabular}{|l|l|l|l|}
\hline Model set-up & Hs RMSE & Per RMSE & Dir RMSE \\
\hline Control & $0.3896 \mathrm{~m}$ & $0.2114 \mathrm{sec}$ & $38.3875^{\circ}$ \\
\hline Jonswap Gamma $=2.0$ & $0.3918 \mathrm{~m}$ & $0.2114 \mathrm{sec}$ & $38.6437^{\circ}$ \\
\hline$C_{d s}=2.36 e-4$ & $0.2310 \mathrm{~m}$ & $0.2791 \mathrm{sec}$ & $37.3712^{\circ}$ \\
\hline$C_{d s}=2.36 e-3$ & $0.1458 \mathrm{~m}$ & $0.2916 \mathrm{sec}$ & $36.8785^{\circ}$ \\
\hline
\end{tabular}

\section{C.3 XBeach model}

An efficient XBeach model was set up to simulate the sediment transport over the course of one year, the model settings can be seen in Table C.13. The XBeach model was forced with water levels, and wave conditions from August 1, 2010August 1, 2011. The model was then run for an entire year with and without the presence of the artificial reef. The wave conditions, and water level were read by XBeach hourly, and the simulated water level, waves, and bed level were output in hourly increments over the course of the simulation. 
Table C.13: Long-term XBeach variables and descriptions

\begin{tabular}{|l|l|l|}
\hline Variable & Value & Description \\
\hline nx, ny & $156 \times 500$ & $\begin{array}{l}\text { Number of nodes in x and y directions, } \\
\text { respectively. }\end{array}$ \\
\hline $\begin{array}{l}\text { Wave } \\
\text { Hydrody- } \\
\text { namics }\end{array}$ & Stationary & Wave forcing option \\
\hline morfac & 5 & $\begin{array}{l}\text { Morphological acceleration factor, used } \\
\text { to decrease computation time by reduc- } \\
\text { ing frequency of bottom-updating. }\end{array}$ \\
\hline dtbc & 3600 & $\begin{array}{l}\text { Frequency at which the wave flux at the } \\
\text { boundary is randomized and updated. } \\
\text { (seconds) }\end{array}$ \\
\hline rt & 3600 & $\begin{array}{l}\text { Frequency XBeach will read a new } \\
\text { boundary condition file and re-compute } \\
\text { wave energy spectrum. (seconds) }\end{array}$ \\
\hline facua & 0.3 & $\begin{array}{l}\text { Asymmetric onshore sediment trans- } \\
\text { port to counteract wave asymmetry. }\end{array}$ \\
\hline tsmin & 10 & $\begin{array}{l}\text { Minimum time step in advection- } \\
\text { diffusion equation. }\end{array}$ \\
\hline tintg & 3600 & $\begin{array}{l}\text { global variable output timestep. (sec- } \\
\text { onds) }\end{array}$ \\
\hline globalvar & zs, zb, H & $\begin{array}{l}\text { global variables output every tintg sec- } \\
\text { onds. }\end{array}$ \\
\hline $\begin{array}{l}\text { Boundary } \\
\text { Forcing }\end{array}$ & $\begin{array}{l}\text { Look-up } \\
\text { table } \\
\text { pendix } \\
1)\end{array}$ & $\begin{array}{l}\text { Method for providing wave boundary } \\
\text { conditions }\end{array}$ \\
\hline Friction & Constant & Bottom friction formulation \\
\hline
\end{tabular}




\section{C.4 Results}

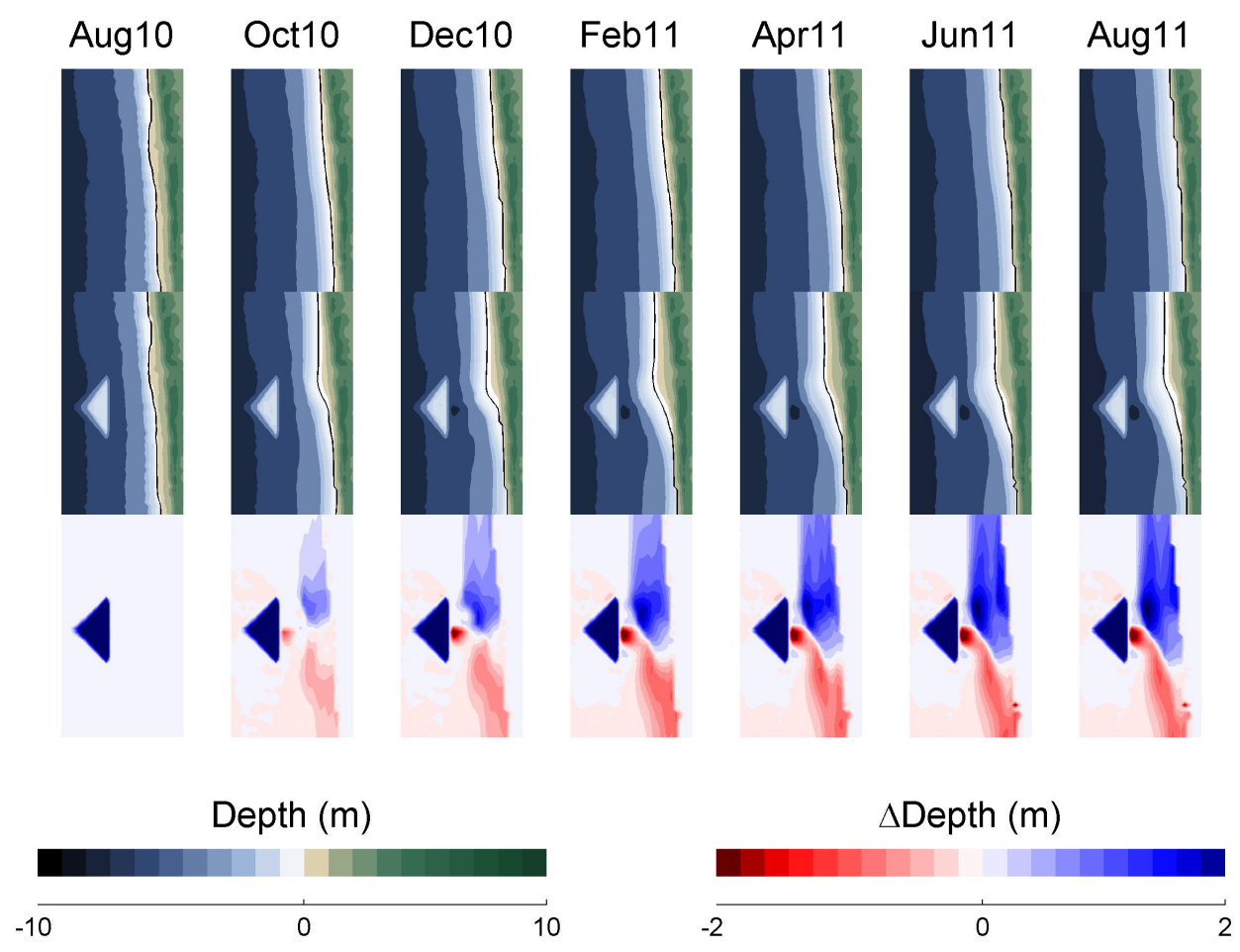

Figure C.42: Change in bathymetry $\left(h_{\text {reef }}-h_{\text {control }}\right)$ over 1 year XBeach simulation, control run(top) in comparison to the artificial reef(middle). The difference between the control run and the Artificial reef is shown below.

Figure C.42 illustrates the formation of a bar in lee of the reef. While both the control simulation and the simulation with the reef develop a winter profile, the area of beach does not decrease behind the reef. The shoreline protected by the reef begins to develop a tombolo, and the shoreline does not recede as the simulation continues. The mean swell direction is incident to the beach contours, (out of the South) the mean longshore sediment transport is from West-East (top to bottom in Figure C.42). This resulted in increased erosion on the East side of the reef, as sediment was deposited behind the reef rather than transported downstream. To the east of the reef, decreased wave energy resulted in an increased rate of sediment 
deposition. This, however, reduces the concentration of sediment downstream of the reef, and results in increased erosion in it's wake.

\section{C.5 Significant Wave height look-up table}

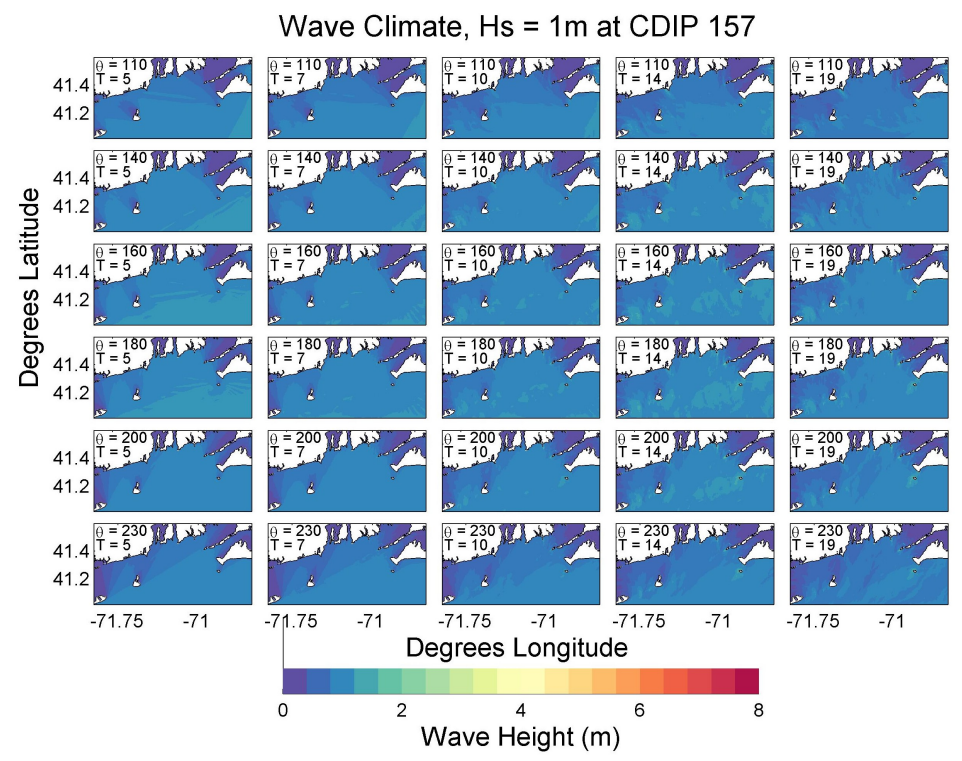

Figure C.43: SWAN model results for $H s=1 \mathrm{~m}$. The wave period varies with each row, direction varies with columns.

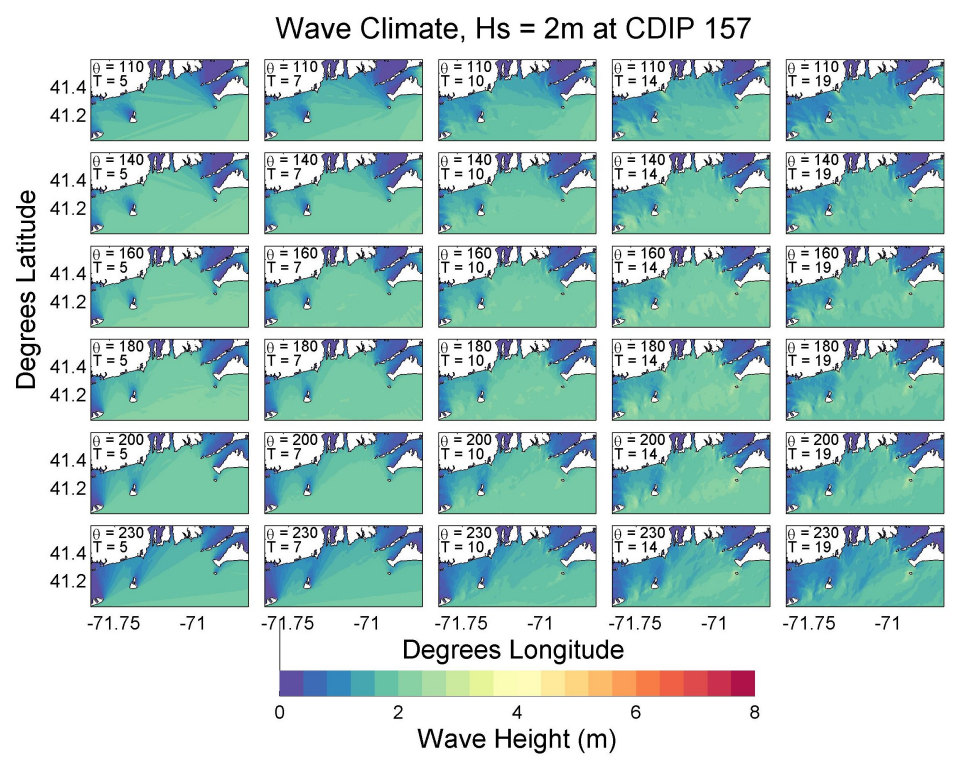

Figure C.44: SWAN model results for $H s=2 m$. The wave period varies with each row, direction varies with columns. 


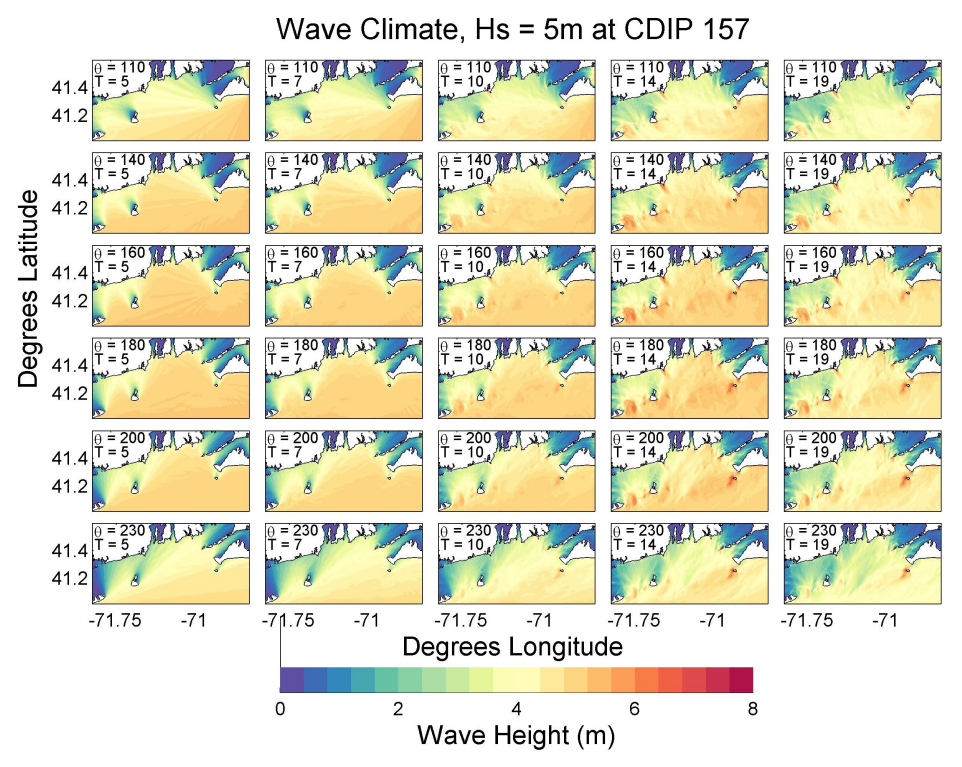

Figure C.45: SWAN model results for $H s=5 \mathrm{~m}$. The wave period varies with each row, direction varies with columns.

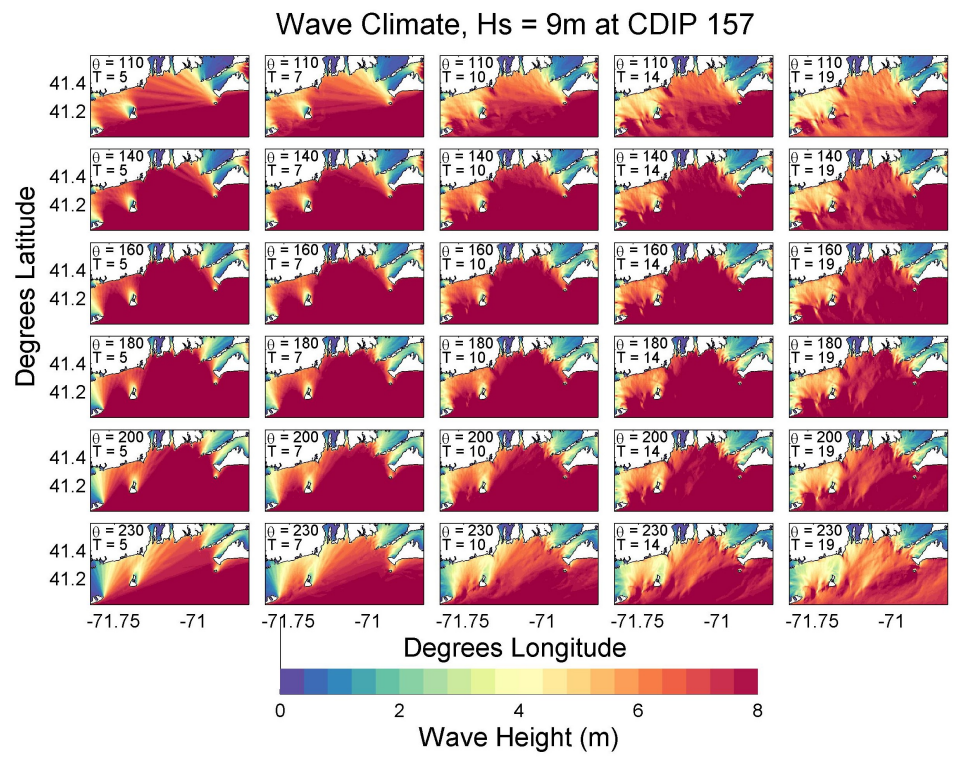

Figure C.46: SWAN model results for $H s=9 \mathrm{~m}$. The wave period varies with each row, direction varies with columns. 


\section{APPENDIX D}

\section{Forecasting model: Bash and MATLAB scripts}

\section{D.1 MATLAB files \\ D.1.1 preprocess1.m}

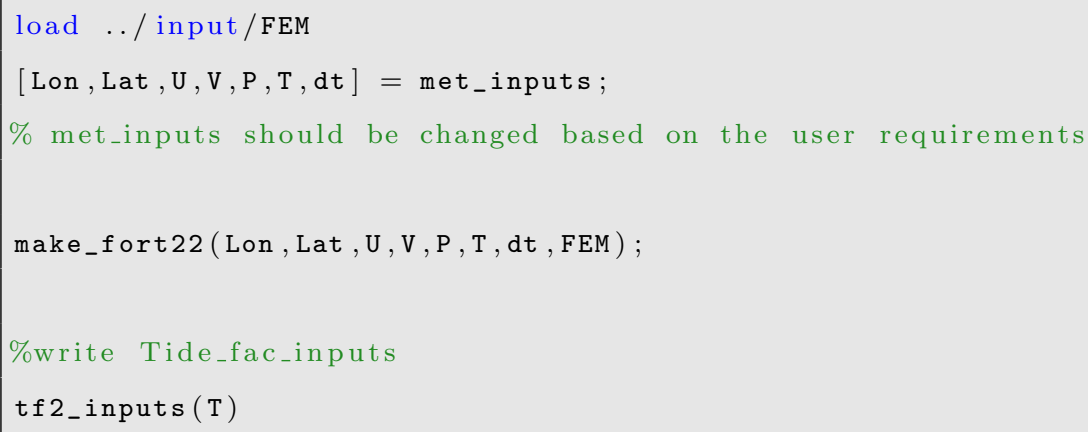

\section{D.1.2 preprocess2.m}

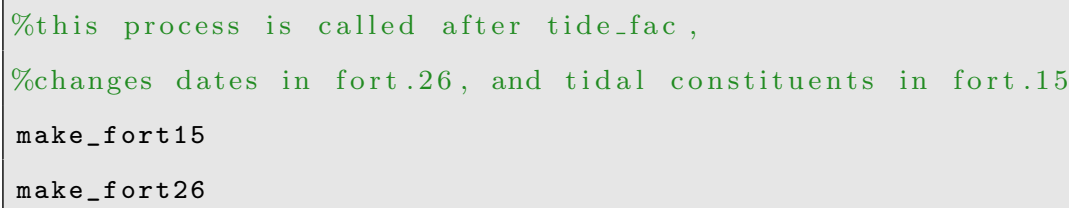

\section{D.1.3 met_inputs.m}

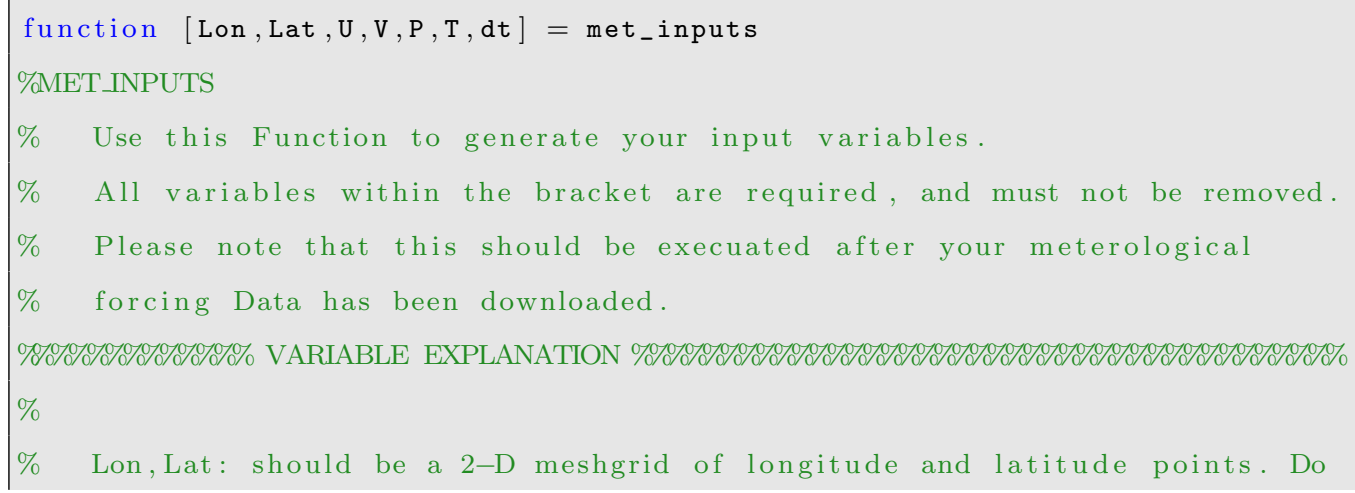




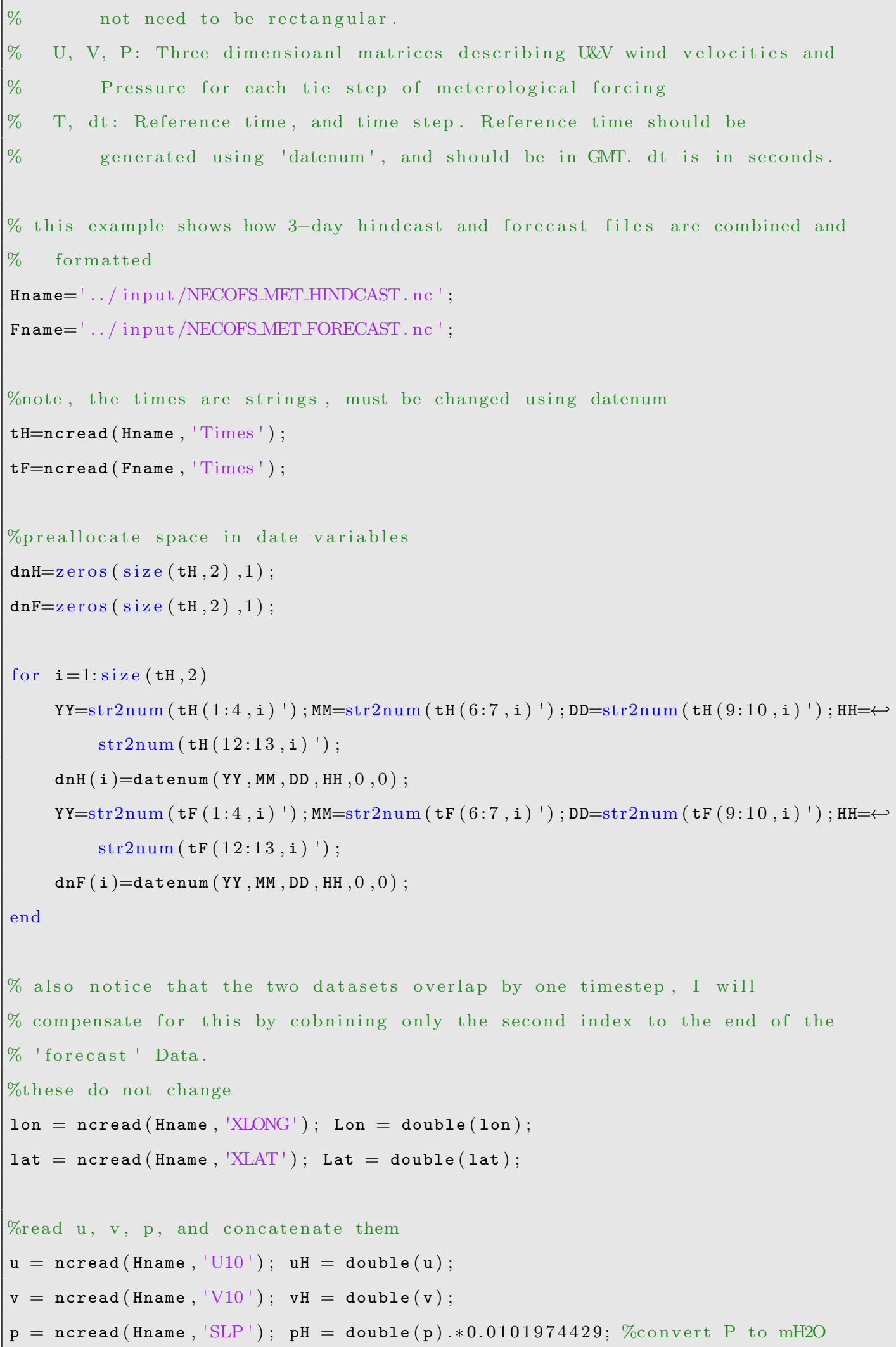




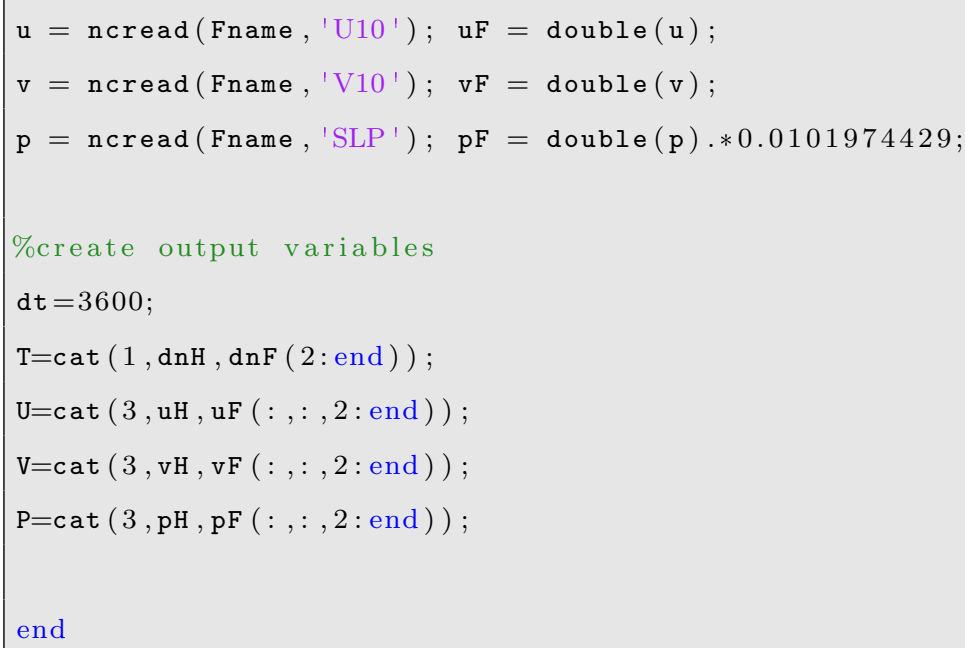

\section{D.1.4 make_fort22.m}

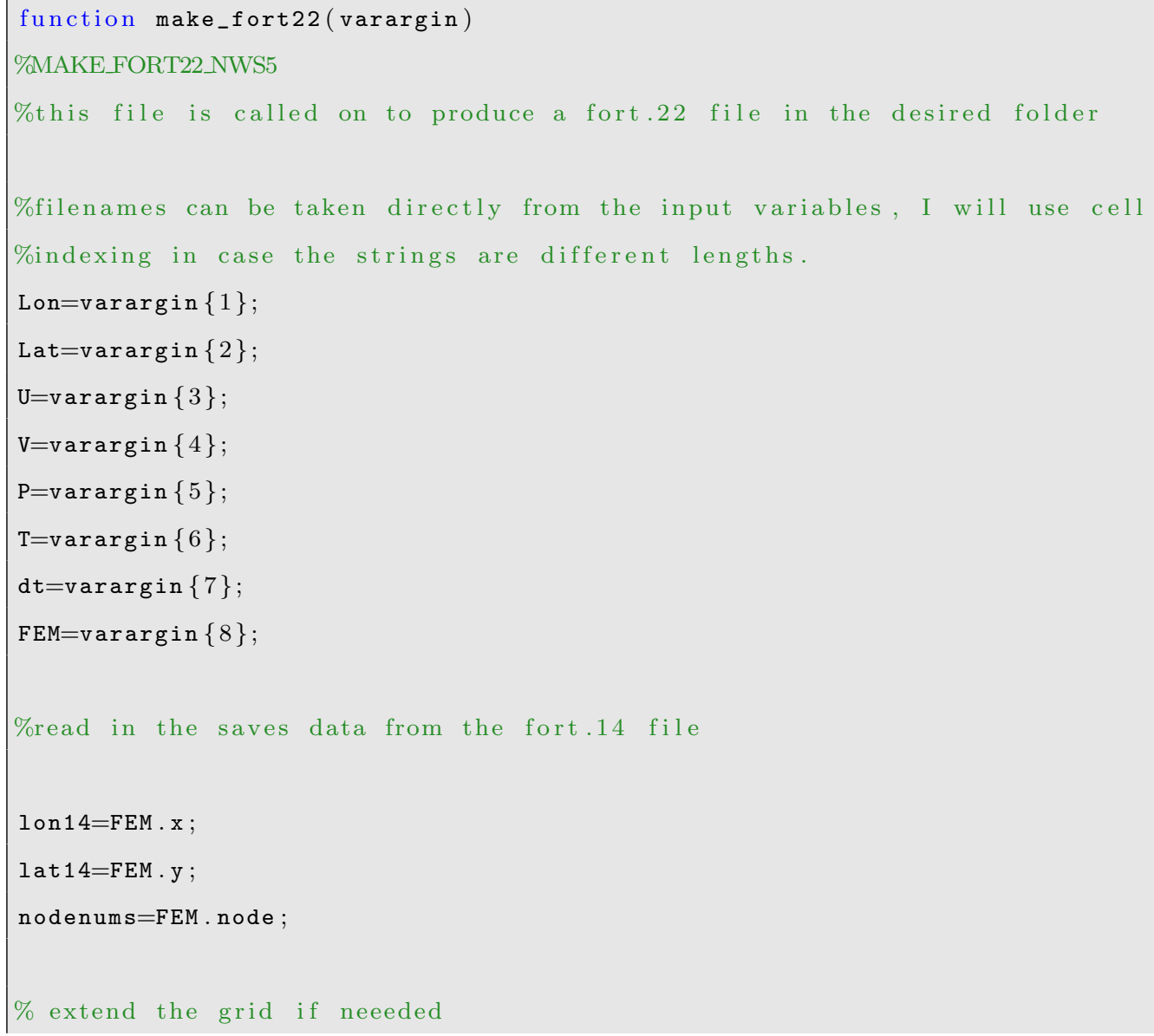




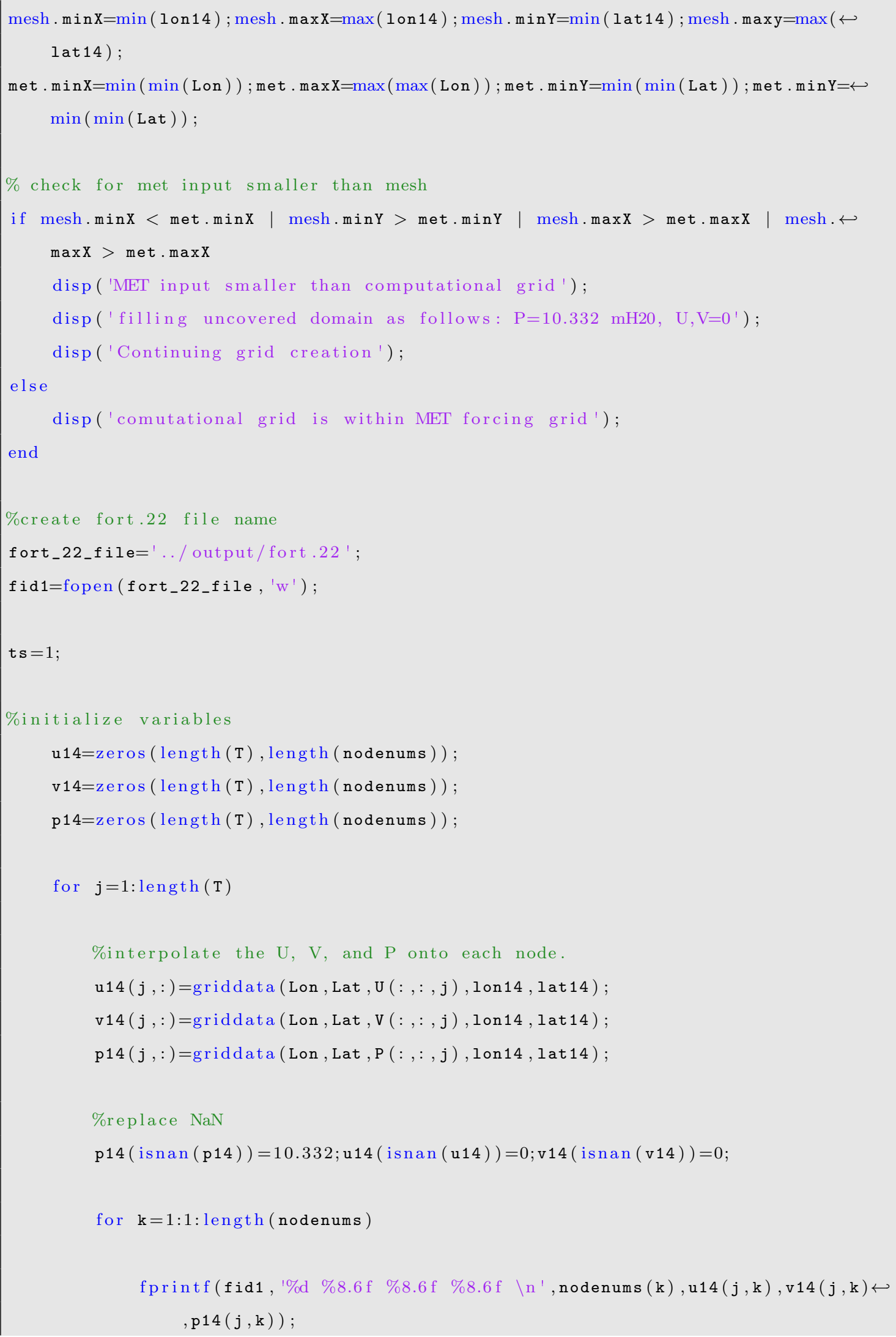


end

progress $=\mathrm{j} /$ length $(\mathrm{T}) * 100$;

disp([ 'Writing fort.22 .. PROGRESS: ' num2str(progress) 1\%'])

end

end

\section{D.1.5 make_fort15.m}

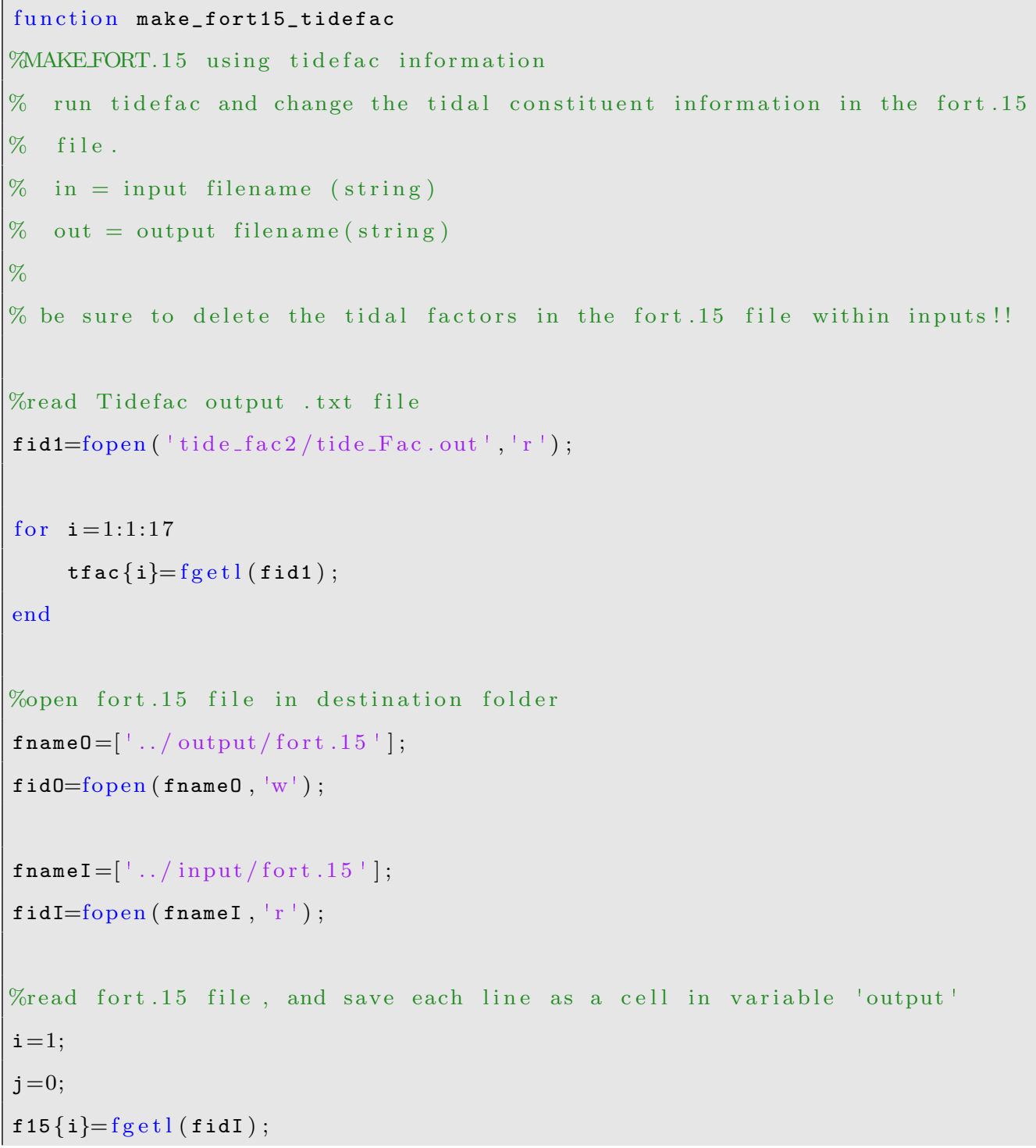




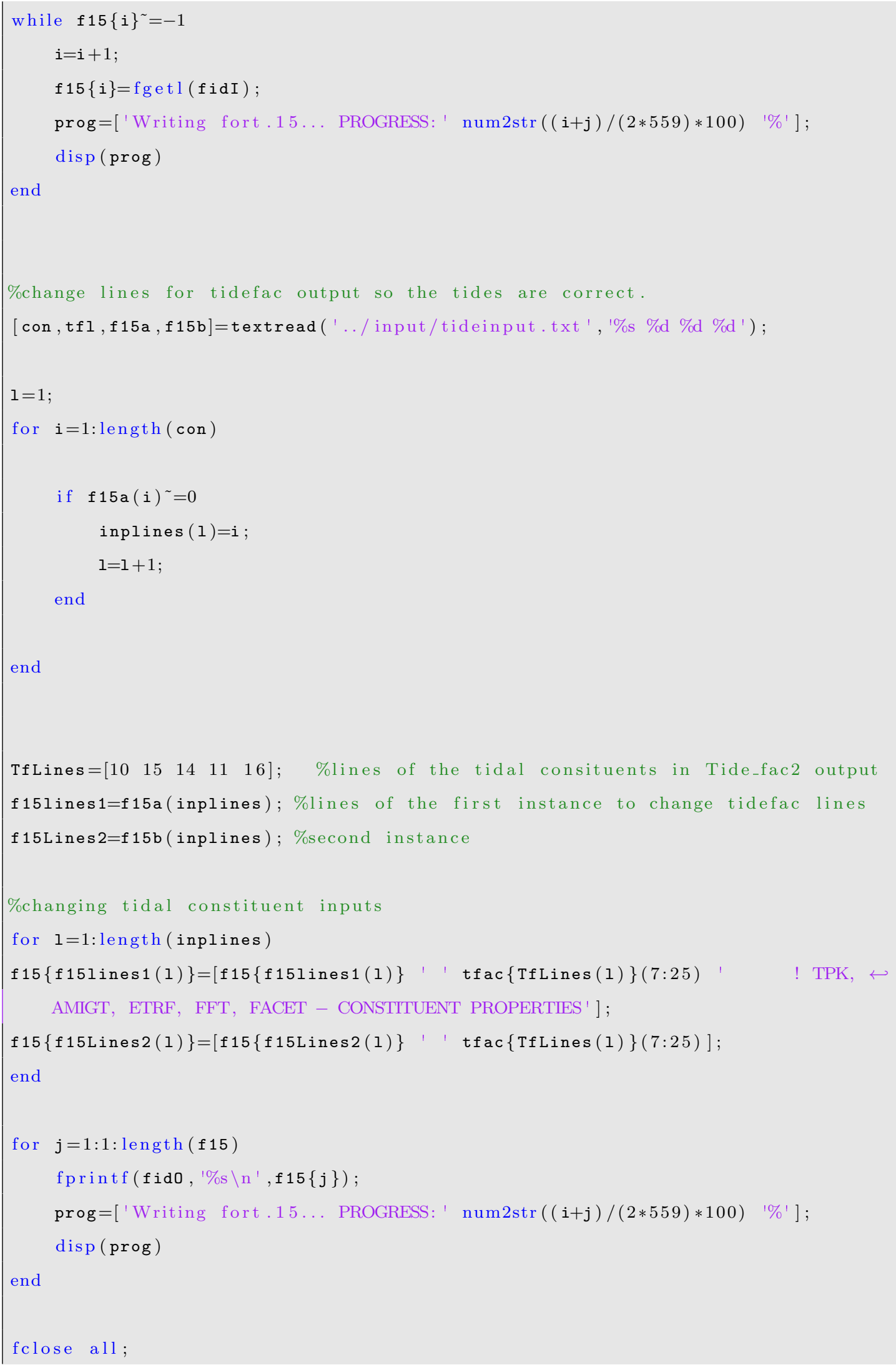




\section{D.1.6 make_fort26.m}

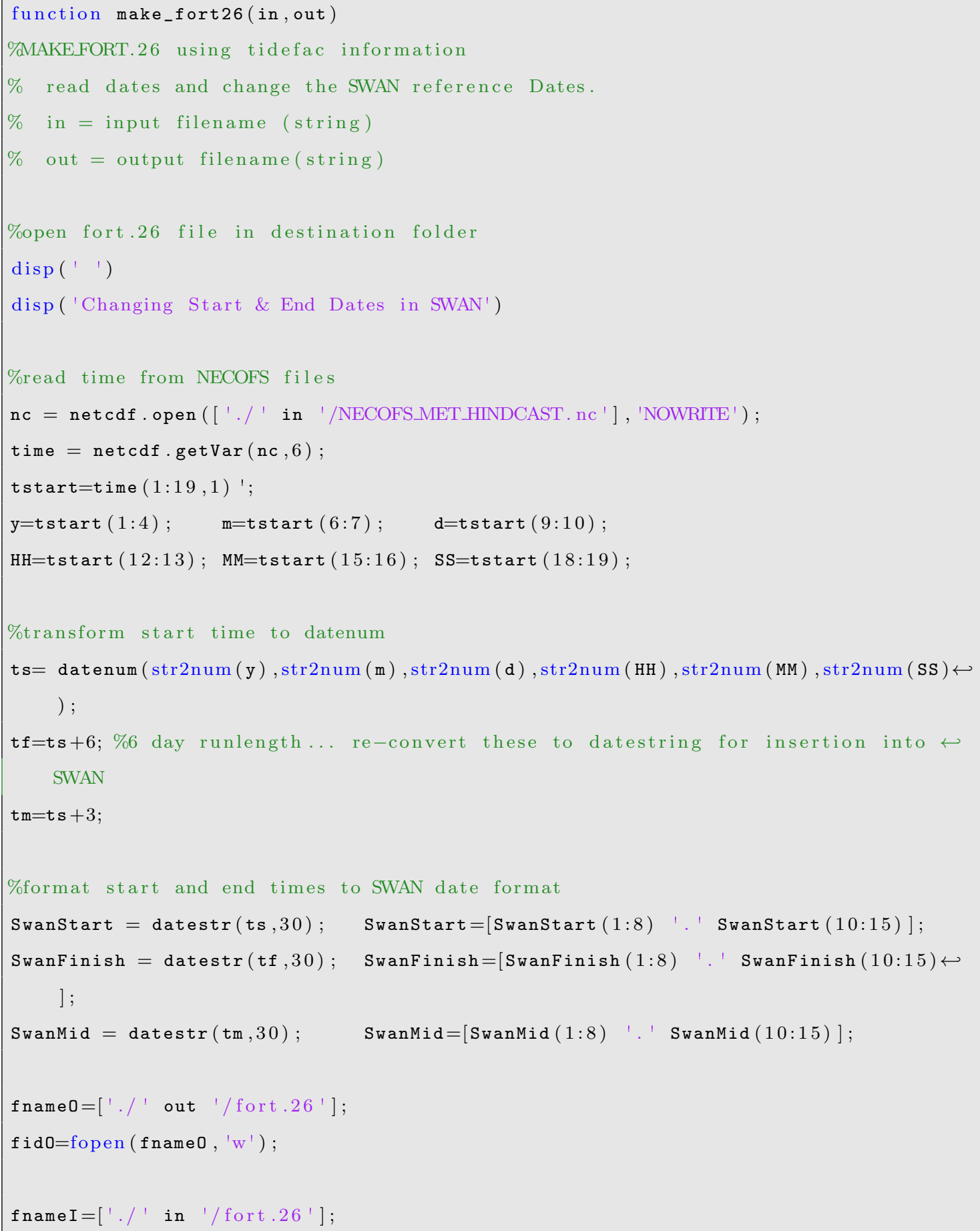




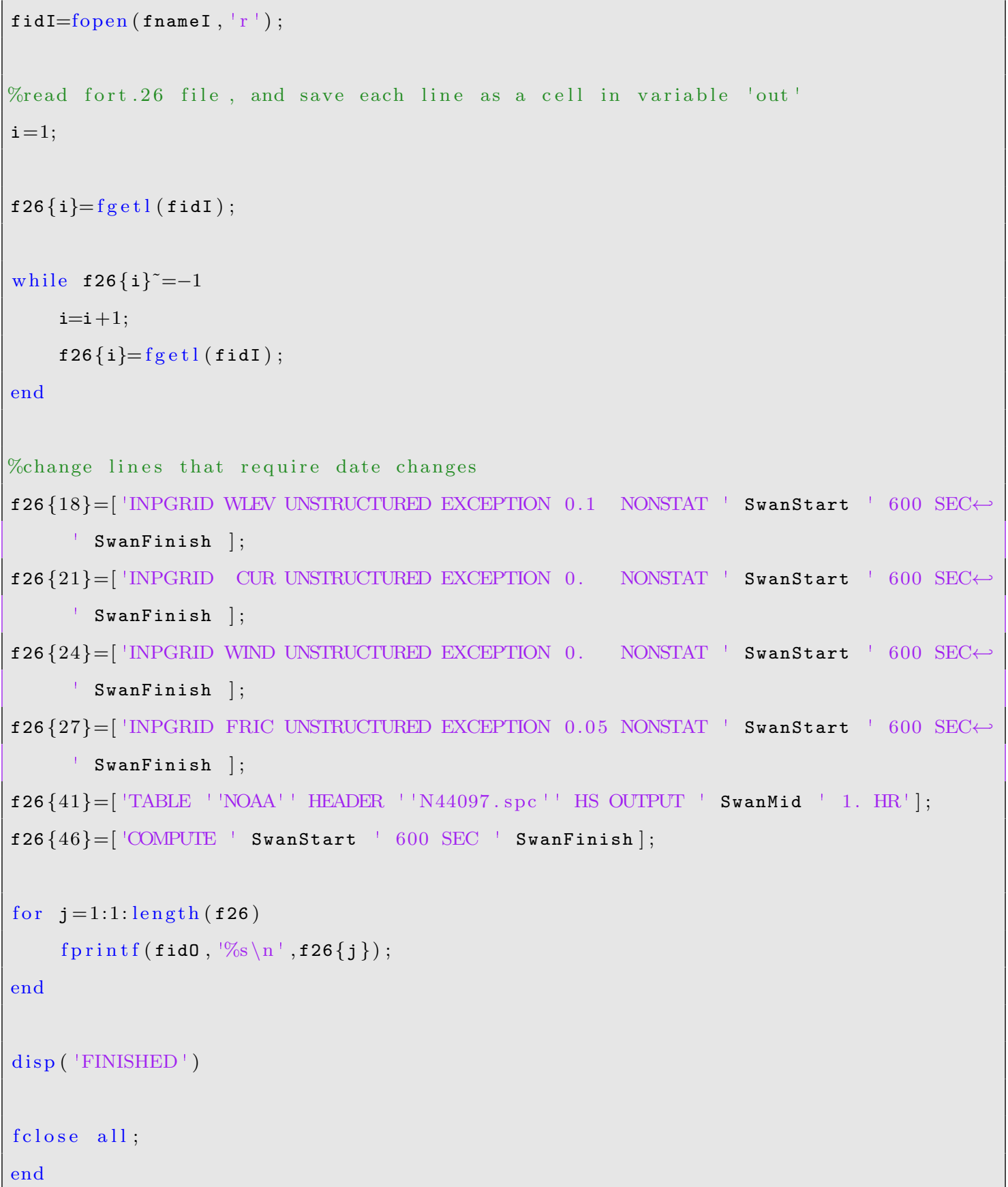

\section{D.2 Bash Files}

D.2.1 forecast 


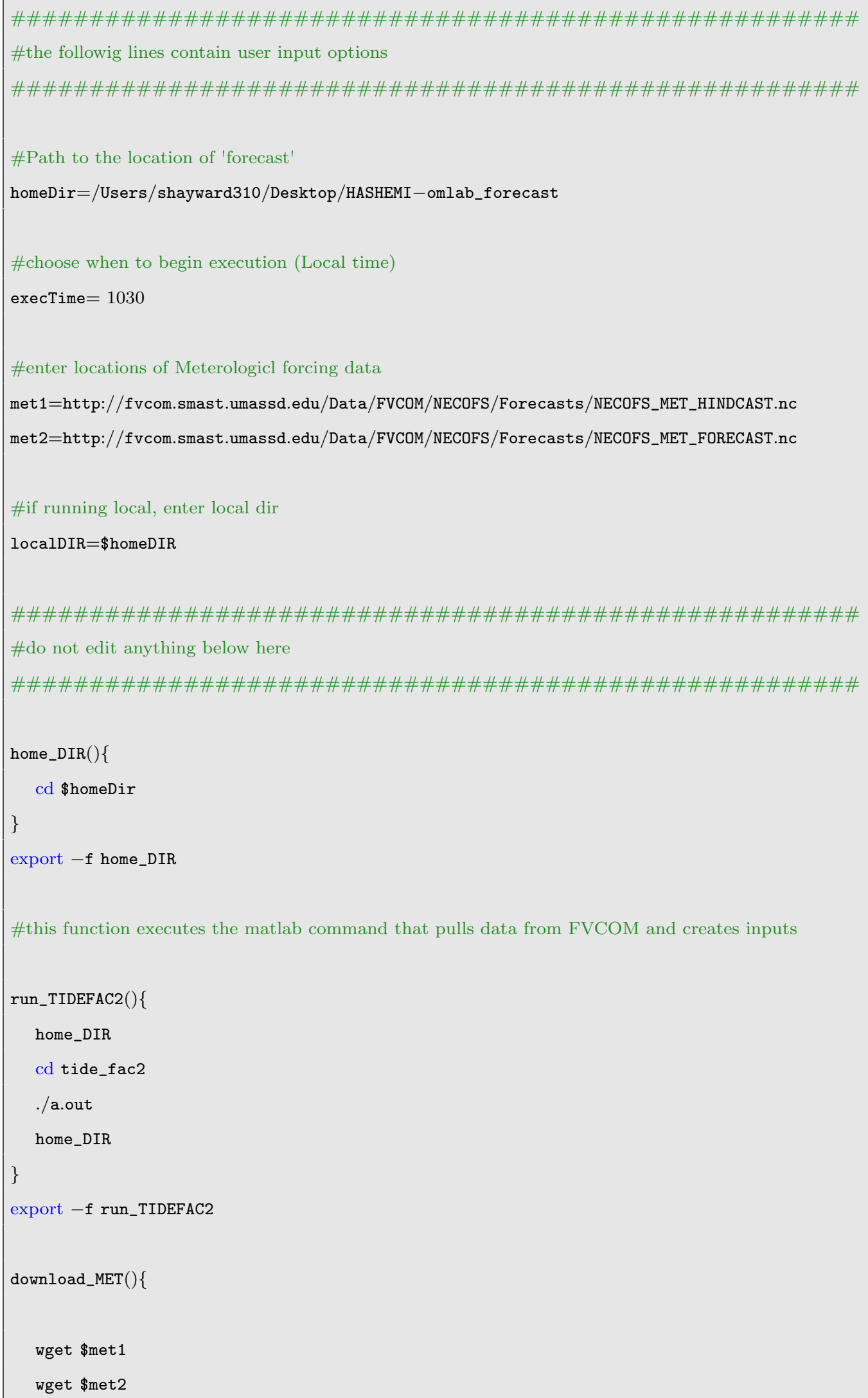




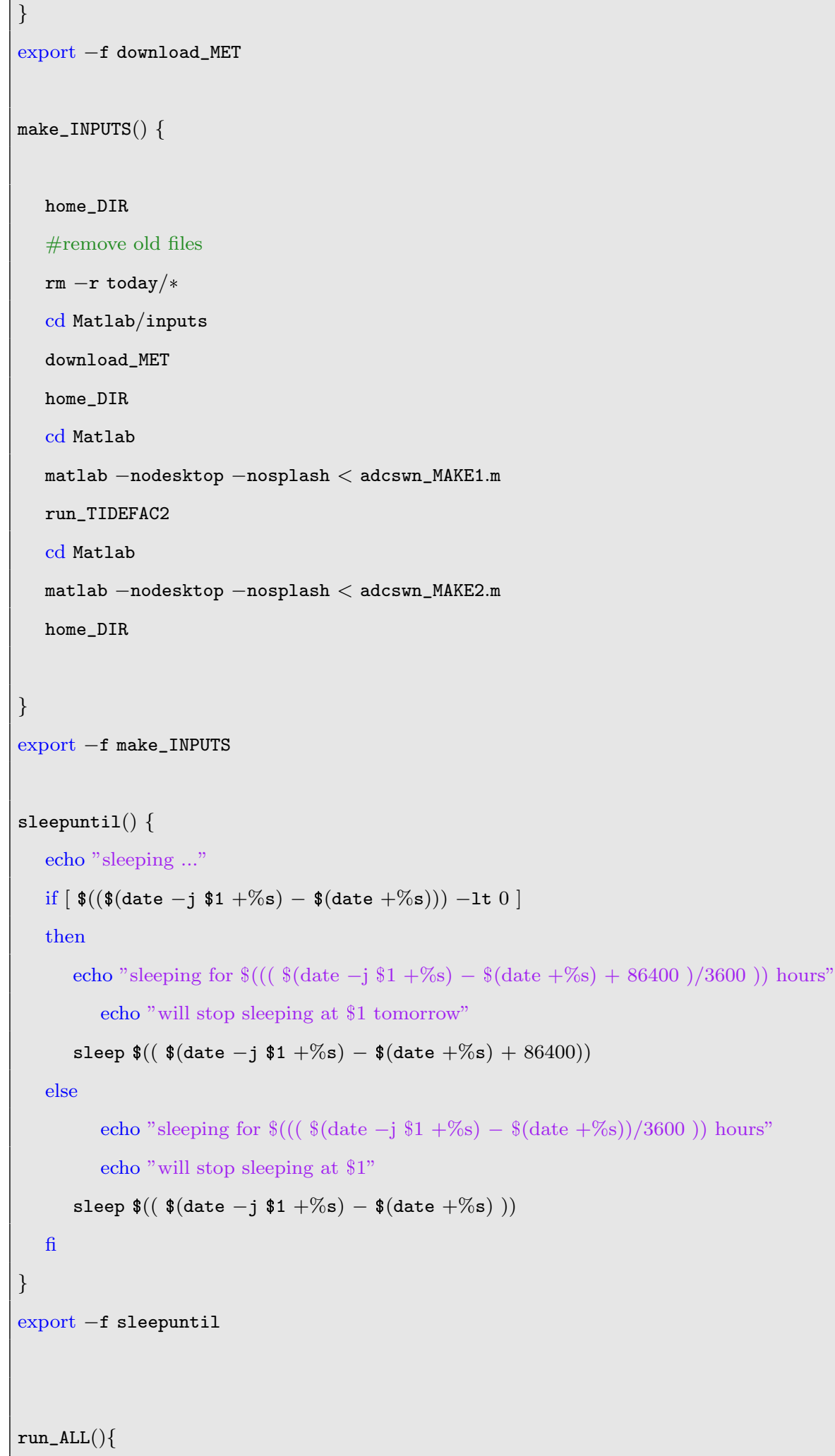




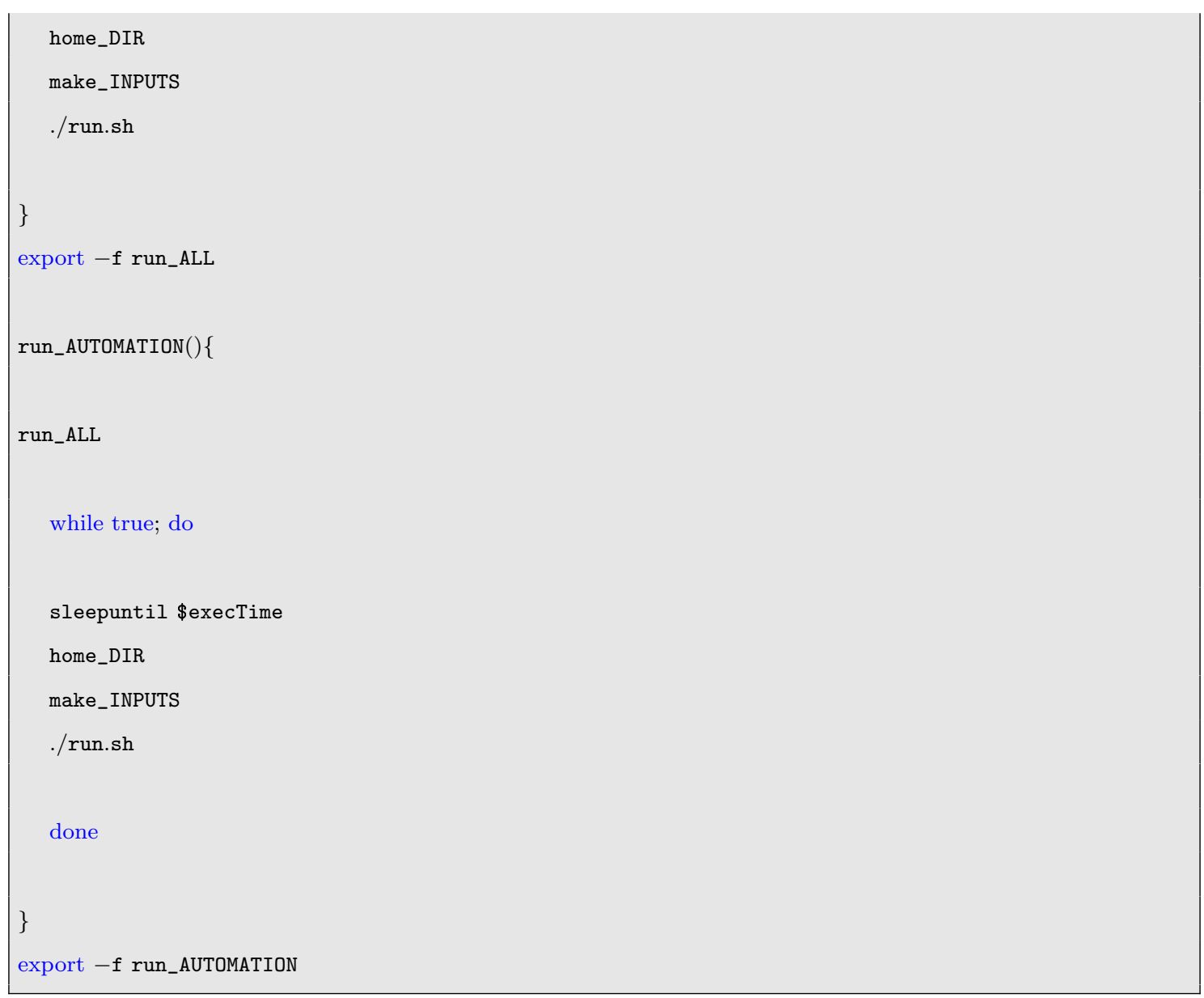

\section{D.2.2 remote.sh}

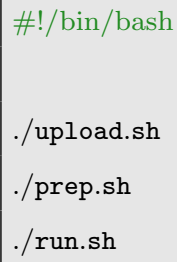

\section{D.2.3 upload.sh}

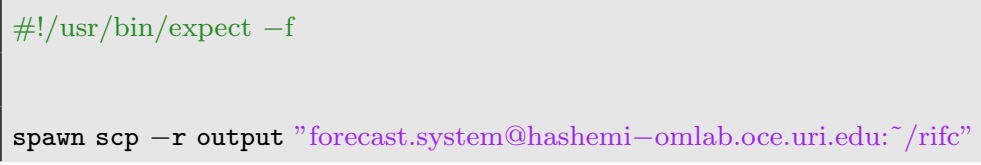


set timeout 100

expect "forecast.system@hashemi-omlab.oce.uri.edu's password: "

send "[enter password here $] \backslash r "$

expect "\$"

\section{D.2.4 prep.sh}

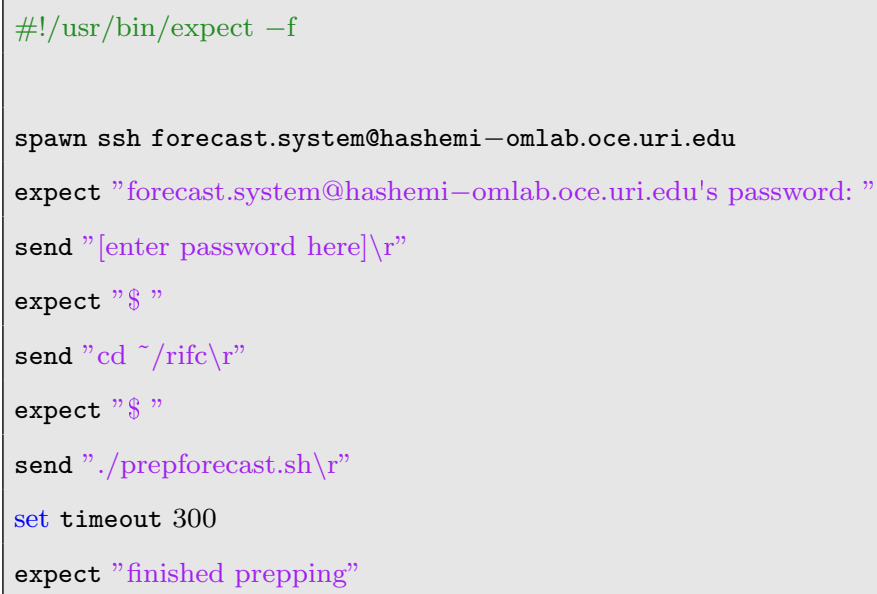

\section{D.2.5 run.sh}

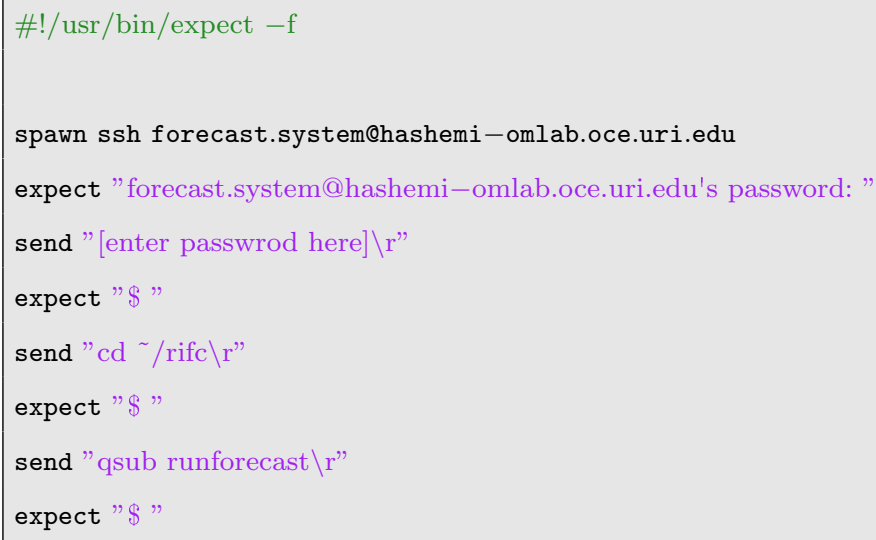




\section{APPENDIX E}

\section{Effect of Sea Level Rise on Historic Storms}

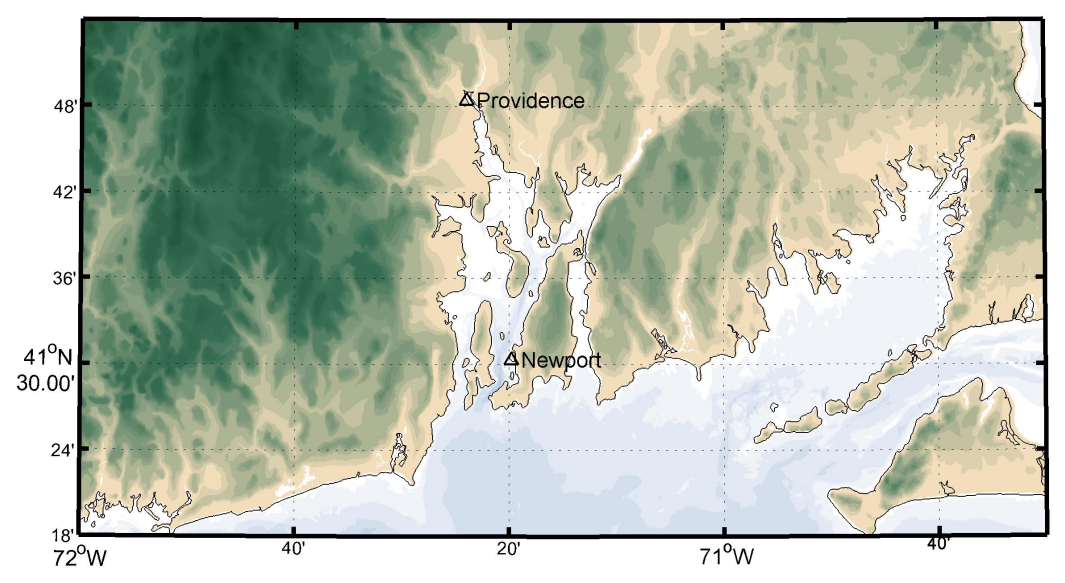

Figure E.47: Locations of water level tidal stations used to analyze the impact of sea level rise.

By the end of the 21st century, rising sea levels will threaten coastal cities and communities worldwide. Retreating shorelines, and increasing water levels will result in greater flooded areas during storms. Less severe storms, with decreasing return periods will flood regions that may have been protected during prior storms. Hurricane Sandy was the second costliest storm in the U.S. history, and significantly impacted a number of cities in the northeast United States. The storm made landfall in New Jersey, more than $200 \mathrm{~km}$ from Rhode Island, large waves and storm surge still caused major damage to communities along the southern coast. Although the damage in Rhode Island was significant, the return period of 
the storm was well bellow 100 years. In this study, Hurricane Sandy was simulated in the state of Rhode Island by assuming a number of sea level rise scenarios. The purpose of this simulation was to assess the nonlinear effects of sea level rise on storm surge. In other words, is it acceptable to simply add sea level rise estimates to the simulation results (using linear superposition), or should the bathymetry be altered, and each simulation run again (nonlinearly)?

Figures E.48 and E.49 compare the water level at Newport and Providence with 0.91 and 2.13 meters (3 and 7 feet) of sea level rise. Sea level rise is added to observed water levels at the water level stations, and compared to the results of using both linear and nonlinear methods. The results of this study showed that the nonlinear effects in Narragansett Bay due to sea level rise are minimal, with little to no difference in peak water level at locations near the tidal observations. 

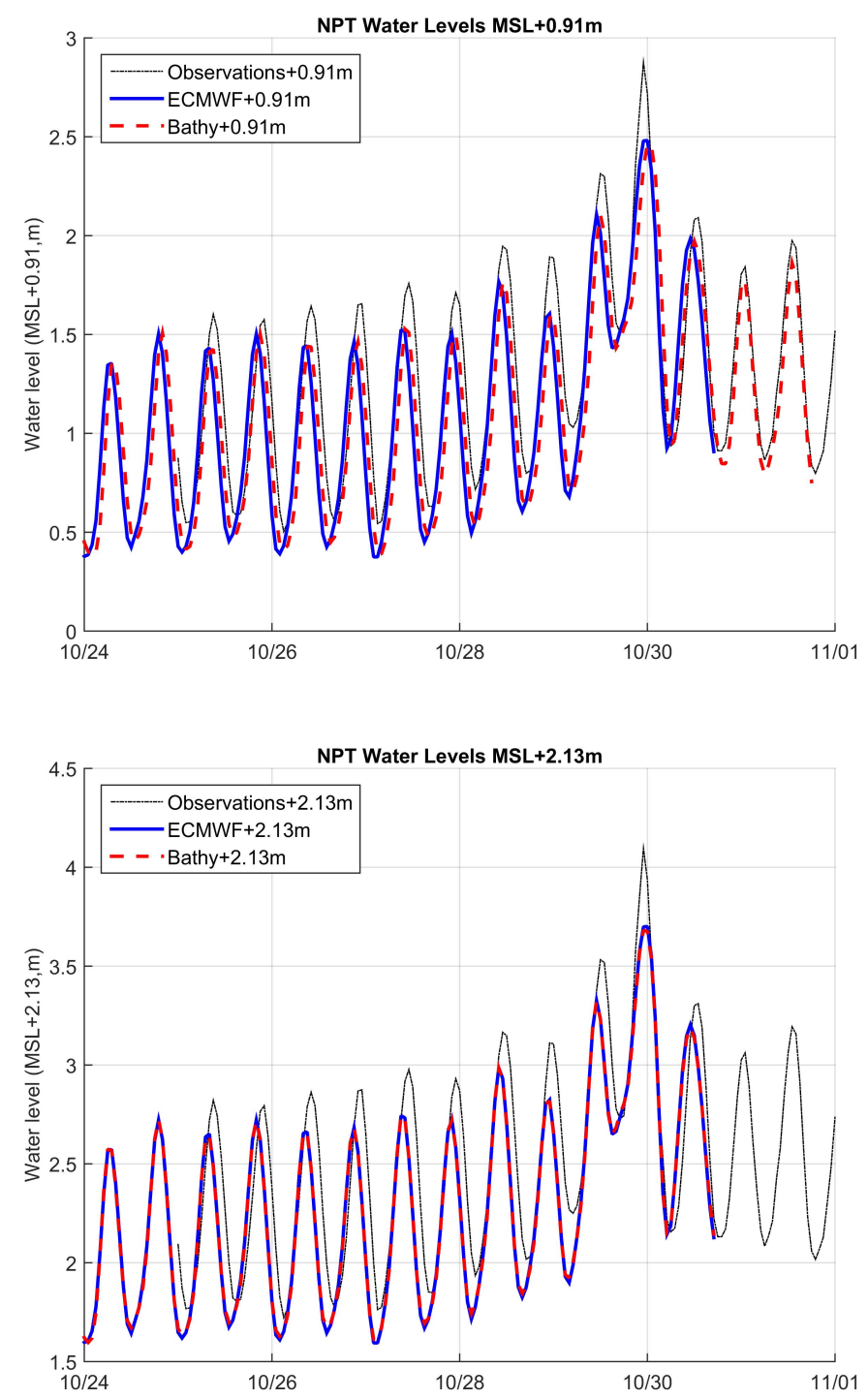

Figure E.48: Comparison of water elevations during hurricane Sandy with 3 feet (top) and 7 feet (bottom) of sea level rise in Newport, Rhode Island. The Observations (black) are compared to the linear (blue) and nonlinear (red dashed) methods. 

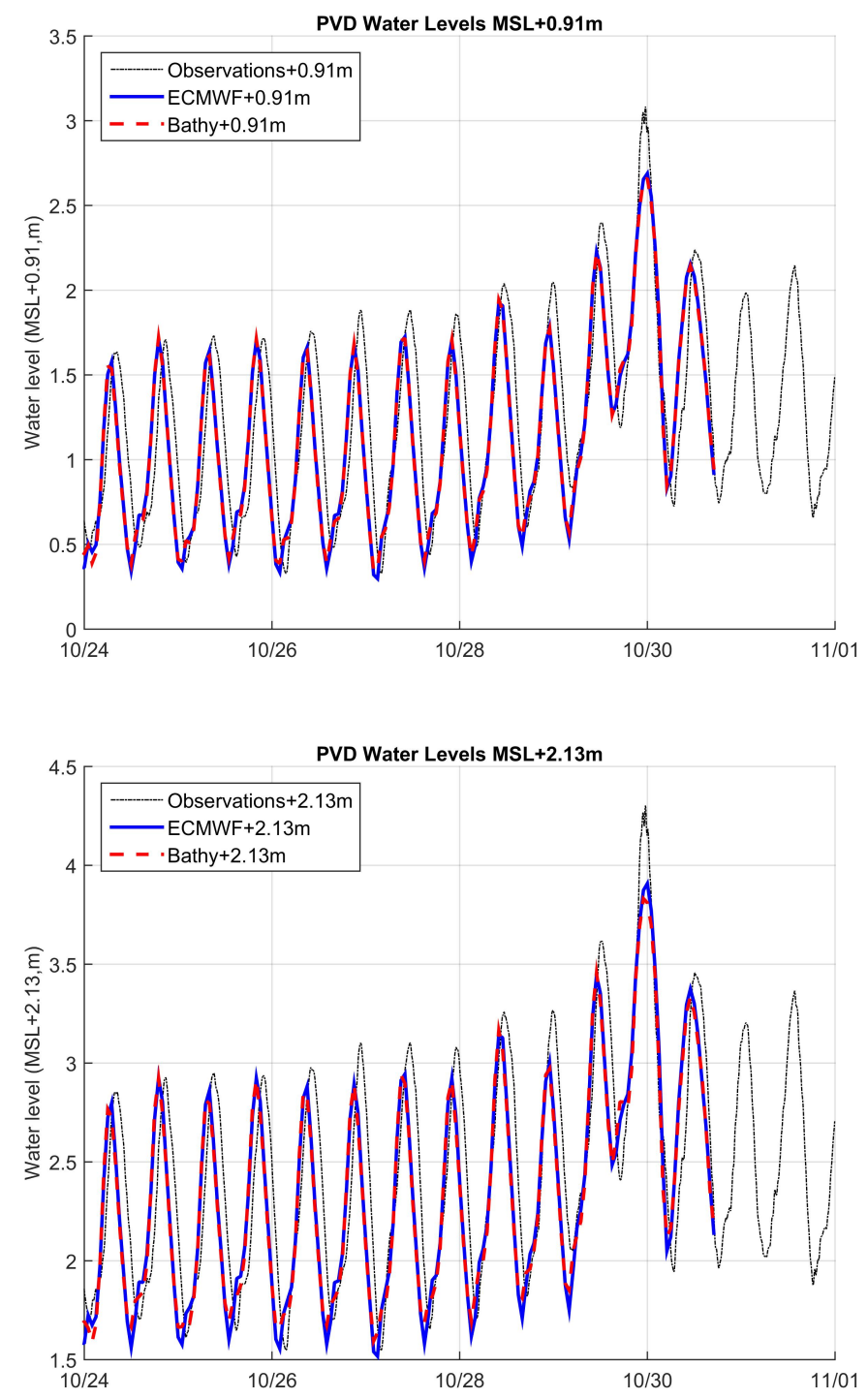

Figure E.49: Comparison of water elevations during hurricane Sandy with 3 feet (top) and 7 feet (bottom) of sea level rise in Providence, Rhode Island. The Observations (black) are compared to the linear (blue) and nonlinear (red dashed) methods. 


\section{E.1 summary}

The effects of Sea level rise in Narragansett bay were analyzed using a variety of methods. With both 0.91 and $2.13 \mathrm{~m}$ of sea level rise, little nonlinear impact of sea level rise was observed. With increasing sea level rise, water levels up Narragansett bay are damped for hurricane Sandy. 


\section{LIST OF REFERENCES}

